\title{
DIVERSIDADE DE MAMÍFEROS DE MÉDIO E GRANDE PORTE EM RELAÇÃO À PAISAGEM DA BACIA DO RIO \\ PASSA-CINCO, SÃO PAULO
}

\author{
Graziela Dotta
}

Dissertação apresentada à Escola Superior de

Agricultura "Luiz de Queiroz", Universidade de São

Paulo, para obtenção do título de Mestre em Ecologia de Agroecossistemas.

P I R A C I C A B A

Estado de São Paulo - Brasil

Abril - 2005 


\title{
DIVERSIDADE DE MAMÍFEROS DE MÉDIO E GRANDE PORTE EM RELAÇÃO À PAISAGEM DA BACIA DO RIO \\ PASSA-CINCO, SÃO PAULO
}

\section{GRAZIELA DotTA}

Bióloga

Orientador: Prof $^{\circ}{ }^{\circ}$ Dr. LUCIANO MARTINS VERDADE

\begin{abstract}
Dissertação apresentada à Escola Superior de Agricultura "Luiz de Queiroz", Universidade de São Paulo, para obtenção do título de Mestre em Ecologia de Agroecossistemas.
\end{abstract}

P I R A C I C A B A

Estado de São Paulo - Brasil

Abril - 2005 
Dados Internacionais de Catalogação na Publicação (CIP) DIVISÃO DE BIBLIOTECA E DOCUMENTAÇÃO - ESALQ/USP

Dotta, Graziela

Diversidade de mamíferos de médio e grande porte em relação à paisagem da bacia do Rio Passa-Cinco, São Paulo / Graziela Dotta. - - Piracicaba, 2005

116 p. : il.

Dissertação (mestrado) - - Escola Superior de Agricultura Luiz de Queiroz, 2005. Bibliografia.

1. Bacia hidrográfica 2. Biodiversidade 3. Comunidades animais 4. Ecossistemas agrícolas 5. Mamíferos 6. Rio Passa-Cinco 7. Uso do solo I. Título

CDD 599

"Permitida a cópia total ou parcial deste documento, desde que citada a fonte - $\mathrm{O}$ autor" 
Dedico este trabalho aos meus pais, que sempre apoiaram todas as minhas decisões (por mais teimosas que pudessem parecer...), e a quem devo o fato de ter conseguido chegar até aqui!!! Dedico também ao Diego, que sempre esteve disposto a discutir o trabalho comigo, mesmo quando eu ultrapassava o horário pré-determinado! 
"E assim escrevo, querendo sentir a Natureza, nem sequer como um homem, Mas como quem sente a Natureza, e mais nada.

E assim escrevo, ora bem, ora mal,

Ora acertando com o que quero dizer, ora errando,

Caindo aqui, levantando-me acolá,

Mas indo sempre no meu caminho como um cego teimoso."

Alberto Caeiro

Das Utopias

"Se as coisas são inatingíveis...ora!

Não é motivo para não querê-las...

Que tristes os caminhos, se não fora

A presença distante das estrelas!"

Mário Quintana 


\section{AGRADECIMENTOS}

Ao $\operatorname{Prof}^{\circ}$ Dr. Luciano Martins Verdade, pela orientação, confiança no meu trabalho, e por tudo o que me ensinou durante estes três anos de convivência.

A CAPES por um ano de bolsa concedida, essencial naquele momento, e à FAPESP pelo financiamento do projeto, com diárias que possibilitaram o desenvolvimento do trabalho de campo.

Ao querido Dr. Peter Crawshaw, sempre muito atencioso e interessado, transmitindo seus imensos conhecimentos sobre os adoráveis carnívoros, e que nos recebeu tão bem em sua casa na FLONA. Pena que a gente não pegou a onça aquele dia!

Ao Prof ${ }^{\circ}$ Dr. Carlos Alberto Vettorazzi pelas importantes sugestões com a parte de uso e cobertura do solo, e por todo o interesse e atenção demonstrados com o projeto.

Ao Prof ${ }^{o}$ Dr. Roberto Shimizu, sempre disposto, pela imensa ajuda que me prestou com as análises estatísticas, fazendo com que eu começasse a entendê-la (trauma da maioria dos biólogos, embora extremamente necessária) e até gostasse dela!

À Prof ${ }^{a}$ Dra. Vânia Pivello pelas sugestões dadas no Exame de Qualificação e por estar sempre disposta a ajudar.

Ao $\operatorname{Prof}^{\circ}$ Dr. Tadeu Gomes de Oliveira, pela atenção com que se dispôs a ajudar e pela confirmação nas identificações dos rastros de pequenos felinos. 
Ao Prof ${ }^{\circ}$ Dr. Júlio Dalponte, pela atenção desde os nossos primeiros contatos, por aceitar fazer parte da banca. Esperando que seja apenas o começo!

Às companheiras de madrugadas, Marli e à Carla, pela ajuda quando preciso, pelas conversas divertidas (mais que necessárias) e pela amizade demonstrada.

À Kátia, por toda boa vontade que sempre teve em ajudar, pela força nos momentos difíceis, pela amizade e por me inserir no 'maravilhoso mundo' do SIG!!!

À Marli, pelas conversas sobre os mais variados assuntos, sempre me passando um pouco da sua experiência de vida e, principalmente, pela amizade tão querida.

A todo o pessoal do LEA, 'ex' e atuais companheiros de 'senzala': André, Anderson, Cláudia, Priscila, Canta, Fábio, Érika e Raquel, e aos da 'casa grande’ Pedro e Kátia, pela diversão e também pelas 'conversas sérias'.

Ao Edson (sem passar mal, hein...) e ao Henrique (Ique) que 'guiaram' (literalmente) os primeiros meses do meu trabalho. Pela companhia, piadas e 'passeios' que fizemos até conhecer direitinho todos os caminhos, e não ficar mais perdidos no meio do mar de eucaliptos....

Ao Jefferson Polizel, do Departamento de Ciências Florestais pelo empréstimo do densitômetro e clinômetro; ao $\operatorname{Prof}^{\circ}$ Dr. Gilberto José de Morais, do Laboratório de Acarologia e Prof ${ }^{\circ}$ Dr. Vinícius Castro Souza, do Departamento de Ciências Biológicas, pelo empréstimo dos podões, possibilitando a realização das parcelas de vegetação.

Aos proprietários das áreas amostradas, por permitirem que o estudo fosse realizado, pelas informações sobre os mamíferos e pela simpatia com que sempre me recebiam. 
A todas as pessoas que me ajudaram em campo: Luíza Longo, Raquel Silveira e Adriana Basile (Dri) por me acompanharem quando precisei ir sozinha com meu carro (muito mais seguro assim, hein garotas! Nada que um facão na nossa mão não pudesse resolver...), Denise Alves (Dê, espero que tenha valido a pena vir de Sampa!), Diego (não conseguiu escapar dessa também...) e todos os que tiveram a coragem para ajudar nas parcelas de vegetação: José Wagner Ribeiro (Xuleta), Paula Martin, Fábio Comin e principalmente à Elis Regina Ribas, sempre super entusiasmada e capaz de ajudar em todos os momentos!

Aos amigos que mesmo estando longe participaram de vários momentos da gestação ao parto dessa dissertação: Maíra Batistoni (Maiara) e Ana Alice Eleutério (Aninha) - minhas 'irmãzinhas' queridas, Renata Moretti (Rê lindinha!), Denise Alves (Dê, sempre presente), Norberto Lopes Hülle (Norbis, meu grande amigo/irmão), Carlos Hotta (Carlitos, mesmo lá da Inglaterra deu uma forcinha!), Elis Regina Ribas (Elis, foi ótimo conhecer você e conquistar tua amizade!) e Eduardo Bessa (que saudades!) pelas discussões constantes no Messenger, sempre úteis de alguma forma, pro trabalho render ou pra evitar o suicídio....

Aos meus queridos pais, Euclides e Marili, e ao meu irmão Rick, que sempre tentaram entender o que eu faço, se interessando pelos assuntos biológicos e dando 'colinho' toda vez que eu precisei!

Ao meu querido Diego, amigo, companheiro, sempre preparado para ajudar. Pela paciência durante os últimos meses, por todo o carinho, alegria e amor de sempre! 


\section{SUMÁRIO}

\section{Página}

LISTA DE FIGURAS......................................................................................

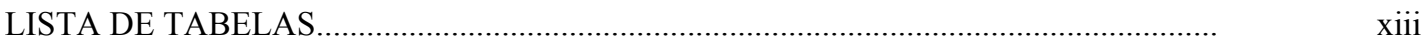

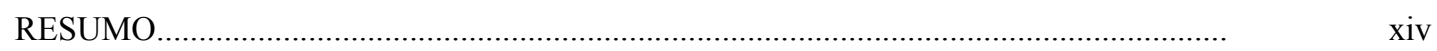

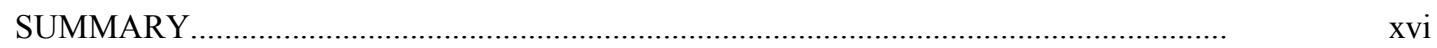

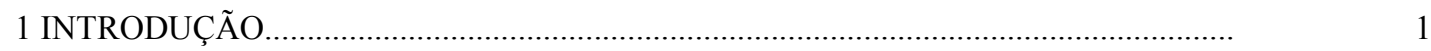

2 REVISÃO DE LITERATURA.........................................................................................

2.1 O Domínio Tropical Atlântico - situação atual e conservação............................................

2.2 A fragmentação dos ambientes - alguns conceitos............................................................

2.3 Efeitos da fragmentação nos mamíferos de médio e grande porte....................................... 11

2.4 Atividades agrossilvopastoris no sudeste do Brasil........................................................ 13

3 MATERIAL E MÉTODOS............................................................................................

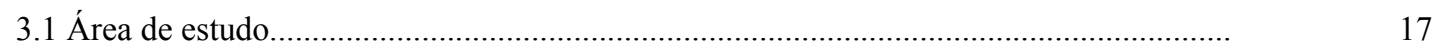

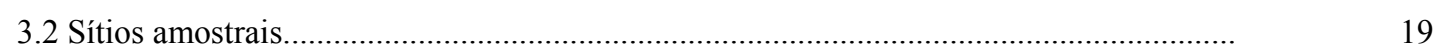

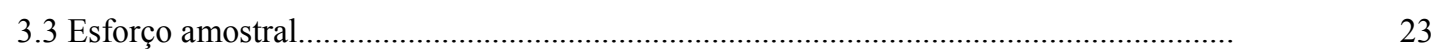

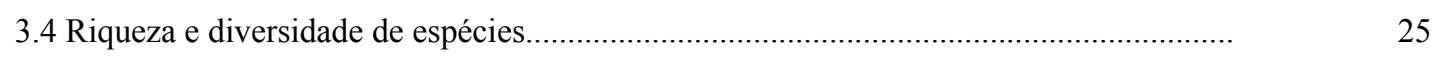

3.5 Estrutura da vegetação...............................................................................................

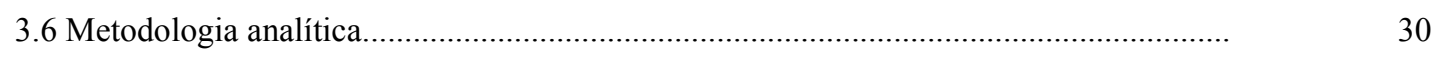

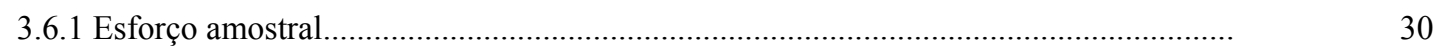

3.6.2 Diferença entre os ambientes quanto à riqueza e freqüência de ocorrência.................... 31

3.6.3 Diferença entre os ambientes quanto à diversidade.......................................................

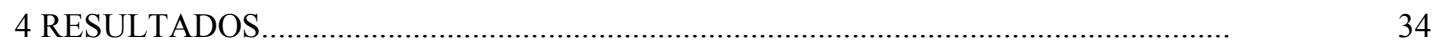

4.1 Esforço amostral.....................................................................................................

4.2 Diferença entre os ambientes quanto à riqueza e freqüência de ocorrência...................... 37

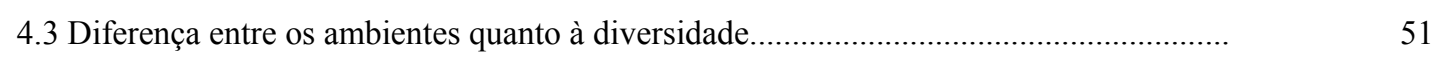

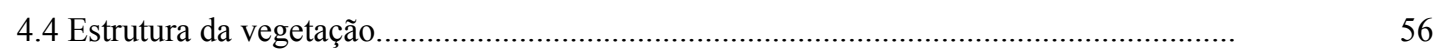

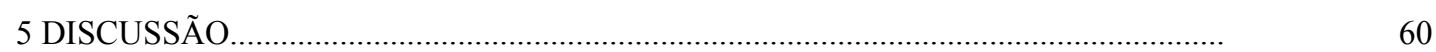


5.1 Esforço amostral..

60

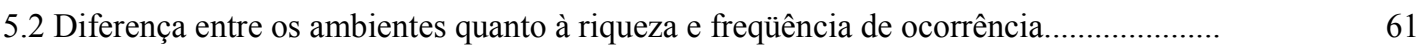

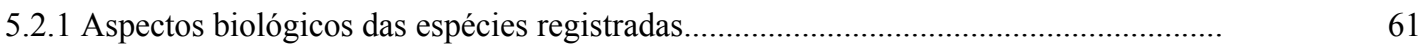

5.2.2 Comunidade de mamíferos de médio e grande porte e categorias tróficas.................... 72

5.3 Diferença entre os ambientes quanto à diversidade......................................................... 74

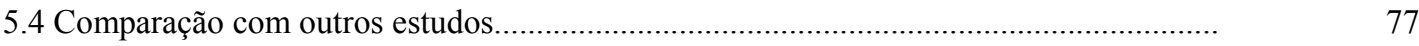

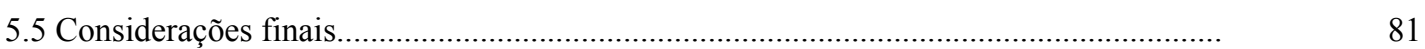

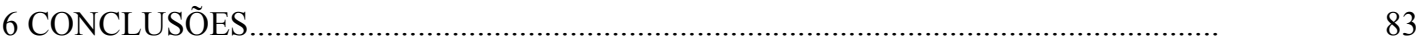

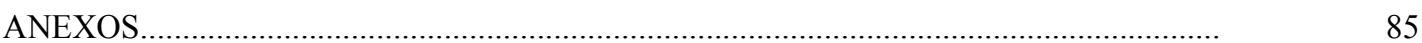

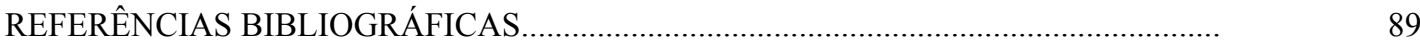




\section{LISTA DE FIGURAS}

\section{Página}

1 Localização da Bacia do Rio Corumbataí, na região centro-leste do Estado de São Paulo, destacando os rios Passa-Cinco e Corumbataí e, em cinza, a bacia do Rio Passa-Cinco......

2 Temperatura $\left({ }^{\circ} \mathrm{C}\right)$ e pluviosidade $(\mathrm{mm})$, na região de coleta da bacia do Rio Passa-Cinco durante o período de amostragem (Dados fornecidos pela RIPASA S.A. Celulose e Papel).

3 Localização dos sítios amostrais na Bacia do Rio Passa-Cinco (C: canavial; P: pastagem; E: eucaliptal e F: floresta nativa).

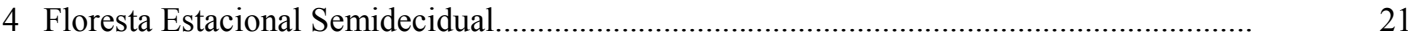

5 Reflorestamento com Eucalyptus spp......................................................................... 21

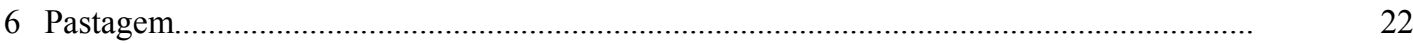

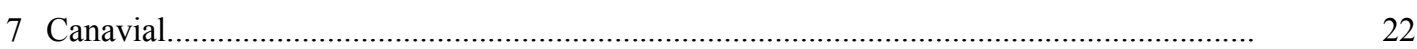

8 Trilhas percorridas em cada sítio amostral na Bacia do Rio Passa-Cinco........................... 24

9 Medidas padrão para rastros de mamíferos: A - Digitígrado, B - Ungulígrado, C1 e C2 Plantígrado. (Modificado de Becker \& Dalponte, 1999).

10 Medidas padrão utilizadas para trilhas de mamíferos (Modificado de Becker \& Dalponte, 1999).

11 Rastros de espécies registradas na região de estudo: A - cangambá (Conepatus semistriatus); B - guaxinim (Procyon cancrivorous) e C - passada de veado-catingueiro (Mazama gouazoubira)

12 Curva do coletor obtida com o estimador não-paramétrico Bootstrap (linha preta contínua), desvio padrão do estimador (linha preta pontilhada) e número de espécies observado (pontos pretos) nas áreas de pastagem.

13 Curva do coletor obtida com o estimador não-paramétrico Bootstrap (linha preta contínua), desvio padrão do estimador (linha preta pontilhada) e número de espécies observado (pontos pretos) nas áreas de canavial 
14 Curva do coletor obtida com o estimador não-paramétrico Bootstrap (linha preta contínua), desvio padrão do estimador (linha preta pontilhada) e número de espécies observado (pontos pretos) nas áreas de eucaliptal.

15 Curva do coletor obtida com o estimador não-paramétrico Bootstrap (linha preta contínua), desvio padrão do estimador (linha preta pontilhada) e número de espécies observado (pontos pretos) nas áreas de Floresta Estacional Semidecidual.

16 Curva do coletor obtida com o estimador não-paramétrico Bootstrap (linha preta contínua), desvio padrão do estimador (linha preta pontilhada) e número de espécies observado (pontos pretos) em toda a área da Bacia do Rio Passa-Cinco.

17 Riqueza de espécies entre os ambientes amostrados (Nested Anova).

18 Freqüência de ocorrência entre os ambientes amostrados (Nested Anova).

19 Riqueza de espécies em cada um dos ambientes, de acordo as categorias tróficas definidas - IO: insetívoro-onívoro, FO: frugívoro-onívoro, CA: carnívoro, FH: frugívoro-herbívoro e HG: herbívoro-pastador. * diferença significativa entre IO e os demais, + diferença significativa entre $\mathrm{CA}$ e $\mathrm{HG}$

20 Freqüência de ocorrência do cachorro-do-mato $(C$. thous) e da lebre européia ( $L$. europaeus) nos ambientes amostrados da Bacia do Rio Passa-Cinco

21 Freqüência de ocorrência das espécies encontradas na bacia do Rio Passa-Cinco......

22 Freqüência de ocorrência das categorias tróficas em cada um dos ambientes amostrados IO: insetívoro-onívoro, FO: frugívoro-onívoro, CA: carnívoro, FH: frugívoro-herbívoro e HG: herbívoro-pastador. * diferença significativa entre IO e os demais, + diferença significativa entre FH e HG.

23 Abundância relativa do cachorro-do-mato (C. thous) e da lebre européia (L. europaeus) nos ambientes amostrados da Bacia do Rio Passa-Cinco

24 Abundância relativa das espécies encontradas na bacia do Rio Passa-Cinco.

25 Abundância relativa das categorias tróficas em cada um dos ambientes amostrados - IO: insetívoro-onívoro, FO: frugívoro-onívoro, CA: carnívoro, FH: frugívoro-herbívoro e HG: herbívoro-pastador. * diferença significativa entre IO e os demais, + diferença significativa entre FH e HG.

26 Distribuição das espécies encontradas no canavial. Segue o modelo de distribuição de Séries Logarítmicas $\left(\chi^{2}=4,61 ;\right.$ g.1. $\left.=6 ; \mathrm{p}>0,5\right)$.

27 Distribuição das espécies encontradas no eucaliptal. Segue o modelo de distribuição de Séries Logarítmicas $\left(\chi^{2}=1,47 ;\right.$ g.1. $\left.=4 ; \mathrm{p}>0,8\right)$.

28 Distribuição das espécies encontradas na Floresta Estacional Semidecidual. Segue o modelo de distribuição de Séries Logarítmicas $\left(\chi^{2}=1,37\right.$; g.l. $\left.=4 ; p>0,8\right)$. 
29 Distribuição das espécies encontradas nas áreas de pastagem. Segue o modelo de distribuição de Séries Logarítmicas $\left(\chi^{2}=1,94 ;\right.$ g.1. $\left.=4 ; p>0,8\right)$..

30 Primeiro e segundo eixos resultantes da análise de correspondência, relacionando as espécies de mamíferos registradas aos ambientes amostrados (Autovalores: 0,248 - eixo 1; 0,200 - eixo 2). Ca: canavial, Pa: pastagem, Eu: eucaliptal e Flo: Floresta Estacional Semidecidual

31 Diagrama de perfil de um dos sítios amostrais em área de Pastagem...

32 Diagrama de perfil de um dos sítios amostrais em área de Canavial, mostrando os três estágios amostrados durante o estudo.

33 Diagramas de perfil de um dos sítios amostrais do presente estudo: A - Eucaliptal e B Floresta Estacional Semidecidual. 


\section{LISTA DE TABELAS}

Página

1 Distância percorrida (quilômetros) em cada um dos sítios amostrais: comprimento das trilhas, total percorrido por sítio amostral, total percorrido por ambiente e total geral.........

2 Lista das espécies de mamíferos de médio e grande porte encontradas na região da Bacia do rio Passa-Cinco, ambiente onde foram encontradas, hábito alimentar e nome comum das espécies. * Espécies domésticas e ** espécies exóticas.

3 Freqüência de ocorrência, das espécies encontradas em cada um dos ambientes amostrados

4 Índice de Abundância Relativa (freqüência de ocorrência/10km percorridos) das espécies encontradas em cada um dos ambientes amostrados.

5 Índice de Diversidade de Shannon (H'), Índice de Eqüitabilidade de Pielou (J') e Índice de Heterogeneidade de Simpson (1/D), obtidos para cada um dos sítios amostrais, com os respectivos valores de Kruskal-Wallis, graus de liberdade (g.l.) e o valor de p

6 Comparação entre o resultado obtido no presente estudo e outros trabalhos realizados no Domínio Atlântico. FA: Floresta Atlântica, FE: Floresta Estacional e Ce: Cerrado. 


\title{
DIVERSIDADE DE MAMÍFEROS DE MÉDIO E GRANDE PORTE EM RELAÇÃO À PAISAGEM DA BACIA DO RIO PASSA-CINCO, SÃO PAULO
}

\author{
Autora: GRAZIELA DOTTA
}

Orientador: Prof $^{\circ}$ Dr. LUCIANO MARTINS VERDADE

\section{RESUMO}

A bacia do Rio Corumbataí é composta por um mosaico de ambientes, fortemente antropizado, com predominância de pastagens e plantações de cana-deaçúcar, além de florestas plantadas de eucalipto e fragmentos de floresta estacional semidecidual. Esta bacia, principal fonte de abastecimento de água da região metropolitana de Campinas, pode ser considerada como um modelo conveniente para o estudo da conservação da diversidade biológica. Subdivide-se em cinco sub-bacias, sendo que a maior, e que apresenta os maiores fragmentos florestais remanescentes, é a do Rio Passa-Cinco. Para verificar a diversidade e a abundância de espécies de mamíferos de médio e grande porte, bem como a utilização que fazem deste mosaico agroflorestal, foram realizados censos por meio de transectos, buscando-se todos os possíveis tipos de registro - diretos e indiretos - como observação direta, fezes, pegadas, arranhões e carcaças. Entre julho de 2003 e junho de 2004 foram percorridos 284,4 km ao todo, e registradas 25 espécies silvestres nativas e duas exóticas, além de seis espécies domésticas. Na floresta nativa foram registradas 23 espécies, no canavial 20, no eucaliptal 17 e nas áreas de pastagem 12. O estimador não-paramétrico Bootstrap calculou 25 espécies para a floresta nativa, 22 para o canavial, 18 para o eucalipto e 13 
para o pasto, indicando que o esforço amostral não foi suficiente para a estabilização da curva de esforço. Os índices de Diversidade (H’ e 1/D), bem como Pielou (J'), mostraram ambientes similares, e o ajuste das curvas de distribuição de espécies ao modelo de séries logarítmicas mostra uma comunidade com uma estrutura composta por poucas espécies abundantes e muitas espécies raras. Quanto à freqüência de ocorrência e à abundância relativa nos quatro ambientes amostrados, as únicas espécies que apresentaram diferenças entre os ambientes foram o cachorro-do-mato (Cerdocyon thous) e a lebre européia (Lepus europaeus), ambas com hábitos generalistas, as duas com maior freqüência no canavial, e a lebre-européia também com maior abundância no canavial. Já em relação à comunidade de mamíferos como um todo, o pasto apareceu como o ambiente com menor riqueza de espécies e com o menor freqüência de ocorrência, enquanto que o canavial obteve a maior freqüência de ocorrência. A análise de correspondência mostrou sete espécies mais relacionadas à floresta nativa, cinco ao eucalipto e nove às áreas abertas (pastagem e canavial). Os resultados obtidos sugerem que a comunidade de mamíferos de médio e grande porte da Bacia do Rio Passa-Cinco é sujeita às modificações ambientais que a região vem sofrendo, e que as espécies de hábitos mais generalistas são as que estão conseguindo se manter com maior facilidade, devido, possivelmente, a seus menores requerimentos de habitat.

Palavras-chave: abundância, agroecossistemas, comunidade, diversidade de espécies, índices de diversidade, mamíferos, paisagem. 


\title{
DIVERSITY OF MEDIUM AND LARGE-SIZED MAMMALS IN RELATION TO THE LANDSCAPE ATTRIBUTES IN THE PASSA-CINCO RIVER BASIN, SÃO PAULO
}

\author{
Author: GRAZIELA DOTTA
}

Advisor: Prof $^{\circ}$ Dr. LUCIANO MARTINS VERDADE

\section{SUMMARY}

The Corumbataí river basin is a landscape with great human influence, with the most relevant agroecosystems of São Paulo. It has been used as one of the major water supplies for the metropolitan region of Campinas. This basin is formed by five subbasins, where the Passa-Cinco river basin is the largest, with the most native remaining fragments. This basin could be considered as a convenient model for the study of biodiversity conservation in agroecosystems. In order to evaluate the distribution and abundance of medium and large-sized mammals, $284,4 \mathrm{~km}$ of transects were censused from July 2003 to June 2004 in Semideciduous native forest, eucalyptus plantations, sugar-cane plantations and pastures. All possible records were recorded such as direct observation, faeces, tracks, scratches, and carcasses. I found 25 native species and two exotic species, besides six domestic species. On the native forest I recorded 23 species, on sugar cane 20 , on eucalypt forest 17 , and on the pasture areas 12 . The diversity and the evenness index suggested that environments were similar, and the distribution species curve (Log-series model) showed few abundant and a majority of rare species. Crab-eating fox and European hare were the only species with differences among habitats in frequency of occurrence, and European hare was the only one with difference 
among habitats in relative abundance. The results suggested that this mammalian community has been influenced by the environmental alteration that this region has been suffering, and the current community is basically formed by generalist species what enhanced its adaptation to an anthropogenic landscape. In such conditions, current environmental laws should be enforced in order to improve forest conservation and mitigate the impacts of agriculture, paper industry, and livestock production.

Key-words: abundance, agroecosystem, community, diversity index, landscape, mammals, species diversity. 


\section{INTRODUÇÃO}

As discussões relativas à perda de diversidade biológica cada vez mais tornam-se parte do cotidiano dos biólogos, especialmente àqueles mais envolvidos com a conservação dos ambientes. Esta perda pode ser atribuída a diversos fatores, destacandose a redução na área dos habitats naturais, bem como sua degradação constante; exploração indevida dos recursos; poluição e caça e pesca predatórias, dentre muitos outros (Fonseca et al., 1997).

A biodiversidade enfrenta situação mais crítica nos países da América Latina Tropical, onde mudanças drásticas ocorrem devido às altas pressões demográficas e às necessidades econômicas, gerando um desenvolvimento e ocupação agrícola desordenados em áreas importantes para a conservação, comprometendo a estabilidade dos recursos naturais (Ojasti, 1984; Wilson, 1988).

Deve-se considerar que, apesar das florestas tropicais cobrirem apenas $7 \%$ da superfície terrestre, nela vivem mais da metade das espécies da biota mundial (Capobianco, 2001b). A destruição rápida e intensa a que estão sendo submetidas tais florestas torna iminente o perigo de que linhagens evolutivas sejam perdidas de maneira irreversível (Wilson, 1988). Da mesma forma, outros domínios tropicais, como o Cerrado brasileiro, passam por situação semelhante. Sua rápida ocupação visando, principalmente, ao avanço das fronteiras agrícolas vem reduzindo drasticamente as áreas de vegetação natural contínua, causando prejuízos visíveis para a diversidade biológica (Buschbacher, 2000; Conservation International et al., 1999; Rocha et al., 1994).

Atualmente, a fragmentação de habitats tem sido considerada como um dos problemas ambientais fundamentais para a conservação da biodiversidade no mundo, 
tornando de suma importância sua compreensão (Fahrig, 2001; Fernandez, 1997; Sih et al., 2000; Wilcox \& Murphy, 1985). Os efeitos da fragmentação sobre a fauna são variáveis de acordo com a biologia da espécie sob foco, de forma que as espécies generalistas tendem a apresentar uma melhor adaptação aos ambientes fragmentados quando comparadas às especialistas (Gentile \& Fernandez, 1999; Oehler \& Litvaitis, 1996).

Não escapando a esta realidade, o Estado de São Paulo apresenta um elevado grau de fragmentação devido às atividades agropecuárias, com muitas áreas de pastagem e uma forte expansão agrícola, principalmente com a silvicultura e o cultivo extensivo de cana-de-açúcar. Considerando-se a cana-de-açúcar, tem-se que cerca de $52 \%$ da produção brasileira ocorre neste Estado, sendo a maior parte concentrada na região sudoeste, entre Piracicaba e Ribeirão Preto. Outra cultura que se destaca no Estado é a da laranja, que representa $83 \%$ da produção nacional. Quanto ao setor pecuário bovino, de corte e de leite, a distribuição de $28 \%$ do total de rebanhos encontra-se na região sudeste. Esta concentração apresenta razões históricas, como a formação dos mercados urbanos nas regiões metropolitanas de São Paulo, Rio de Janeiro e Belo Horizonte, mas também está relacionada à facilidade de exportação da carne, pela proximidade aos grandes portos (Oliveira, 2001).

Além disso, a partir de 1965, a política de incentivos fiscais do Governo Federal aos projetos de reflorestamento vem contribuindo para a alteração do uso da terra em várias regiões do país. Desta forma, a expansão da indústria de papel e celulose e dos derivados de madeira, estimulou o reflorestamento de vastas áreas com monocultivos de pinus (Pinus spp.) e eucaliptos (Eucalyptus spp.), principalmente nos Estados de São Paulo, Paraná, Espírito Santo e Bahia. Nestes dois últimos encontram-se ainda as maiores áreas reflorestadas com eucalipto no país (Oliveira, 2001). No entanto, nos últimos anos tem havido um crescimento considerável de áreas de reflorestamento em São Paulo, principalmente na região central do Estado, onde ocorrem os encraves de Cerrado, com o estabelecimento de diversas indústrias de papel e celulose nesta região.

Na Bacia Hidrográfica do Rio Corumbataí, que se localiza na Depressão Periférica Paulista, esta situação de intervenção antrópica pode ser bem observada, 
apresentando uma intensa atividade agropecuária em toda sua extensão. Sua ocupação teve início no século XIX, com a fundação das cidades de Corumbataí e de Rio Claro, quando já predominava uma economia baseada na agropecuária, inicialmente com o cultivo do café, seguido pela intensificação das pastagens. Com a demanda da industrialização, houve um crescimento da urbanização, aliado a mudanças no uso do solo e dos recursos ambientais. Este processo desordenado de uso e ocupação do solo acabou por refletir num elevado nível de fragmentação, que pode ter como conseqüências problemas no abastecimento hídrico de centros urbanos e perda da capacidade produtiva dos solos devido à erosão (Koffler, 1993; Valente \& Vettorazzi, 2003).

Cinco sub-bacias são integrantes da Bacia do Corumbataí: Ribeirão Claro, PassaCinco, Alto Corumbataí, Médio Corumbataí e Baixo Corumbataí, sendo que a maior delas, com 52.757,60 ha, é a do Passa-Cinco. Esta última apresenta uma matriz de pastagem, que ocupa $51,72 \%$ de sua superfície, seguida por plantações de cana-deaçúcar (14,13\%); florestas estacionais semideciduais (15,67\%); floresta plantada de eucalipto $(10,75 \%)$ e cerrado $(0,74 \%)$, sendo a que apresenta os maiores remanescentes de floresta nativa dentre todas (Valente, 2001).

Para o desenvolvimento de estratégias efetivas de conservação da biodiversidade são necessários estudos que permitam conhecer as respostas individuais para as espécies, assim como para as comunidades, frente à modificação da paisagem que ocorre devido à fragmentação dos habitats, ou seja, é preciso saber como os diferentes táxons utilizam os fragmentos remanescentes, bem como a matriz ao seu redor (Forman, 1995; Lindenmayer et al., 2000). Tais estudos são cada vez mais importantes, especialmente nas regiões neotropicais onde as ameaças tornam-se maiores a cada dia.

Dadas as características descritas, e visando compreender melhor os padrões de distribuição dos mamíferos de médio e grande porte no mosaico de ambientes existente na bacia do Rio Passa-Cinco, foram propostos os seguintes objetivos:

a) Determinar a riqueza de espécies de mamíferos de médio e grande porte nos ambientes mais abundantes da bacia do Rio Passa-Cinco, quais sejam, fragmentos 
florestais nativos, plantações de cana-de-açúcar, florestas implantadas de eucalipto e pastagens;

b) verificar a freqüência de ocorrência das espécies de mamíferos de médio e grande porte encontradas em cada um desses ambientes;

c) verificar a abundância relativa das espécies de mamíferos de médio e grande porte encontradas em cada um dos ambientes e,

d) verificar a diversidade e a composição específica dos mamíferos de médio e grande porte em cada um dos ambientes.

A hipótese nula do presente estudo pode ser definida como:

$$
\mathrm{H}_{0}: \mathrm{KCa}=\mathrm{KEu}=\mathrm{KFl}=\mathrm{KPa}
$$

Onde: $\mathrm{K}=$ descritor de diversidade (riqueza, freqüência de ocorrência ou abundância)

$\mathrm{Ca}=$ plantações de cana-de-açúcar

$\mathrm{Eu}=$ florestas implantadas de eucalipto

$\mathrm{Fl}=$ fragmentos florestais nativos

$\mathrm{Pa}=$ pastagens 


\section{REVISÃO DE LITERATURA}

\subsection{O Domínio Tropical Atlântico - situação atual e conservação}

O Brasil abriga a maior extensão contínua de ecossistemas florestais, sendo a Amazônia o mais significativo deles. A Floresta Atlântica aparece como o segundo complexo de florestas tropicais brasileiras mais biodiversas, originalmente abrangendo cerca de um milhão e meio de quilômetros quadrados, isto é, 1/3 da área total ocupada pela Floresta Amazônica (Capobianco, 2002). Apresenta notáveis diferenças morfológicas e topográficas, com sub-áreas diferenciadas que variam desde tabuleiros na Zona da Mata nordestina, passando por escarpas tropicais na Serra do Mar e na Serra da Mantiqueira, chegando aos 'mares de morros' na região sudeste (Ab' Saber, 2003). Atualmente restam menos de 7\% desta área, distribuída principalmente nos Estados de São Paulo, Paraná, Santa Catarina e Rio Grande do Sul, sendo que destes 7\%, 73\% encontram-se em propriedades privadas (Tessller, 2001).

No Estado de São Paulo, as florestas tropicais de planaltos ocupavam cerca de $82 \%$ do território, sendo que redutos de cerrados e cerradões apareciam em outros $15 \%$. Estas florestas penetravam pelos planaltos interiores, com irregularidades na Depressão Periférica, onde ocorre um mosaico de cerrados e matas em faixas de calcário e terras roxas (Ab' Saber, 2003). Os redutos de cerrado, atualmente, encontram-se principalmente na região centro-norte do Estado, próximos a Campinas, Ribeirão Preto e Franca (Lyra-Jorge, 1999)

A partir da chegada dos colonizadores portugueses em 1500 iniciou-se a degradação das florestas, primeiramente com a exploração do pau-brasil (Caesalpinia echinata) e de outras madeiras de valor. Em São Paulo, esta degradação teve início por volta de 1530, com a produção açucareira na capitania de São Vicente. No século XVI 
as plantações de uva, café, algodão e trigo, combinadas com a criação de gado, provocaram a interiorização dos paulistas (Fausto, 2001). Todas estas atividades contribuíram para o desaparecimento das formações vegetais do Domínio, que atualmente ocupa menos de $100.000 \mathrm{~km}^{2}$ (Capobianco, 2001a; Tanizaki-Fonseca \& Moulton, 2000). Além disto, em sua área de distribuição estão presentes importantes pólos industriais, e nela vivem aproximadamente $80 \%$ da população brasileira (Bergallo et al., 2000; SMA, 2000; Tanizaki-Fonseca \& Moulton, 2000).

Devido a este histórico de degradação, no Domínio Atlântico é encontrada grande parte das espécies animais ameaçadas de extinção no Brasil, contando com 185 dentre as 265 espécies de vertebrados ameaçadas - 100 delas endêmicas - além de 203 espécies vulneráveis, dentre as quais 69 mamíferos (Brasil, 2003).

Além da alta biodiversidade, a Floresta Atlântica apresenta um elevado índice de endemismos, com aproximadamente 8.000 espécies de plantas vasculares, cerca de 180 espécies de aves, 253 de anfíbios, 60 répteis e 73 mamíferos (Fonseca et al., 1996). Seu alto grau de ameaça e degradação, aliado ao grande número de endemismos, qualificamna como um hotspot de biodiversidade, destacando-se como o quinto mais ameaçado do mundo (Myers et al., 2000).

A Floresta Atlântica é protegida, primeiramente, pelo Código Florestal, considerado como uma das mais importantes leis de proteção ao meio ambiente no país, instituído pela Lei Federal n⿳o 4.771/65. Conta com o título de Patrimônio Nacional, fato declarado na Constituição Federal de 1988 (art. 225, § 4), bem como de Patrimônio Natural da Humanidade, concedido pela UNESCO (Myers et al., 2000; Tessller, 2001).

Posteriormente, o Decreto Federal 99.547 de 25 de setembro de 1990 estabeleceu a intocabilidade da Floresta Atlântica, proibindo completamente a exploração de seus espécimes vegetais. No entanto, apresentou uma série de lacunas, destacando-se o fato de não ter definido o conceito de 'Mata Atlântica', levando unicamente à proteção das Florestas Ombrófilas, e também pelo fato de ignorar os problemas sociais gerados a populações tradicionais ao proibir toda e qualquer exploração de recursos vegetais (Tessller, 2001). 
A partir de 1991 o Conselho Nacional do Meio Ambiente (CONAMA) procurou alternativas ao Decreto 99.547/90, trazendo inovações principalmente quanto à definição do Domínio Atlântico e à proteção de seus estágios sucessionais. Desta forma, passaram a receber a denominação genérica de 'Mata Atlântica' áreas que continham as cinco tipologias florestais existentes no Brasil (Floresta Ombrófila Densa, Floresta Ombrófila Mista, Floresta Ombrófila Aberta, Floresta Estacional Decidual e Floresta Estacional Semidecidual), além dos ecossistemas a ela associados (formação pioneira de dunas, restingas, manguezais, campos de altitude e brejos interioranos do nordeste) (Capobianco, 2001b).

As diretrizes aprovadas pelo CONAMA serviram de base para o Decreto Federal 750/93 (10/02/93) que definiu o Domínio da Floresta Atlântica. O decreto não só classificou e reconheceu todas as suas formações vegetais, como também estabeleceu regras para sua exploração econômica e normatizou a questão urbana (Capobianco, 2001b; Tessller, 2001).

Em 1993 a Floresta Atlântica tornou-se o primeiro Domínio brasileiro a ser declarado pela UNESCO (Organização para a Educação, a Ciência e a Cultura das Nações Unidas) como Reserva da Biosfera, contemplando uma área de 29 milhões de hectares. De acordo com este título, passa a ser uma região especialmente protegida, fazendo parte de uma rede internacional de intercâmbio e cooperação que visa à conservação da biodiversidade no mundo por meio de uma relação equilibrada entre o homem e a natureza (MAB-UNESCO, 2003).

Apesar de toda esta proteção, seus maiores e menos alterados remanescentes, concentram-se ao longo do litoral do país, principalmente nas serras do Mar e de Paranapiacaba, lugares próximos a grandes centros urbanos como São Paulo e Rio de Janeiro, o que faz com que mereçam atenção e cuidados especiais (Bergallo et al. 2000; Tanizaki-Fonseca \& Moulton, 2000). Dentre estes remanescentes, 22\% são de Floresta Ombrófila, 8,5\% de Floresta Ombrófila Mista, 4,2\% de Floresta Estacional Semidecidual, e menos de 2\% de Floresta Estacional Decidual (Capobianco, 2001b).

Por fim, deve-se ter em conta a importância da conservação dos ecossistemas que englobam o Domínio Atlântico, destacando-se as importantes funções ecológicas que 
estes prestam ao ser humano, atuando como reguladores do fluxo dos mananciais hídricos; comportando as nascentes de rios essenciais para o abastecimento de muitas cidades da região; atuando para o controle do clima e da retenção e fertilidade do solo; evitando o assoreamento de leitos fluviais; fornecendo proteção de escarpas e encostas de serras; além do fornecimento de diversos produtos como madeira, remédios e alimentos (Tanizaki-Fonseca \& Moulton, 2000).

\subsection{A fragmentação dos ambientes - alguns conceitos}

A fragmentação, insularização e coalescência, existentes em decorrência dos ciclos do paleoclima, podem ser evidenciadas nos diferentes domínios morfoclimáticos brasileiros. Estas devem ser distinguidas, temporal e espacialmente, daquelas antropogênicas, que isolam manchas de habitat nativo por meio das alterações antrópicas nos habitats vizinhos. Segundo Santos-Filho (1995), este isolamento pode ocorrer em função da substituição de áreas de habitat nativo por outro ecossistema, restando apenas manchas isoladas do habitat original circundadas por uma matriz de 'não-habitat'.

Os padrões e processos envolvidos na fragmentação são muito estudados utilizando-se dos conceitos provenientes da Teoria de Biogeografia de Ilhas (Mac Arthur \& Wilson, 1967) e/ou dos processos de metapopulação (Hanski \& Gilpin, 1997). Atualmente, o conceito de 'não-habitat' vem sendo substituído, já que a matriz não se trata de uma barreira impermeável para todas as espécies (Lindenmayer et al., 2003), e pelo fato de que se deve considerar a paisagem como um todo, ou seja, com os diferentes graus de fragmentação e não somente como duas fases: habitat contínuo vs. habitat fragmentado (Fahrig, 2003).

A redução na área total da floresta nativa pode resultar em perda de espécies devido à exposição dos organismos a condições distintas da original, aliada ao fato de geralmente haver uma relação estreita entre a área ocupada por uma comunidade e sua riqueza de espécies (Murcia, 1995). Segundo Fernandez (1997), o processo de fragmentação é uma das maiores ameaças à biodiversidade e pode ocorrer, essencialmente, de duas maneiras - em curto prazo com diminuição no número de 
espécies devido à redução do habitat, e em longo prazo devido a insularização dos ambientes.

A formação de manchas de habitat onde antes havia vegetação contínua provoca alterações nas características abióticas e bióticas dos ecossistemas, o que pode resultar em efeitos danosos para algumas espécies. Dentre as modificações, pode-se destacar o efeito de borda, que gera aumento da luminosidade, redução da umidade, maior incidência de vento, variação de temperatura, além de favorecer espécies invasoras e vegetação heliófila (Murcia, 1995; Saunders et al., 1991). Também pode haver morte de indivíduos, atingindo o grau máximo com a extinção de alguns grupos (Murcia, 1995; Wilcox \& Murphy, 1985). Laurance et al. (2002) encontraram efeitos de borda negativos para diversos taxa na Floresta Amazônica, efeitos que parecem não ser tão evidentes em florestas temperadas, segundo Kremsater \& Bunnel (1999). Isto sugere que os efeitos da fragmentação são maiores em sistemas tropicais, embora ainda não existam estudos suficientes sobre isto (Fahrig, 2003).

As mudanças no ambiente podem, ainda, provocar alterações nos processos ecológicos, que vão desde os genes até as funções do ecossistema. Geneticamente, temse subdivisão de populações, o que pode causar a perda de populações viáveis devido à endogamia e à perda de heterozigose nas populações remanescentes (Wilcox \& Murphy, 1985). Laurance et al. (1997), em estudo realizado na Floresta Amazônica, puderam constatar um declínio no acúmulo de biomassa vegetal nos remanescentes florestais, indicando uma mudança na estrutura da comunidade a curto e médio prazo. Quanto à estrutura das comunidades animais, esta também pode ser alterada pela fragmentação, ocorrendo um aumento das espécies generalistas de borda, bem como o das espécies exóticas, e uma redução de espécies mais especializadas, principalmente aquelas de interior de florestas e das que exigem grandes áreas de vida (Andrén et al., 1997; Forman, 1995; Laurance 1991; 1994).

Um elemento muito importante, e freqüentemente ignorado, para a manutenção da fauna de uma região fragmentada é a matriz, isto é, o tipo de habitat que predomina numa paisagem. Ela é fundamental na evolução da dinâmica dos fragmentos por diversas razões, dentre as quais o fato de que freqüentemente age como filtro seletivo ao 
movimento das espécies na paisagem. Desta forma, uma maior ou menor permeabilidade desta pode influenciar na permanência ou não de determinadas espécies numa região (Franklin, 1993). Sua importância como zona 'tampão' em áreas com florestas nativas pode ser essencial para a manutenção da biodiversidade, função exercida com maior sucesso nos casos de menor contraste entre a matriz e o habitat em questão. Além disto, matrizes diferentes exercem influências distintas quanto aos efeitos de borda incidentes sobre o fragmento, que podem ser menos pronunciados quando a matriz é estruturalmente semelhante ao habitat original, possibilitando uma redução nos impactos ecológicos sobre a comunidade (Gascon et al., 1999; Laurance, 1994).

É esperado que as espécies características de floresta apresentem alguma variação quanto ao requerimento de permeabilidade da matriz, havendo espécies mais tolerantes que outras (Laurance, 1990; 1991; 1994). A capacidade de determinada matriz para suportar espécies típicas de floresta é largamente determinada pela história e intensidade de uso do solo, sendo que regiões com maior distúrbio geralmente apresentam riqueza de espécies menor (Tocher, 1998).

A matriz também pode exercer uma forte influência na dinâmica da comunidade restante, sendo que espécies a ela associadas podem invadir os remanescentes florestais, alterando a composição de espécies em alguns grupos taxonômicos. Segundo Murcia (1995), florestas antropizadas em matriz de baixa complexidade estrutural, como são as áreas de pastagem, apresentam grandes diferenças no microclima da região, amplificando os efeitos de borda e suas alterações na comunidade.

O grau de isolamento das áreas florestais nativas também é um fator importante para a conservação da biodiversidade, e a matriz pode servir como um corredor, facilitando a conectividade entre estas áreas (Franklin, 1993). Percebe-se, assim, que para a manutenção da diversidade biológica em uma paisagem, a matriz exerce um papel fundamental, aliado à preservação dos habitats originais.

A complexidade da fragmentação torna difícil ou impossível predizer efeitos mais específicos, embora em níveis gerais alguns destes efeitos possam ser preditos (Bissonette \& Storch, 2002). As diferenças existentes entre os riscos de extinção das espécies, de acordo com a sensibilidade de cada uma delas, proporciona largas 
implicações para teorias ecológicas e evolutivas, principalmente para a determinação de prioridades e identificação de espécies-alvo para a conservação (Henle et al., 2004b).

Desta forma, para a conservação da diversidade biológica, é necessário o conhecimento sobre aspectos relevantes da composição de espécies na paisagem e, para a conservação das espécies numa determinada região, é necessário identificar quais são mais vulneráveis à perda de habitat, bem como tentar estimar o mínimo de habitat necessário para garantir sua sobrevivência (Lindenmayer et al., 2000). Assim, somente com um manejo da paisagem, e não somente dos remanescentes de vegetação original, a manutenção e a integração das necessidades humanas com a conservação dos ambientes poderá ser assegurada.

\subsection{Efeitos da fragmentação nos mamíferos de médio e grande porte}

Os mamíferos têm um importante papel na manutenção e na regeneração das florestas tropicais, pois apresentam funções ecológicas vitais e são chaves na estruturação das comunidades biológicas, predação e dispersão de sementes, polinização, folivoria e frugivoria. Estão entre os grupos mais utilizados pelos seres humanos para a alimentação, como animais de estimação e como artefatos, sendo componentes da religião e da cultura em algumas comunidades, além de serem fonte de recursos econômicos (Cuarón, 2000).

Para predizer diferenças interespecíficas nas respostas à fragmentação, os atributos ecológicos e comportamentais são bastante importantes, destacando-se a territorialidade, sociabilidade e dispersão de proporção sexual como fatores para a colonização das espécies em ambientes fragmentados (Wolff et al., 1997). Sabe-se que as espécies "percebem" a paisagem sob perspectivas diferentes, com espécies grandes e generalistas exibindo uma diferença relativamente pequena em relação à seleção de recursos, enquanto que espécies pequenas e especialistas aparentemente são mais confinadas espacialmente na sua seleção de recursos (Gehring \& Swihart, 2003). Espécies de grande massa corpórea são particularmente sensíveis durante os primeiros 
estágios da perda de habitat e tais efeitos se tornam mais bem distribuídos nos estágios mais avançados de fragmentação (Henle et al., 2004b).

Atributos da paisagem, elementos espaciais e características do habitat são importantes preditores da presença ou ausência das espécies. Espécies generalistas são beneficiadas pela fragmentação de habitats induzida pela expansão da agricultura, pois freqüentemente se tratam de animais com grande mobilidade, hábeis para uso de diversos habitats e itens alimentares, sendo capazes de explorar também as bordas. Gehring \& Swihart (2003) observaram que as respostas de alguns mesopredadores à fragmentação estão de acordo com as características descritas acima.

Considerando-se que, nos trópicos, os vertebrados costumam exibir alguns traços distintos como a raridade de algumas espécies, a distribuição agrupada e a especialização ecológica, tem-se este grupo como sendo bastante susceptível à fragmentação (Laurance, 1990). Espécies com alto requerimento individual de área, baixa abundância, alta flutuação populacional, baixo potencial reprodutivo, baixo poder de dispersão e forte especialização de habitat mostram-se mais sensíveis (Henle et al., 2004a).

Os grandes predadores, fortemente dependentes da floresta, tendem a desaparecer da maior parte dos fragmentos, sendo substituídos por predadores de menor tamanho e com hábitos generalistas (Laurance, 1994). Tal fato se deve a que as respostas destes predadores à fragmentação de habitats freqüentemente são mais sensíveis que a das populações de presas, já que estes animais estão entre as espécies que se apresentam em baixas densidades e ocupam grandes áreas de vida (Chiarello, 1999; Conservation International et al., 1999; Sih et al., 2000; Weber \& Rabinowitz, 1996). Há cada vez mais evidências de que tais predadores atuem como espécies-chave, desempenhando um importante papel na regulação da estrutura da comunidade, juntamente com a disponibilidade de recursos no ambiente (Estes, 1996; Wright et al., 1994).

Predadores generalistas podem responder à proximidade das bordas, tamanho da manchas e diversidade de habitats, sendo que taxas de predação maiores nas bordas, geralmente rodeadas por matrizes antropizadas, podem ocorrer devido a uma resposta 
numérica destes predadores, já que há uma grande diversidade e alta densidade de presas associadas a estes tipos de habitats (Oehler \& Litvaitis, 1996).

Também se destaca a perda de frugívoros, já que estes também necessitam de grandes áreas de vida para buscar seu alimento, que geralmente encontra-se distribuído em manchas, espacial e temporalmente; e de grandes herbívoros, que também sofrem com a redução da área disponível para sua utilização e ficam reclusos a pequenos espaços, terminando por não manter populações reprodutivamente viáveis, aliado ao fato de serem muito susceptíveis à pressão de caça (Chiarello, 1999).

No Brasil, alguns trabalhos relativos à fragmentação e seus efeitos sobre os mamíferos têm sido realizados principalmente na Amazônia e na Floresta Atlântica, sendo que a maior parte destes trata de estudos com comunidades de pequenos mamíferos (Barros-Battesti et al., 2000; Bernard \& Fenton, 2002; Castro \& Fernandez, 2004; D'Andrea, et al., 1999; Figueiredo \& Fernandez, 2004; Gentile \& Fernandez, 1999; Pardini, 2001; Pires et al., 2002; Reis et al., 2003) e alguns poucos enfocando mamíferos de médio e grande porte (Chiarello, 1999; 2000a; 2000b; Cullen Júnior. et al., 2000; 2001; González-Solís et al., 2002).

Dentre os estudos citados acima, os resultados encontrados para os mamíferos de médio e grande porte concordam com o fato de que as espécies generalistas são menos afetadas pela fragmentação de habitats, além de encontrarem uma maior riqueza de espécies nas áreas de maiores remanescentes nativos. Estes estudos geralmente comparam remanescentes florestais nativos de diferentes tamanhos, e terminam por não considerar as demais coberturas vegetais existentes, como a própria matriz.

Percebe-se, assim, a necessidade de outros estudos para uma melhor compreensão das respostas das espécies no mosaico de ambientes gerado pelas alterações de habitat.

\subsection{Atividades agrossilvopastoris no sudeste do Brasil}

A evolução da agropecuária no Brasil ocorreu a partir da década de 1970, quando esta passou a apresentar um poder discriminatório quanto as suas áreas de ocorrência, 
atividades e produtores. A industrialização da agricultura provocou uma intensificação na concentração da estrutura fundiária brasileira, já que passou a existir uma exigência mínima de recursos financeiros para manutenção dos equipamentos e insumos necessários, provocando não uma generalização do progresso técnico, mas sim sua concentração espacial e setorial (IBGE, 1988; Oliveira, 2001). Percebe-se que a concentração da produção dos principais produtos agrícolas ocorre principalmente no sul e sudeste do País.

Nas últimas décadas houve uma expansão dos produtos de exportação em detrimento dos produtos alimentícios destinados ao mercado interno, como ocorreu no Estado de São Paulo com o rápido crescimento da citricultura entre as décadas de $1970 \mathrm{e}$ 1980, devido à introdução do suco de laranja nacional nos mercados norte-americano e europeu, concentrando $83 \%$ da produção citrícola nacional, com novas áreas surgindo no Triângulo Mineiro, Paranavaí (PR) e Sorocaba (SP). O cultivo do café, inicialmente intenso no Estado de São Paulo, alterou sua expansão geográfica para Minas Gerais e Espírito Santo, mas São Paulo manteve-se com o segundo lugar em produção, com 22\% (Oliveira, 2001).

Percebe-se também uma forte ação do Estado com políticas de incentivos fiscais, principalmente para os grandes produtores, já que os financiamentos agrícolas não são obtidos pelos pequenos produtores, que respondem por mais de $70 \%$ do volume total da produção. Um bom exemplo são a cultura de cana-de-açúcar e a pecuária bovina, pouco praticadas nos estabelecimentos de menor área, e sendo beneficiadas por incentivo fiscal aos grandes estabelecimentos, provocando concentração da produção (IBGE, 1988).

O rebanho bovino, concentrado no Centro-Sul do país, com 28\% no Centro-Oeste e no Sudeste e $19 \%$ no Sul, apresenta sua distribuição ligada às formações dos grandes mercados urbanos nas regiões metropolitanas de São Paulo, Rio de Janeiro e Belo Horizonte, bem como a facilidade para a exportação da carne. A grande expansão da pecuária bovina deu-se no vale do Paraíba, sul de Minas Gerais e oeste de São Paulo, chegando também ao sertão e agreste nordestinos e Amazônia, devido às políticas de incentivo da SUDAM a partir de 1966 (Oliveira, 2001). 
Já a cana-de-açúcar teve sua expansão em função dos programas de incentivo governamentais, com destaque para o Pró-Álcool, implantado em 1975. O Estado de São Paulo concentra 52\% da produção brasileira, principalmente nas regiões de Piracicaba e Ribeirão Preto, onde a expansão ocorreu principalmente em detrimento às áreas de pastagens e de cultivos de produtos alimentícios (IBGE, 1988). Entretanto, nos Estados do Paraná, Goiás, Rio de Janeiro e Zona da Mata Nordestina também são encontradas grandes plantações de cana.

O eucalipto, originário da Austrália, chegou ao Brasil em 1825 como planta ornamental, sendo amplamente utilizado nas ruas e jardins públicos de Vassouras, Estado do Rio de Janeiro, a partir de 1871. Curiosamente, as árvores foram arrancadas em 1882, pois lhes era atribuída a culpa pelo aparecimento de febre amarela na região (Lima, 1996). Seu aproveitamento para fins econômicos só teve início em 1903, quando passou a ser empregado na produção de dormentes ferroviários e lenha para alimentar as locomotivas a vapor da época. As plantações industriais, atualmente são estabelecidas pelas indústrias de papel e celulose em suas próprias terras e, em alguns casos, em terras arrendadas de pequenos produtores rurais. Políticas de incentivo fiscal foram adotadas desde 1965, como ocorreu no Vale do Jequitinhonha até a década de 1990 com o programa federal de incentivos iniciado após o golpe de estado de 1964 (Lima, 1996).

Em abril de 2003 foi apresentado o Projeto de Lei 302/2003, visando ao estabelecimento de parâmetros para os projetos de reflorestamento, ficando estes sujeitos ao licenciamento ambiental, a ser concedido pela Secretaria Estadual do Meio Ambiente. De acordo com o projeto, áreas reflorestadas com até cinco hectares ficariam isentas de licenciamento, para as áreas entre cinco e 100 hectares seria exigido um Relatório Ambiental Preliminar (RAP), e nas áreas acima de 100 hectares seria exigido o Estudo de Impacto Ambiental (EIA).

No Brasil, poucos trabalhos têm sido realizados nestes tipos de ambientes. Dietz et al. (1975) e Stallings (1989) estudaram a comunidade de pequenos mamíferos em áreas com plantações de eucalipto em Minas Gerais. Os primeiros autores encontraram uma maior riqueza de espécies nas áreas de vegetação natural, enquanto os resultados 
obtidos por Stallings (1989) destacaram a importância da presença de um sub-bosque nas áreas de plantação de eucalipto, a fim de manter a diversidade de espécies.

Stallings (1990) trabalhou em Minas Gerais com a comunidade de mamíferos em florestas de eucalipto homogêneas e florestas de eucalipto com sub-bosque de espécies nativas, destacando a importância deste último para garantir a ocorrência de algumas espécies. Silva (2001), estudando a comunidade de mamíferos não-voadores em áreas de remanescentes de Floresta Atlântica e plantações de eucalipto, na região de Pilar do Sul, Estado de São Paulo, observou a importância da manutenção dos remanescentes nativos para a conservação das espécies, embora os mamíferos utilizem os plantios de eucalipto.

Quanto às áreas influenciadas por agropecuária, quase não existem estudos no Brasil. Chiarello (2000a) realizou um levantamento de aves e mamíferos num fragmento de floresta semidecídua localizado numa região de agricultura intensa, no Estado de São Paulo, priorizando as áreas de vegetação nativa para o levantamento, e encontrou um predomínio de espécies habitat-generalistas.

Gallina et al. (1996) realizaram um trabalho no México, estudando a diversidade de mamíferos em plantações de café, e perceberam a necessidade de se manter uma certa complexidade estrutural, isto é, conservar principalmente a diversidade no estrato arbóreo, para garantir recursos alimentares e a manutenção das espécies. 


\section{MATERIAL E MÉTODOS}

\section{1 Área de estudo}

A área de estudo trata-se da bacia do Rio Passa-Cinco (52.757,60 ha), cujo rio principal, o Passa-Cinco, é tributário do Rio Corumbataí, na região centro-leste do Estado de São Paulo (Figura 1). A região apresenta áreas de topografia íngreme e forma uma paisagem com um mosaico de ambientes, caracterizando-se como um agroecossistema, sendo a matriz composta por pastagens $(51,72 \%)$, além de áreas com plantação de cana-de-açúcar (14,1 \%), florestas plantadas de Eucaliptus spp. (10,75\%) e fragmentos florestais nativos $(15,67 \%)$, tanto de cerrado, como de floresta estacional semidecídua (Koffler, 1993; Valente, 2001).

O clima da região, segundo a classificação de Köppen, é do tipo Cwa, subtropical, seco no inverno e chuvoso no verão, com temperatura média do mês mais quente superior a $22{ }^{\circ} \mathrm{C}$. As temperaturas mais altas ocorrem no período de dezembro a março e as mais baixas no bimestre junho-julho, com $17{ }^{\circ} \mathrm{C}$ de média (Koffler, 1993).

O regime de chuvas é tropical com duas estações definidas, sendo um período seco de março a setembro e um período chuvoso de outubro a fevereiro, com um total de precipitação anual em torno de $1.390 \mathrm{~mm}$ (Valente, 2001).

Durante o período de estudo, a temperatura e a pluviosidade médias mensais na estação seca foram de $19,2{ }^{\circ} \mathrm{C}$ e $39,3 \mathrm{~mm}$, respectivamente, enquanto na chuvosa foram de $23,6{ }^{\circ} \mathrm{C}$ e $193,8 \mathrm{~mm}$, com maior concentração de chuvas entre os meses de novembro de 2003 a fevereiro de 2004 e pluviosidade total de $1.399 \mathrm{~mm}$. Desta forma, considerando-se tanto as temperaturas como a pluviosidade, o período de estudo apresentou-se como um ano típico (Figura 2). 


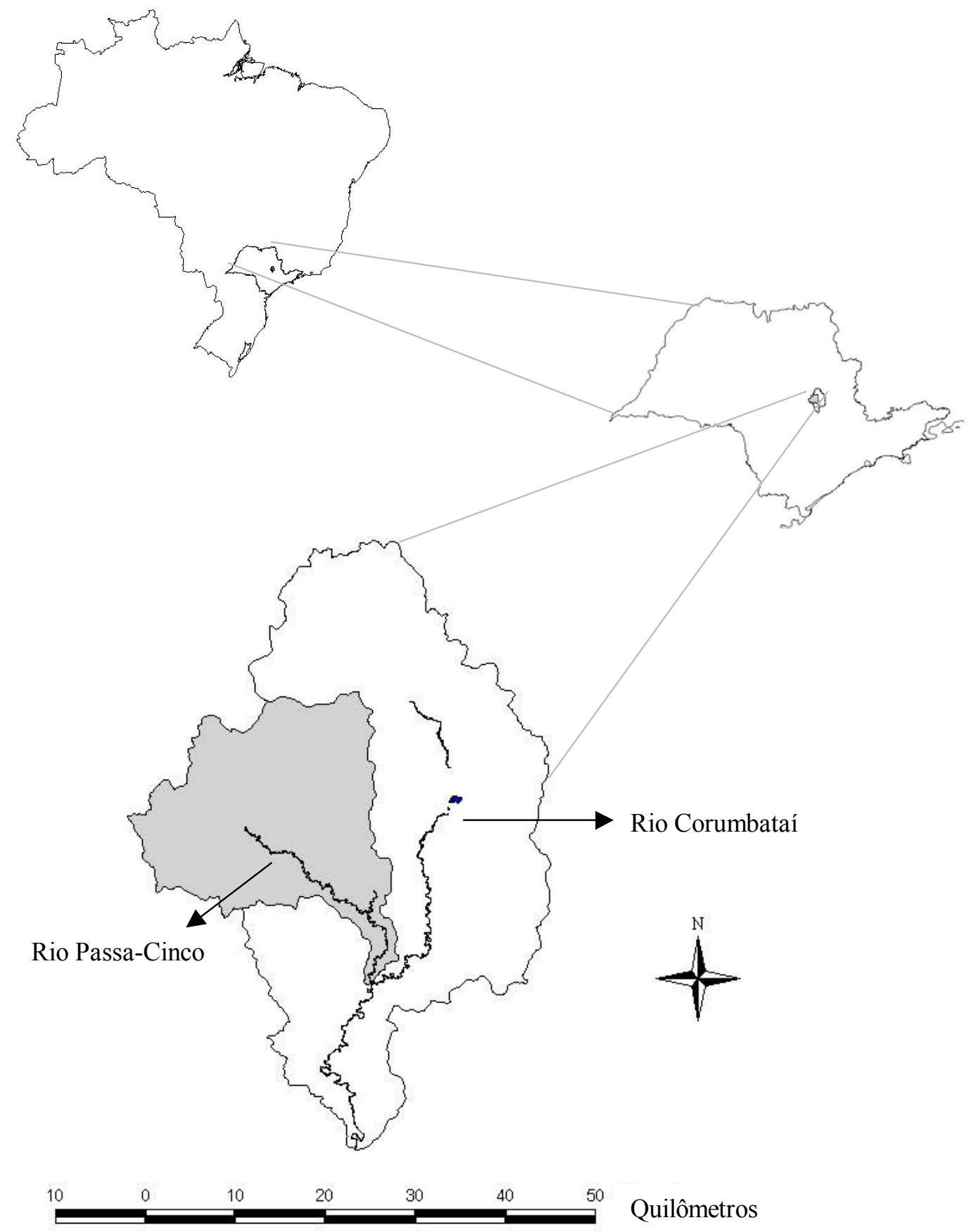

Figura 1 - Localização da Bacia do Rio Corumbataí, na região centro-leste do Estado de São Paulo, destacando os rios Passa-Cinco e Corumbataí e, em cinza, a bacia do Rio Passa-Cinco 


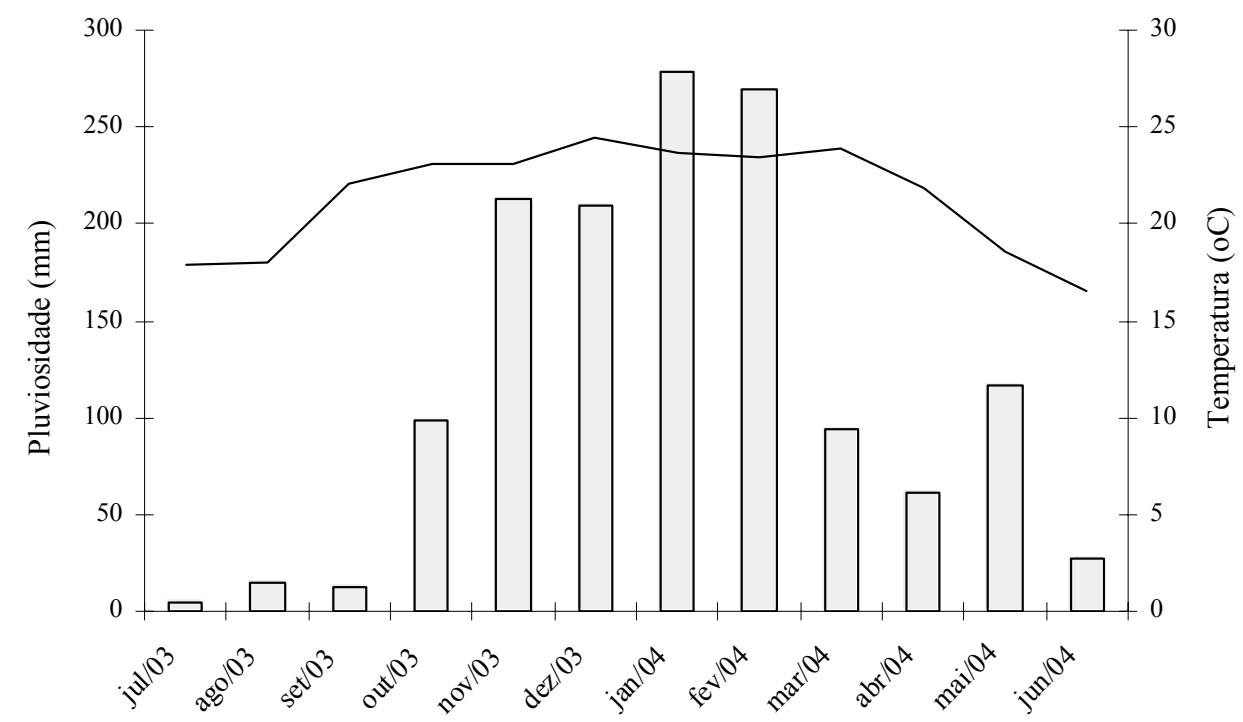

Figura 2 - Temperatura $\left({ }^{\circ} \mathrm{C}\right)$ e pluviosidade $(\mathrm{mm})$, na região de coleta da bacia do Rio Passa-Cinco durante o período de amostragem (Dados fornecidos pela RIPASA S.A. Celulose e Papel)

\subsection{Sítios amostrais}

Por meio de imagens de satélite (SPOT-4, passagem do dia 22 de setembro de 1999) e mapas de uso e cobertura do solo, com auxílio do programa IDRISI (Eastman, 1999), foram determinados 16 sítios amostrais na bacia do Rio Passa-Cinco. Para a determinação dos pontos de amostragem foram selecionados os quatro maiores fragmentos florestais nativos, plantações de eucalipto e canaviais, distribuídos de forma relativamente agrupada entre si. Desta forma, a bacia foi dividida em quatro regiões que contivessem os quatro tipos de ambiente mais freqüentes: pastagens (matriz), canaviais, florestas plantadas de eucalipto e floresta estacional semidecídua, obtendo-se assim quatro réplicas 'aninhadas' (sensu Zar, 1999: pág.303) de cada um dos ambientes (Figura 3). Posteriormente, realizou-se a confirmação dos pontos em campo, e alguns dos sítios foram substituídos, por razões logísticas ou operacionais, tais como dificuldade de acesso ou falta de permissão do proprietário para executar o trabalho, atendendo-se o melhor possível aos critérios anteriormente descritos. 
O aspecto geral das áreas de fragmentos florestais nativos pode ser observado na Figura 4, das florestas implantadas de eucalipto na Figura 5, dos canaviais na Figura 6 e das áreas de pastagem na Figura 7.

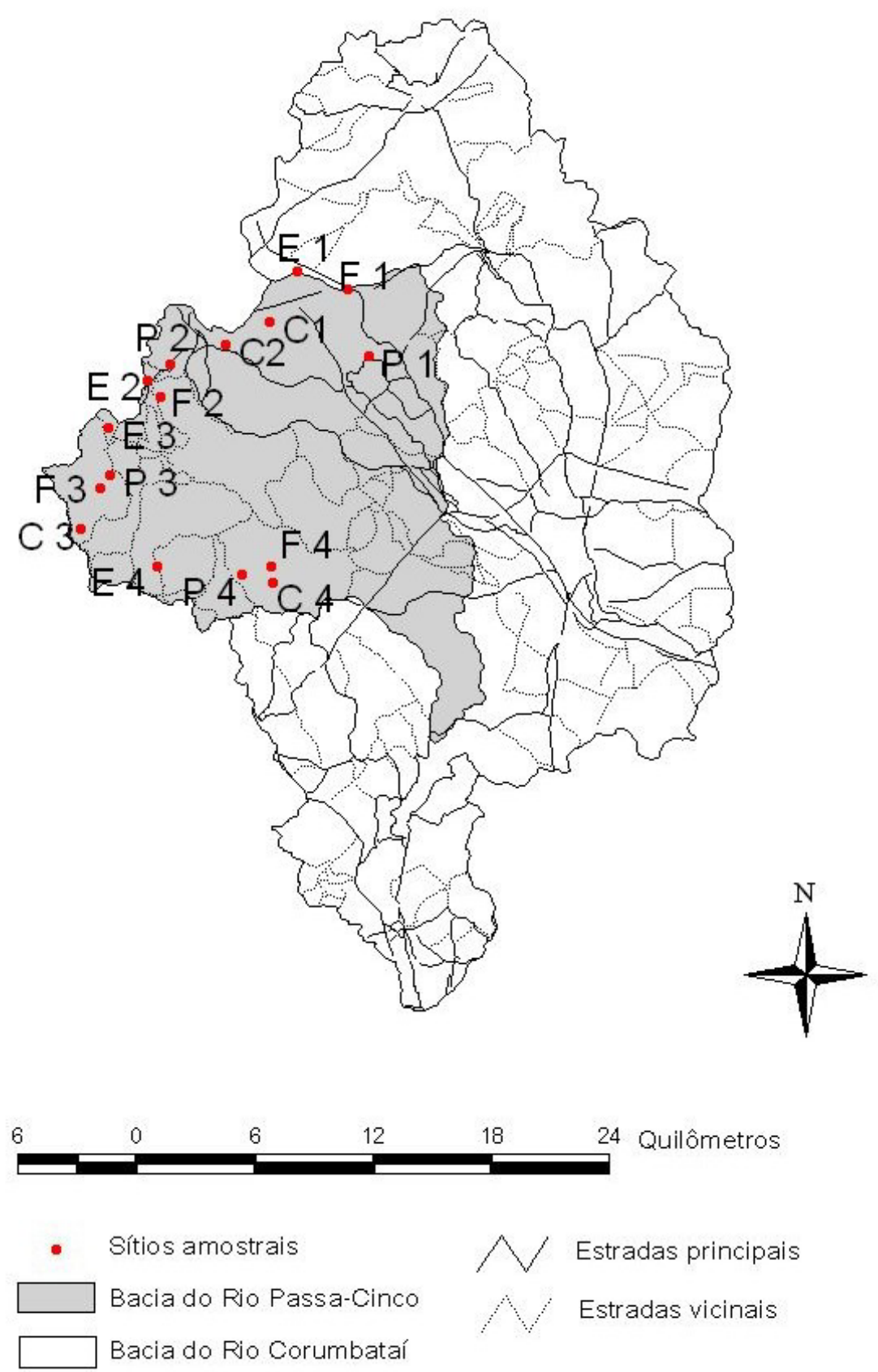

Figura 3 - Localização dos sítios amostrais na Bacia do Rio Passa-Cinco (C: canavial; P: pastagem; E: eucaliptal e F: floresta nativa) 


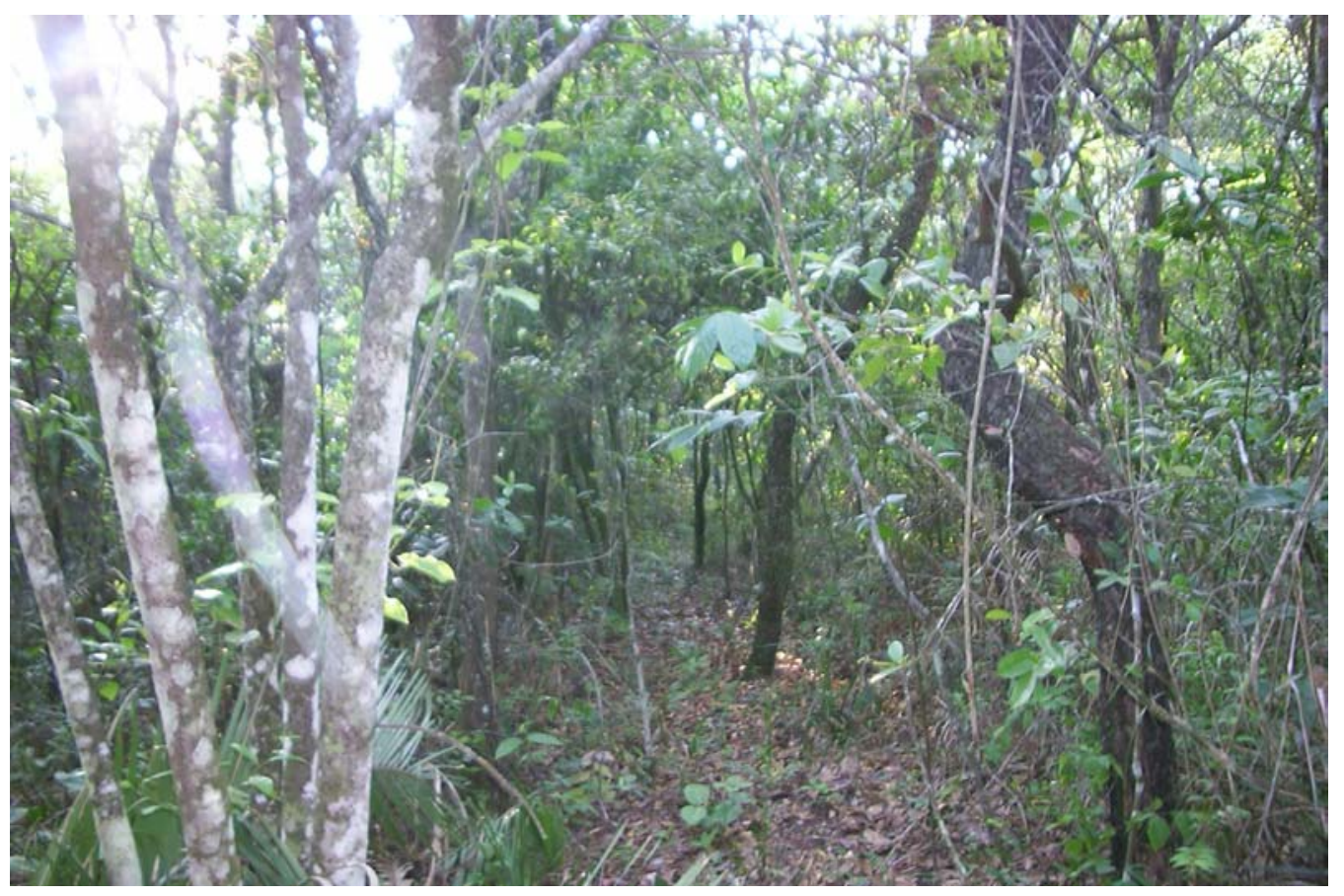

Figura 4 - Floresta Estacional Semidecidual

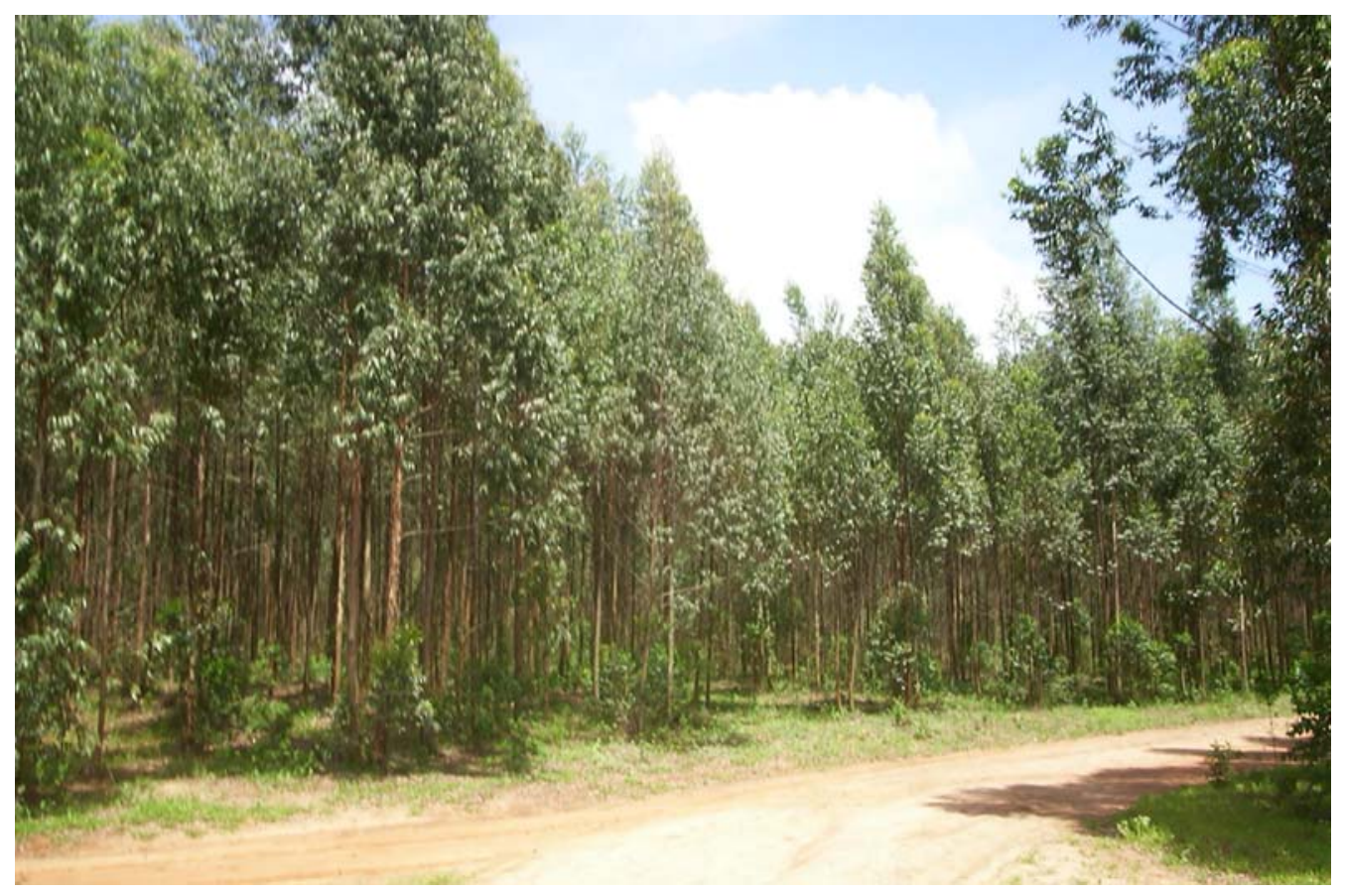

Figura 5 - Reflorestamento com Eucalyptus spp. 


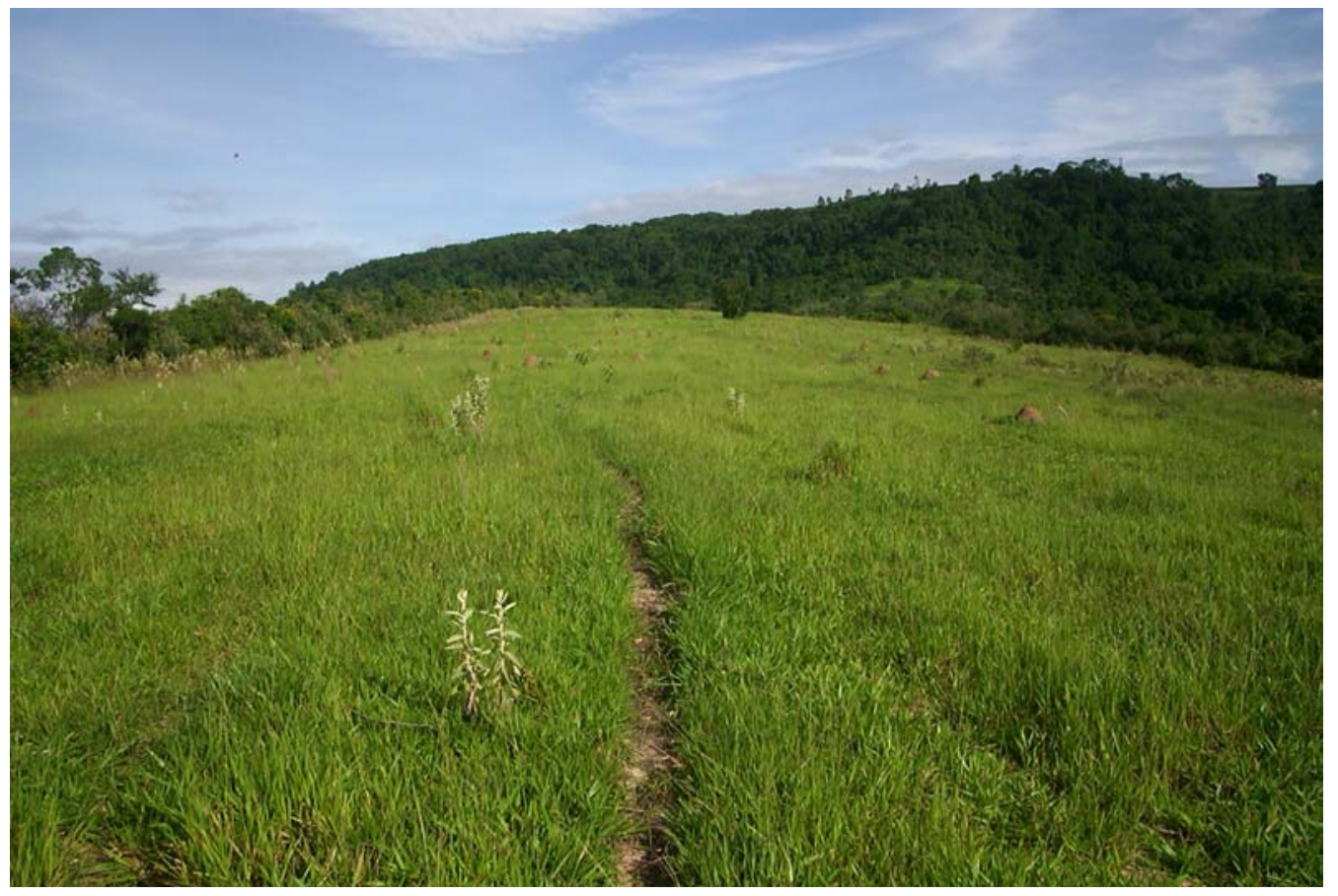

Figura 6 - Pastagem

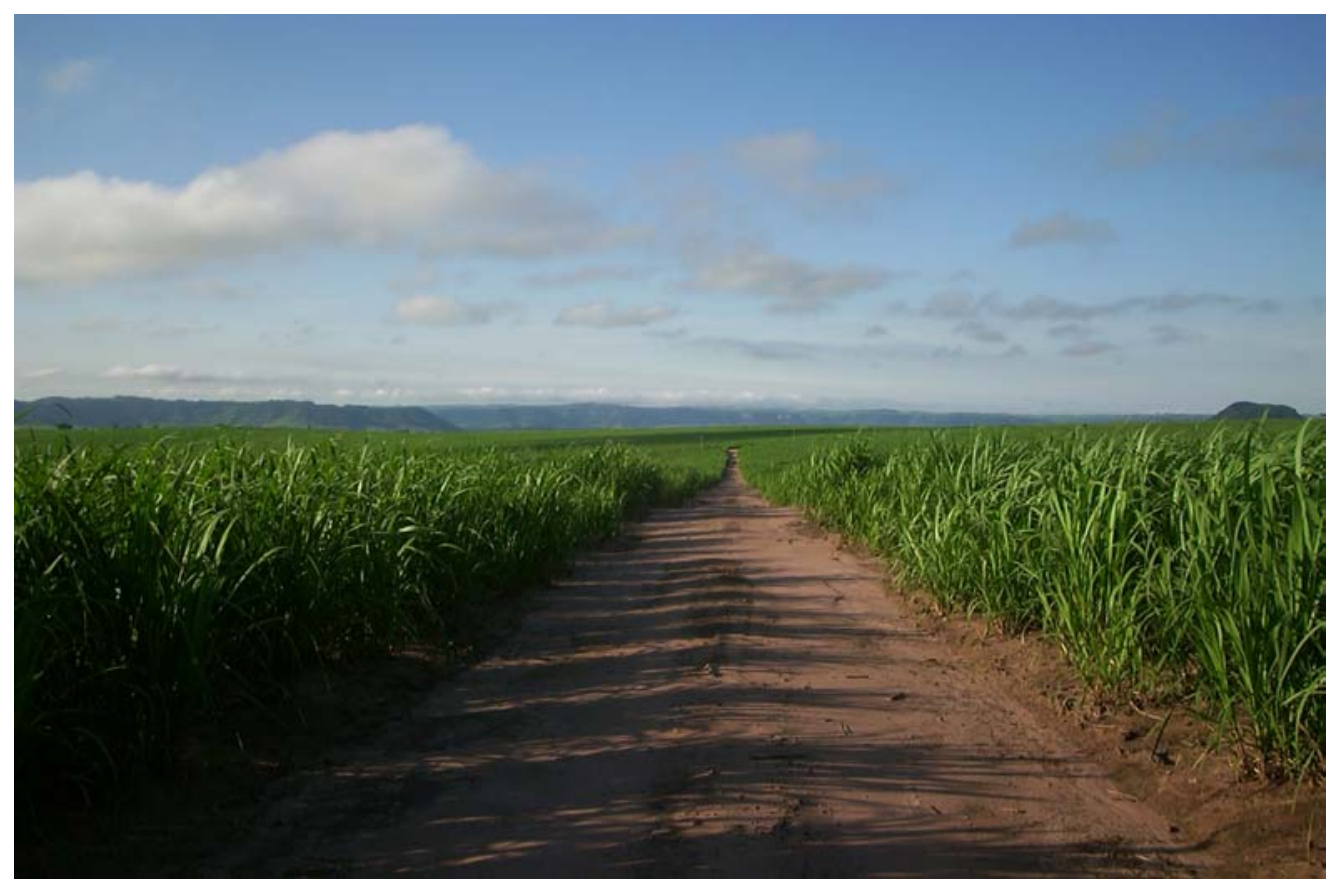

Figura 7 - Canavial 


\subsection{Esforço amostral}

As amostragens foram realizadas durante um período de 12 meses, de julho de 2003 a junho de 2004, sendo que nos meses de janeiro e abril de 2004 não houve coleta. Os quatro grupos de sítios amostrais foram sorteados previamente ao início do trabalho de campo, ordenando as coletas a serem efetuadas em cada um deles, sempre garantindo que a cada dois meses todos os sítios amostrais das quatro regiões fossem visitados. A permanência em campo por agrupamento foi de quatro dias, sendo um dia para cada um dos quatro ambientes. Totalizaram-se três campanhas de coleta durante o período seco (maio-setembro) e duas campanhas durante o período úmido (outubro-abril).

A distância percorrida não foi igual em todos os sítios, pois os mesmos variavam quanto à área e topografia, principalmente no caso dos remanescentes de floresta nativa, sendo impraticável o estabelecimento de trilhas longas em alguns deles (Figura 8). Foi estabelecida uma distância ótima de $4 \mathrm{~km}$ e, nos casos onde este total não foi possível, percorreu-se a pé a maior distância possível (Tabela 1). 


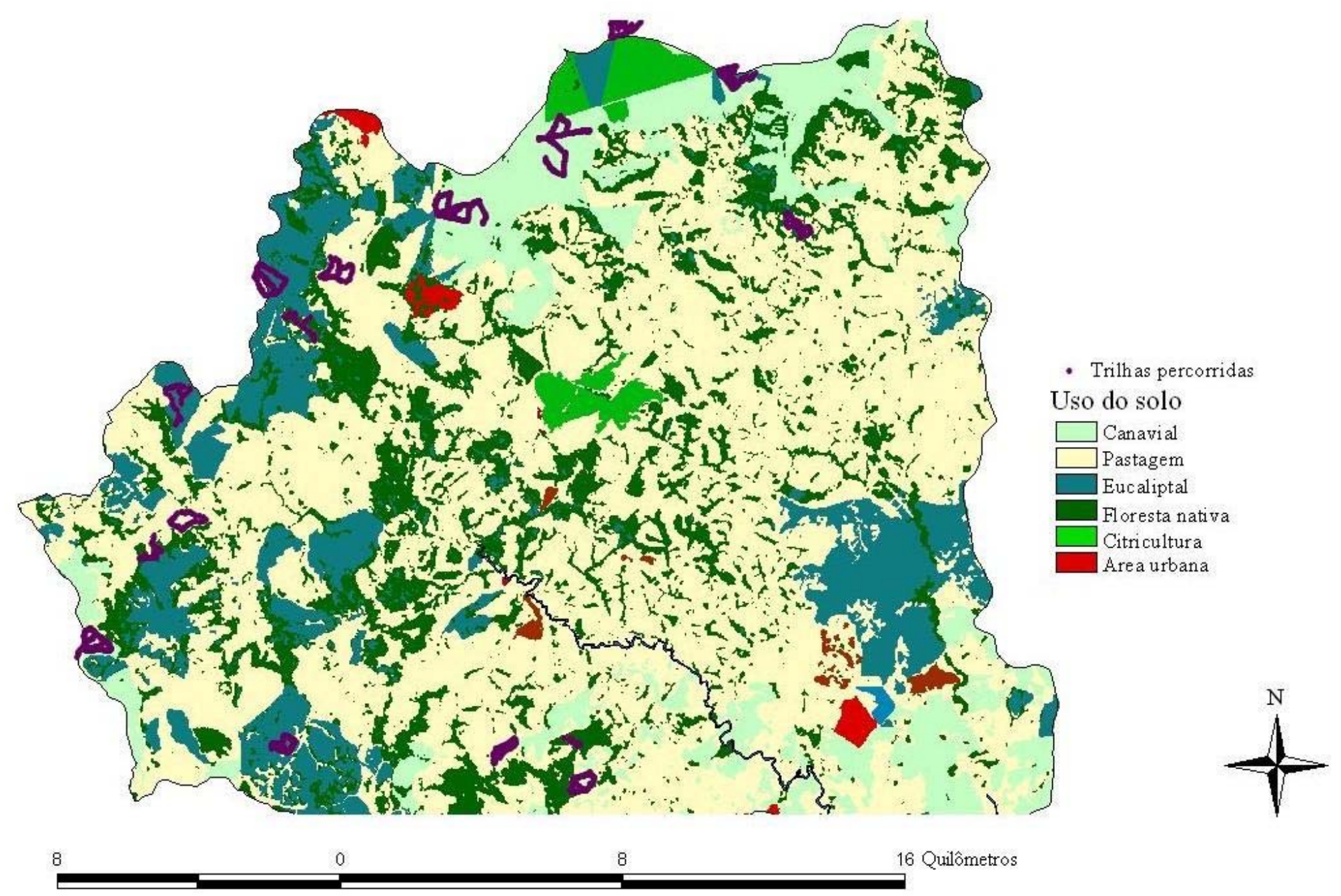

Figura 8 - Trilhas percorridas em cada sítio amostral na Bacia do Rio Passa-Cinco 
Tabela 1. Distância percorrida (quilômetros) em cada um dos sítios amostrais: comprimento das trilhas, total percorrido por sítio amostral, total percorrido por ambiente e total geral

\begin{tabular}{lcccc}
\hline Ambiente & Bloco & Trilha & Total percorrido & Total no ambiente \\
\hline Pastagem & 1 & 3,7 & 18.5 & \\
Pastagem & 2 & 3,7 & 18.5 & 71.1 \\
Pastagem & 3 & 3,1 & 15.6 & \\
Pastagem & 4 & 3,7 & 18.5 & \\
Canavial & 1 & 4,0 & 20.0 & \\
Canavial & 2 & 4,0 & 20.0 & 78.0 \\
Canavial & 3 & 4,0 & 20.0 & \\
Canavial & 4 & 3,6 & 18.0 & \\
Floresta & 1 & 3,0 & 15.0 & \\
Floresta & 2 & 2,8 & 14.0 & \\
Floresta & 3 & 2,8 & 14.0 & \\
Floresta & 4 & 3,7 & 18.5 & \\
Eucaliptal & 1 & 2,8 & 13.8 & \\
Eucaliptal & 2 & 4,0 & 20.0 & \\
Eucaliptal & 3 & 4,2 & 21.0 & \\
Eucaliptal & 4 & 3,8 & 19.0 & \\
& & Total & & \\
\hline
\end{tabular}

\subsection{Riqueza e diversidade de espécies}

Para estimar a diversidade de espécies foram utilizados tanto métodos diretos (contato visual) como indiretos (registros de fezes, carcaças, pegadas, marcações e sons), permitindo o registro de espécies diurnas, crepusculares e noturnas (Voss \& Emmons, 1996; Wilson et al., 1996). Com estes métodos foram obtidos dados de riqueza de espécies, freqüência de ocorrência e abundância relativa dos mamíferos de médio e grande porte.

Foi utilizado o método de observação em transectos lineares (i.e., trilhas), percorridos a pé, segundo Buckland et al. (1996). As caminhadas, com duração entre 3:00 h e 4:00 h, foram realizadas de manhã entre 6:00 h e 10:00 h, com velocidade constante e próxima de $1 \mathrm{~km} / \mathrm{h}$, com paradas a cada 50-100 m para observação detalhada 
do local, conforme sugerido por Cullen Júnior et al. (2000; 2001). Foram anotados os horários de início e fim do percurso, bem como o horário de encontro, espécie avistada, localização na trilha, tamanho do grupo e sexo (quando possível), além de dados meteorológicos como umidade relativa do ar, temperatura e precipitação (Buckland et al., 1996; Chiarello, 1999; Cullen Júnior et al., 2000; 2001). Esporadicamente também foram realizadas caminhadas à tarde, entre 15:00 h e 19:00 h, e à noite, entre 19:00 h e 22:00 h.

As mesmas trilhas foram utilizadas para observação de pegadas, considerando-se cada registro como um indivíduo encontrado. Tomou-se o cuidado de não registrar o mesmo animal mais de uma vez, seguindo-se os rastros ao longo das trilhas. Foram considerados indivíduos diferentes apenas os casos em que as pegadas de mesma idade apareciam lado a lado no mesmo sentido. Todas as pegadas encontradas foram identificadas com base na experiência prévia do observador, guias de campo (Aranda, 1981; Becker \& Dalponte, 1999; Emmons \& Feer, 1990) e consulta a especialistas, no caso de felinos.

Sempre que possível foram tomadas algumas medidas das pegadas, tais como: comprimento e largura totais, comprimento e largura da palma para os digitígrados e comprimento e largura totais para os ungulígrados, bem como comprimento total da passada (Figuras 9 e 10) (Becker \& Dalponte, 1999; Smallwood \& Fitzhugh, 1995). 


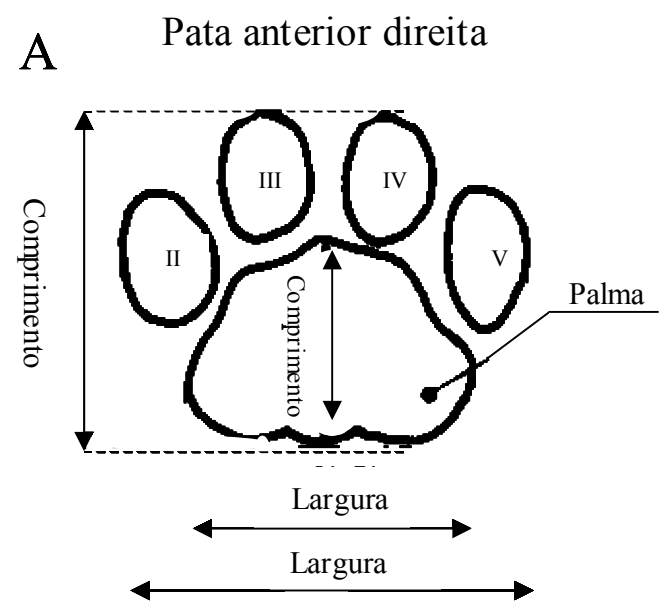

C 1 Pata Anterior Direita
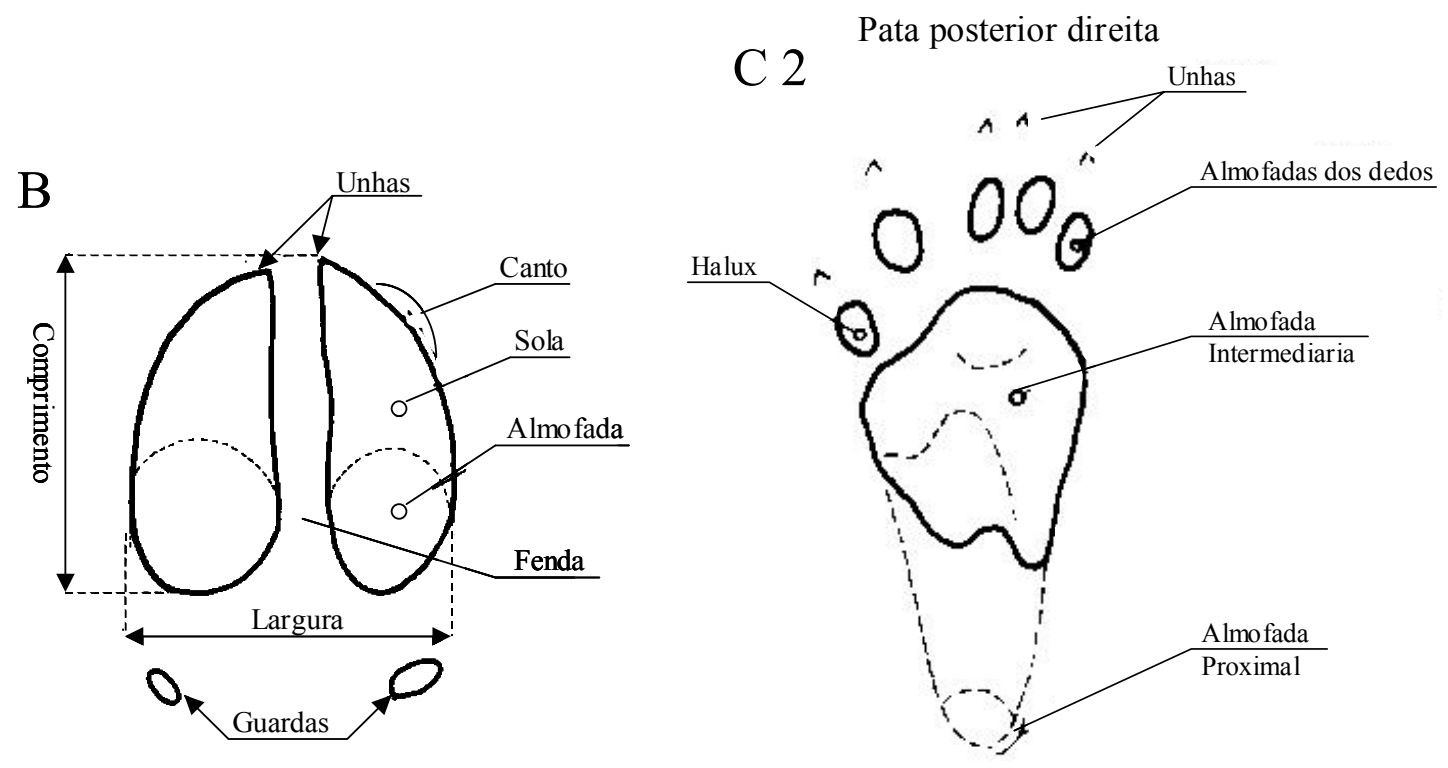

Figura 9 - Medidas padrão para rastros de mamíferos: A - Digitígrado, B - Ungulígrado, C1 e C2 Plantígrado. (Modificado de Becker \& Dalponte, 1999) 


\section{Eixo e sentido de marcha}

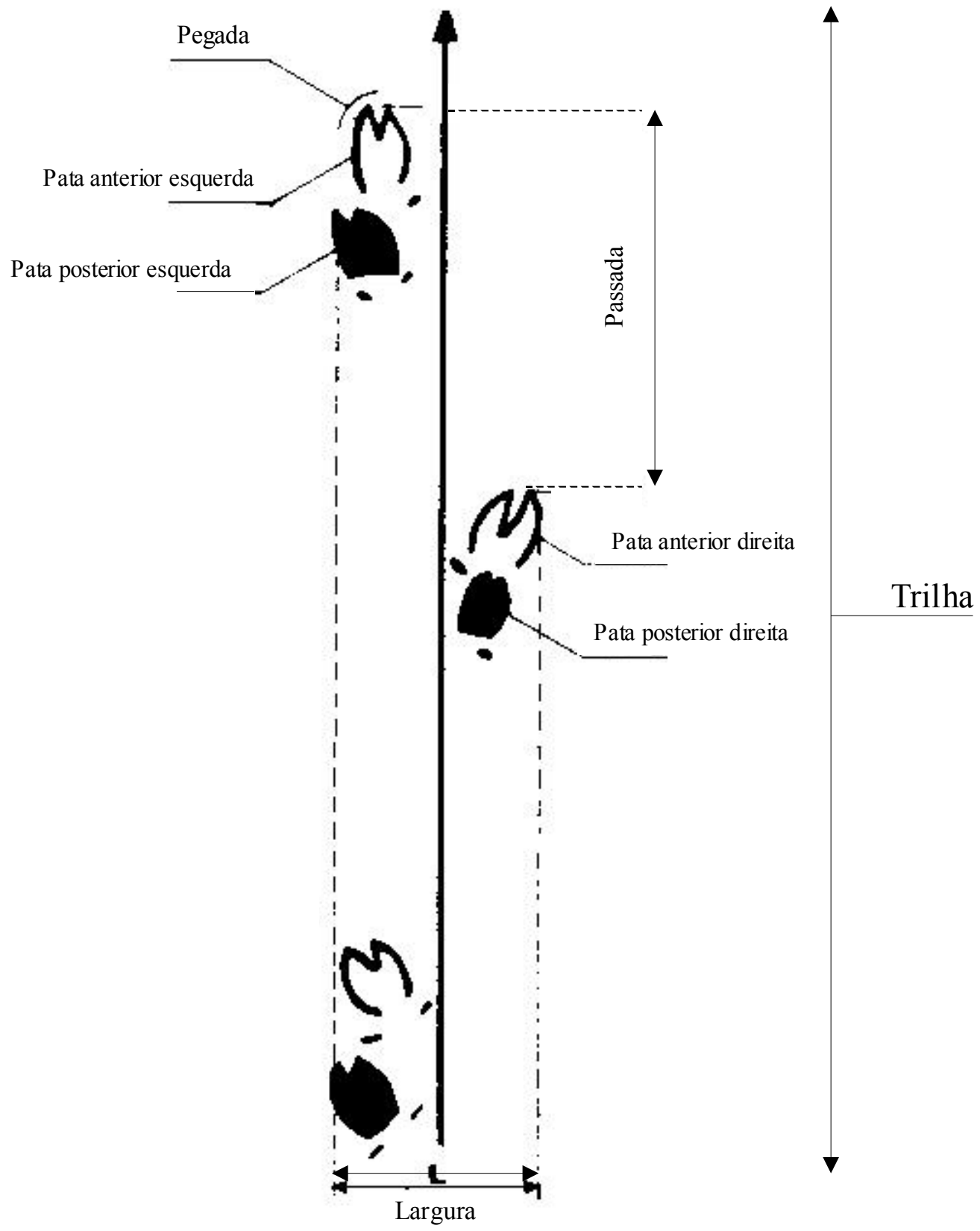

Figura 10 - Medidas padrão utilizadas para trilhas de mamíferos (Modificado de Becker \& Dalponte, 1999) 
As pegadas encontradas em boas condições foram reproduzidas em folha de acetato com o auxílio de uma placa de vidro e fotografadas (Figura 11), como forma de registro permanente (Wilson et al., 1996). Tal processo também auxiliou a identificação das espécies, principalmente para aquelas que apresentam características similares, como é o caso dos felinos.
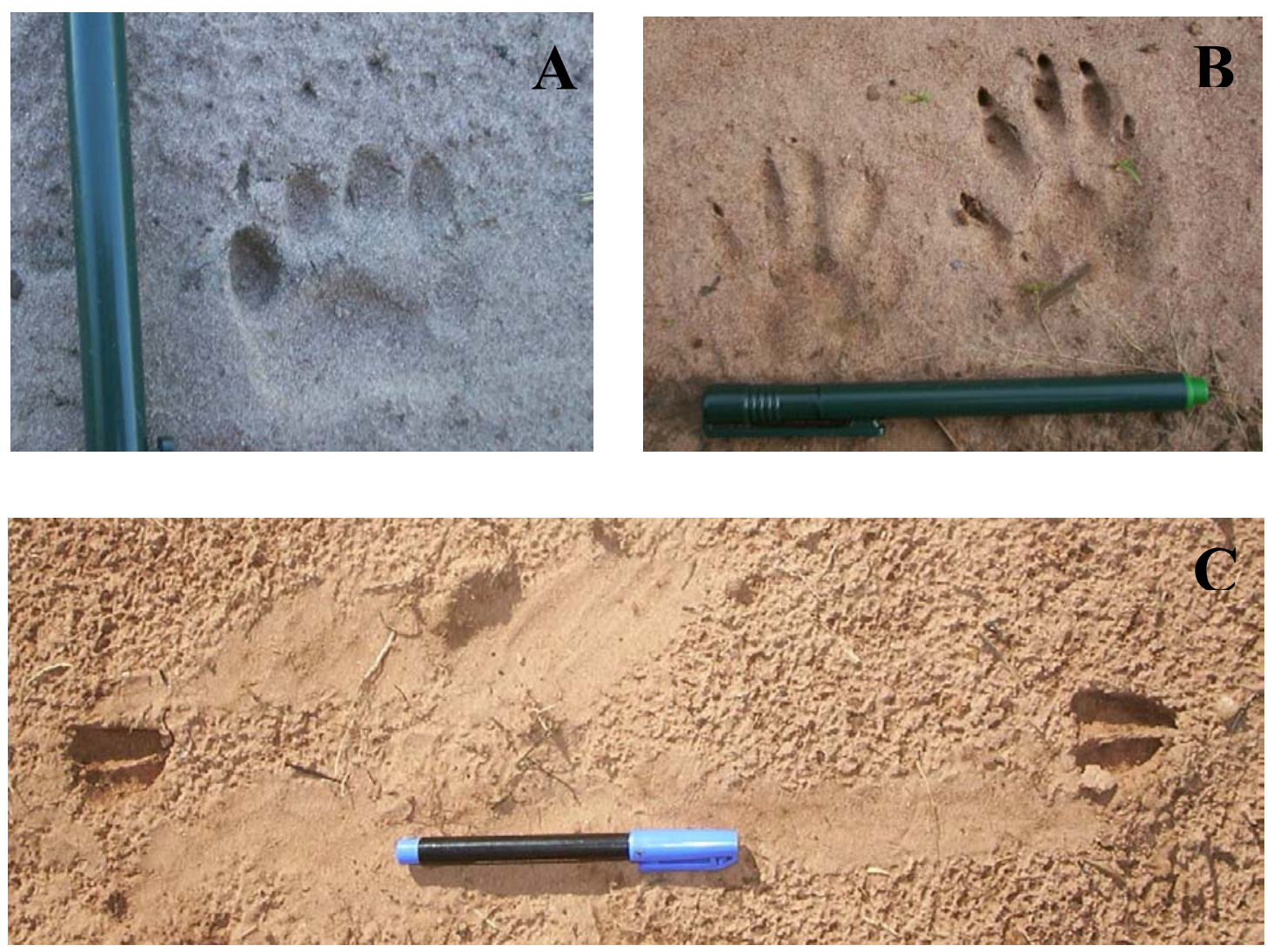

Figura 11 - Rastros de espécies registradas na região de estudo: A - cangambá (Conepatus semistriatus); B - guaxinim (Procyon cancrivorous) e C - passada de veado-catingueiro (Mazama gouazoubira)

\subsection{Estrutura da vegetação}

A caracterização da vegetação dos sítios amostrais foi realizada por meio da análise das seguintes características estruturais: porcentagem de cobertura do dossel e porcentagem de cobertura do solo (estratos herbáceo e arbustivo) com auxílio de um 
densitômetro (GRS Densitometer), número de estratos, altura média dos estratos, número de morfoespécies com DAP $>10 \mathrm{~cm}$, altura média das árvores, número de morfoespécies arbustivas (exceto nos fragmentos florestais nativos, onde esta foi considerada como porcentagem de cobertura do solo), número de troncos caídos, altura da serrapilheira, porcentagem de lianas e porcentagem de bromélias.

No caso das áreas de fragmentos florestais nativos foram caracterizadas três parcelas de $10 \mathrm{~m} \times 10 \mathrm{~m}$, nos plantios de eucalipto três parcelas de $5 \mathrm{~m} \times 5 \mathrm{~m}$, no caso do canavial e da pastagem foram feitas três parcelas de $3 \mathrm{~m} \times 3 \mathrm{~m}$ por se tratarem de ambientes com presença predominante de herbáceas. Para cada sítio amostral também foi feito um diagrama de perfil da vegetação, o que facilita a caracterização da estratificação dos ambientes.

\subsection{Metodologia analítica}

\subsubsection{Esforço amostral}

Para a riqueza de espécies, foram feitas curvas de acúmulo para cada um dos ambientes e para a bacia como um todo, agrupando-se os sítios amostrais. Estas curvas foram ajustadas com uso de um estimador não-paramétrico, utilizando-se o programa EstimateS Win 700 (Colwell, 1994-2004). Optou-se pelo uso de um estimador nãoparamétrico porque, em geral, estes apresentam desempenho bastante acurado quando comparados diretamente ao uso direto das curvas de acúmulo, sendo, portanto, menos tendenciosos (Brose et al., 2003). Assim, utilizou-se o estimador Bootstrap, pois, à medida que novas espécies são acrescentadas ao total, este passa a ser independente do tamanho amostral (Colwell \& Coddington, 1994).

Devido ao fato de que, em qualquer curva do coletor, a ordem na qual as amostras são adicionadas ao total afeta o formato da mesma, foi realizado o procedimento de rarefação, pelo qual são feitas aleatorizações das amostras a fim de se eliminar esta arbitrariedade (Colwell \& Coddington, 1994). Para todas as curvas foram realizadas 1000 aleatorizações das amostras (Tozetti, 2002). 
Para verificar se as curvas obtidas apresentam diferenças significativas quanto à inclinação, foram gerados modelos de regressão de cada uma delas e foi feita uma Análise de Co-Variância (Ancova) para verificar uma possível diferença entre suas inclinações (sensu Zar, 1999, página 369), tendo seu nível de significância ajustado pelo procedimento de correção de Bonferroni (Sokal \& Rohlf, 1969).

\subsubsection{Diferença entre os ambientes quanto à riqueza e freqüência de ocorrência}

A riqueza e a freqüência de ocorrência da comunidade de mamíferos, como um todo, foram comparadas entre os diferentes ambientes amostrados por meio de Análise de Variância Aninhada (Nested Anova) e, quando detectada alguma diferença, utilizouse o teste a posteriori Tukey HSD ('honest significant difference') a fim de indicar a origem de tal diferença. A Análise de Variância Aninhada foi utilizada, pois se pretendeu testar a presença de uma variação entre os quatro agrupamentos amostrados e, além disso, se houve variação entre os ambientes per se, pois ambos são considerados hierárquicos já que os ambientes estão dentro dos agrupamentos (Sokal \& Rholf, 1969).

O número de registros de cada espécie foi considerado como sua freqüência de ocorrência, e estes valores foram obtidos para cada um dos ambientes amostrados. A densidade de cada espécie foi expressa como um índice de abundância relativa, considerando-se a freqüência de ocorrência a cada $10 \mathrm{~km}$ percorridos. Para ambas, os valores foram comparados com o teste não-paramétrico de Kruskal-Wallis (Siegel, 1956) seguido do procedimento de comparação múltipla de Dunn (Zar, 1999).

Devido à diferença na distância percorrida em cada um dos sítios amostrais, para os cálculos relativos à freqüência de ocorrência e ao índice de abundância relativa, foi feita uma padronização do número de registros obtidos. Com o valor total percorrido na bacia dividido pelos 16 sítios amostrais, obteve-se a distância esperada para cada um deles, de modo que todos fossem amostrados igualmente. Pôde-se, assim, calcular a freqüência de ocorrência das espécies e, a partir desta, o índice de abundância relativa.

As espécies foram, então, agrupadas em categorias tróficas: insetívoro-onívoro (IO); frugívoro-onívoro (FO); carnívoro (CA); frugívoro-herbívoro $(\mathrm{FH})$ e herbívoro- 
pastador (HG), adaptadas de Eisenberg (1981), Fonseca et al. (1996) e Robinson \& Redford (1986a; 1986b). Para testar possíveis diferenças na riqueza de espécies, freqüência de ocorrência e abundância relativa de cada categoria trófica entre as diferentes categorias e também entre os quatro ambientes amostrados, utilizou-se a Análise de Variância (Anova) dois fatores (Zar, 1999). O teste a posteriori Tukey HSD foi utilizado para determinar a origem das diferenças quando detectadas.

Para todas as análises foram utilizados os pacotes estatísticos BioEstat 3.0 (Ayres et al., 2003), Statistica 6.0 (StaSoft Inc., 2001) e Minitab 14 (Minitab Inc., 2003).

\subsubsection{Diferença entre os ambientes quanto à diversidade}

A diversidade de espécies foi calculada para cada sítio amostral utilizando-se o Índice de Shannon (H') para amostras aleatórias. Este índice subestima a diversidade de populações em amostras pequenas, mas tal fato é minimizado quando o número de amostras aumenta (Zar, 1999). Também foi calculada a homogeneidade, ou Índice de Eqüitabilidade de Pielou (J'), que utiliza o valor obtido com o índice de diversidade de Shannon (H') e o valor máximo de diversidade esperada (H'máx). Este varia de zero a um, sendo que valores próximos a um indicam a maior eqüitabilidade das espécies na amostra, ou seja, as espécies apresentam abundâncias semelhantes. Como geralmente o número de espécies é subestimado, J' é um valor tendencioso, superestimando a homogeneidade da população (Zar, 1999).

Devido ao fato de muitos autores desaprovarem o uso do índice de Shannon, por considerá-lo uma medida insensível aos atributos da distribuição das espécies (May, 1975) e não apresentar uma interpretação biológica direta (Goodman, 1975), também foi calculado o índice de heterogeneidade de Simpson, que é uma opção sugerida por Alatalo \& Alatalo (1977), Peet (1974) e Routledge (1979). Este índice é uma medida de dominância, ponderando sobre a abundância das espécies mais comuns, mais do que fornecendo uma medida de riqueza (Magurran, 1988). É usualmente expresso como 1/D, computando assim a heterogeneidade das amostras. Quanto maior o valor obtido (1/D), mais diversa a amostra. Os valores obtidos em cada um dos três índices foram 
comparados pelo teste não-paramétrico de Kruskal-Wallis (Siegel, 1956) seguido do procedimento de comparação múltipla de Dunn (Zar, 1999).

Também foram feitas curvas de distribuição das espécies, por ambiente, e estas foram testadas, utilizando-se o teste do $\chi^{2}$ de aderência, a diferentes modelos para verificar qual o tipo de distribuição que apresentaram. O uso de modelos permite atentar para uma base teórica com a intenção de compreender a relação entre riqueza de espécies e abundância. Os modelos testados foram: Séries geométricas, Log-Normal, Séries Logarítmicas e 'Broken Stick', de acordo com o apresentado em Magurran (1988).

As constituições específicas dos ambientes foram comparadas por meio de Análise de Correspondência. Esta análise é utilizada geralmente na ecologia vegetal, mas vêm sendo bastante empregada em outros estudos ecológicos, podendo ser aplicada neste caso, já que trata de uma correlação entre a comunidade de mamíferos (espécies) e os ambientes (Manly, 1994). Todos os cálculos foram realizados com auxílio dos pacotes estatísticos BioEstat 3.0 (Ayres et al., 2003) e Statistica 6.0 (StaSoft Inc., 2001). 


\section{RESULTADOS}

\subsection{Esforço amostral}

As curvas de acúmulo de espécies (curvas do coletor) foram ajustadas com o estimador não-paramétrico Bootstrap. Para as áreas de pastagem, estimou-se 13 espécies e foram registradas 12 (Figura 12); para as áreas de canavial foi estimado um número de 22 espécies, contra as 20 registradas (Figura 13); para o eucaliptal estimou-se 18 espécies e foram registradas 17 (Figura 14); para a floresta estacional semidecidual foi estimada a presença de 25 espécies, sendo registradas 23 (Figura 15).

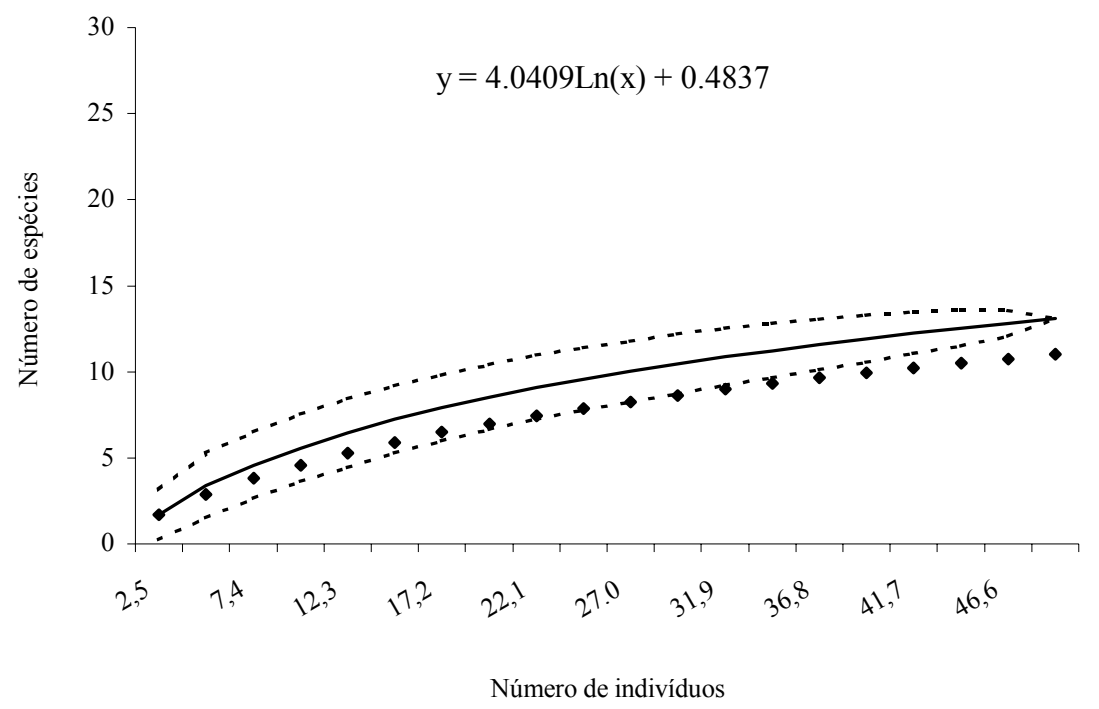

Figura 12 - Curva do coletor obtida com o estimador não-paramétrico Bootstrap (linha preta contínua), desvio padrão do estimador (linha preta pontilhada) e número de espécies observado (pontos pretos) nas áreas de pastagem 


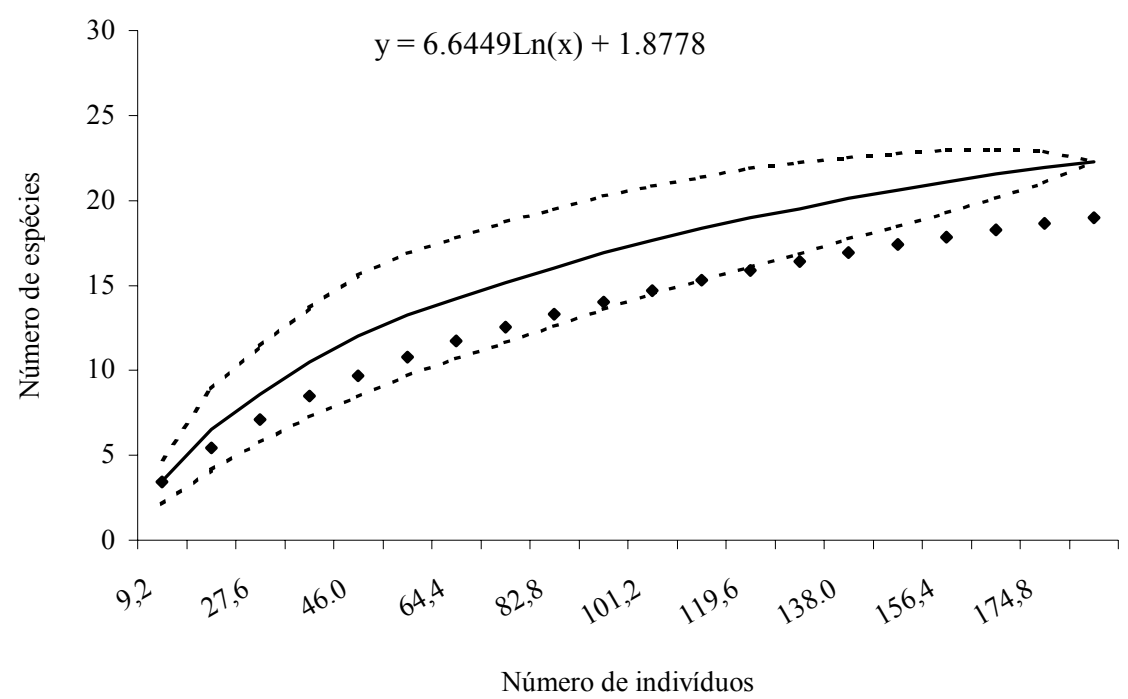

Figura 13 - Curva do coletor obtida com o estimador não-paramétrico Bootstrap (linha preta contínua), desvio padrão do estimador (linha preta pontilhada) e número de espécies observado (pontos pretos) nas áreas de canavial

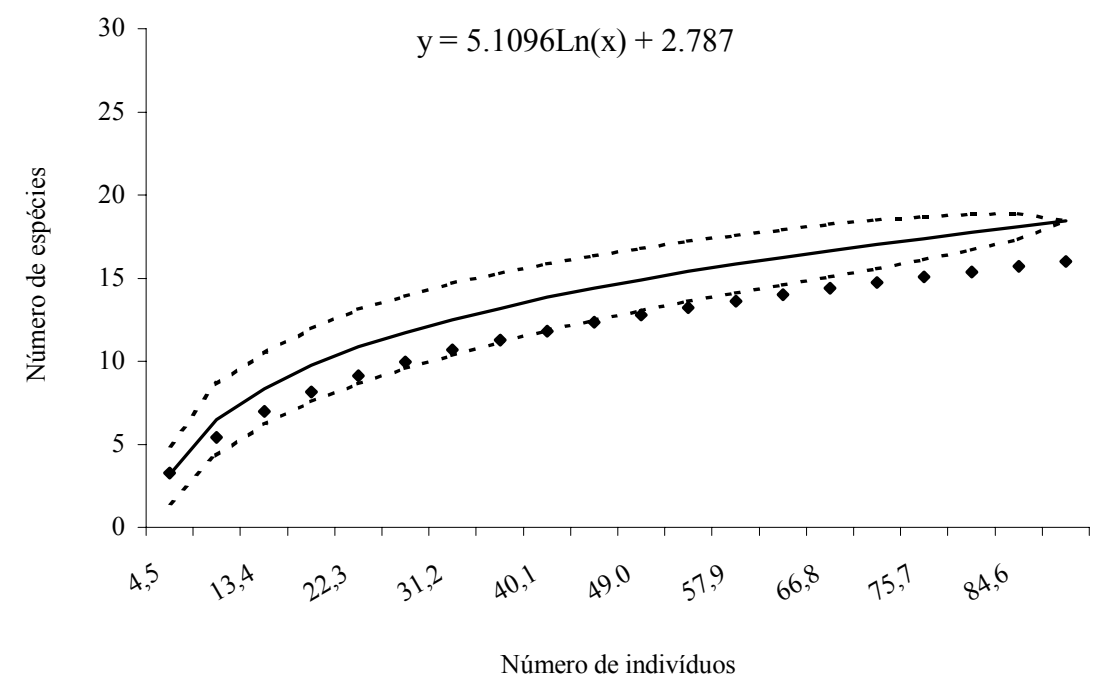

Figura 14 - Curva do coletor obtida com o estimador não-paramétrico Bootstrap (linha preta contínua), desvio padrão do estimador (linha preta pontilhada) e número de espécies observado (pontos pretos) nas áreas de eucaliptal 


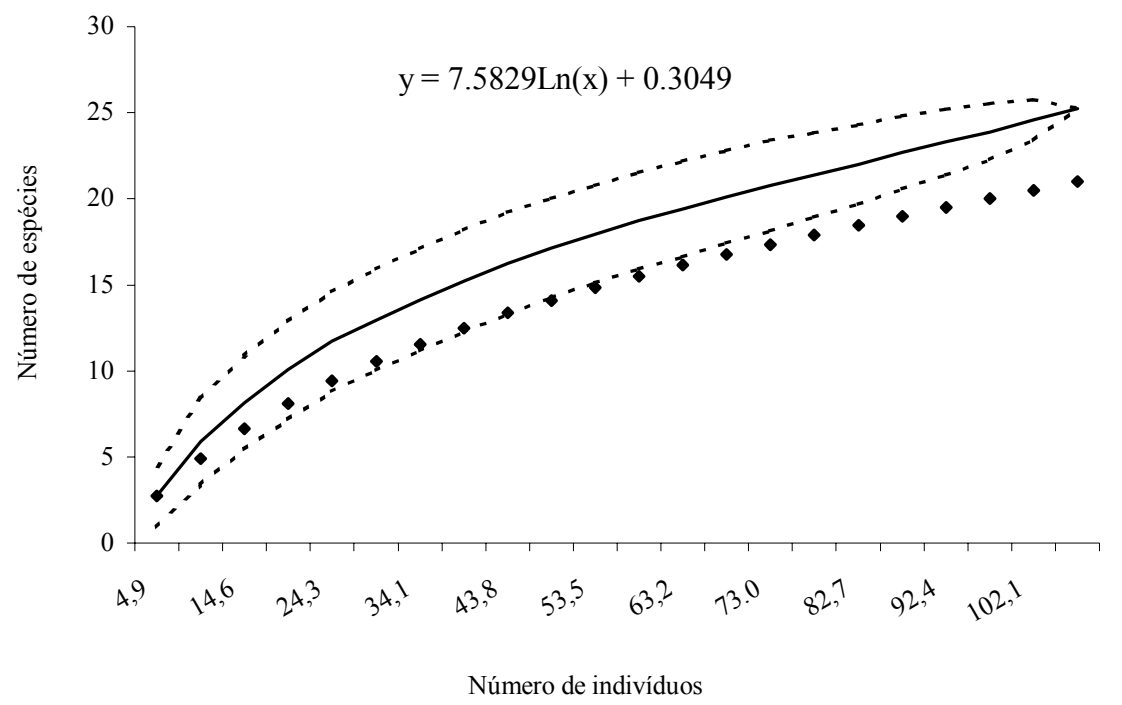

Figura 15 - Curva do coletor obtida com o estimador não-paramétrico Bootstrap (linha preta contínua), desvio padrão do estimador (linha preta pontilhada) e número de espécies observado (pontos pretos) nas áreas de Floresta Estacional Semidecidual

A Análise de Co-variância apresentou resultado significativo $\left(\mathrm{F}_{3,74}=33,8069\right.$; $\mathrm{p}<0,00001$ ), detectando diferenças entre as inclinações obtidas para cada ambiente. Esta diferença se deu entre as curvas de canavial e pastagem $\left(\mathrm{F}_{1,36}=37,8025 ; \mathrm{p}<\right.$ $0,00001)$, eucaliptal e pastagem $\left(\mathrm{F}_{1,36}=12,2814 ; \mathrm{p}<0,0012\right)$, canavial e eucaliptal $\left(\mathrm{F}_{1,36}\right.$ $=14,4215 ; \mathrm{p}<0,0005)$, e também entre canavial e floresta nativa $\left(\mathrm{F}_{1,38}=60,6619 ;\right.$ $\mathrm{p}<0,00001)$.

A curva do coletor feita para toda a região da Bacia do Rio Passa-Cinco estimou um total de 26 espécies, contra as 25 registradas (Figura 16). 


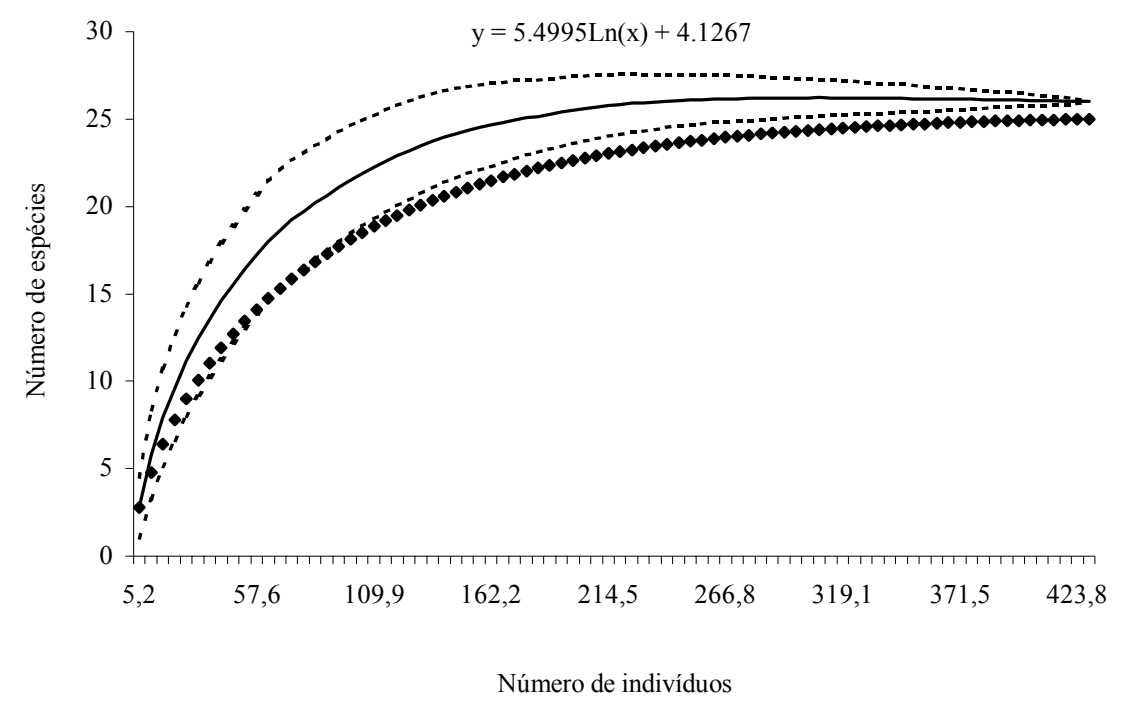

Figura 16 - Curva do coletor obtida com o estimador não-paramétrico Bootstrap (linha preta contínua), desvio padrão do estimador (linha preta pontilhada) e número de espécies observado (pontos pretos) em toda a área da Bacia do Rio Passa-Cinco

\subsection{Diferença entre os ambientes quanto à riqueza e freqüência de ocorrência}

$\mathrm{Na}$ região da bacia do Rio Passa-Cinco foi encontrado um total de 27 espécies silvestres, sendo 25 nativas e duas exóticas. Além destas, também foram observadas seis espécies domésticas na região (Tabela 2). A estimativa da riqueza e da diversidade de espécies foi feita, principalmente, com a observação de vestígios indiretos (226 registros - 93\%). Devido ao baixo número de encontros (15 visualizações - 7\%, aproximadamente $19 \mathrm{~km}$ percorridos/visualização), não foi estimada a densidade das espécies por este método, já que para estimativas precisas é recomendado um número mínimo de 40 observações independentes (Cullen Júnior \& Rudran, 2003).

Dentre as espécies encontradas, 24 foram registradas no canavial, sendo quatro domésticas; 26 na floresta nativa, sendo três domésticas; 21 no eucaliptal, das quais quatro domésticas; e 17 nas áreas de pastagem, dentre elas cinco domésticas (Lista de espécies por sítio amostral - Anexo A). Cabe ressaltar que as análises que seguem não levam em consideração as espécies domésticas registradas, bem como, Sylvilagus 
brasiliensis e Dasypus septencinctus, já que as primeiras não foram quantificadas e as duas últimas foram detectadas fora do censo.

Em relação à comunidade de mamíferos como um todo, tanto a comparação de riqueza de espécies como a da freqüência de ocorrência entre os ambientes apresentaram resultado significativo $\left(\mathrm{F}_{6,60}=6,3099 ; \mathrm{p}<0,00003\right)$ (Figuras 17 e 18). O teste de Tukey HSD realizado para detectar a origem da diferença encontrada mostrou que, quanto à riqueza, as áreas de pastagem apresentaram o menor número de espécies $(p<0,01)$ em relação ao eucaliptal e canavial. No caso da freqüência de ocorrência, a diferença encontrada deveu-se a um maior número de registros no canavial $(\mathrm{p}<0,02)$, sem diferenças entre os demais ambientes. 
Tabela 2. Lista das espécies de mamíferos de médio e grande porte encontradas na região da Bacia do rio Passa-Cinco, ambiente onde foram encontradas, hábito alimentar e nome comum das espécies. * Espécies domésticas e ** espécies exóticas

\begin{tabular}{|c|c|c|c|}
\hline Espécie & Ambiente & Dieta & Nome comum \\
\hline \multicolumn{4}{|l|}{ XENARTHRA } \\
\hline \multicolumn{4}{|l|}{ Dasypodidae } \\
\hline Cabassous unicinctus & Eu, Fl & $\mathrm{IO}$ & tatu-de-rabo-mole \\
\hline Dasypus novemcinctus & $\mathrm{Ca}, \mathrm{Eu}, \mathrm{Fl}, \mathrm{Pa}$ & IO & tatu-galinha \\
\hline Dasypus septencinctus & $\mathrm{Fl}$ & $\mathrm{IO}$ & tatuí \\
\hline Euphractus sexcinctus & $\mathrm{Ca}, \mathrm{Eu}, \mathrm{Fl}, \mathrm{Pa}$ & $\mathrm{IO}$ & tatu-peba, tatu-peludo \\
\hline Dasypodidae n. Id. & $\mathrm{Ca}, \mathrm{Eu}, \mathrm{Fl}, \mathrm{Pa}$ & $\mathrm{IO}$ & tatu \\
\hline
\end{tabular}

\section{PRIMATES}

\section{Cebidae}

Cebus apella

Callicebus nigrifrons

F1

FO macaco-prego

F1 FO sauá, guigó

\section{CARNIVORA}

\section{Canidae}

$\begin{array}{lccc}\text { Canis familiaris } * & \mathrm{Ca}, \mathrm{Eu}, \mathrm{Fl}, \mathrm{Pa} & & \text { cachorro doméstico } \\ \text { Cerdocyon thous } & \mathrm{Ca}, \mathrm{Eu}, \mathrm{Fl}, \mathrm{Pa} & \mathrm{IO} & \text { cachorro-do-mato } \\ \text { Chrysocyon brachyurus } & \mathrm{Ca}, \mathrm{Eu}, \mathrm{Pa} & \mathrm{FO} & \text { lobo-guará, guará }\end{array}$

\section{Felidae}

Felis catus *

$$
\mathrm{Ca}, \mathrm{Pa}
$$

gato doméstico

Leopardus pardalis

$\mathrm{Ca}, \mathrm{Eu}, \mathrm{Fl}$

CA

jaguatirica

Leopardus wiedii

$$
\mathrm{Ca}, \mathrm{Fl}
$$

CA

gato-maracajá

Leopardus tigrinus

$\mathrm{Ca}, \mathrm{Fl}$

CA

gato-do-mato-pequeno

Herpailurus yagouaroundi

$\mathrm{Ca}, \mathrm{Eu}, \mathrm{Fl}$

CA

gato-mourisco, jaguarundi

Puma concolor

$\mathrm{Eu}, \mathrm{Fl}, \mathrm{Pa}$

CA

onça-parda, suçuarana

\section{Mustelidae}

Conepatus semistriatus

Eira barbara

$\mathrm{Ca}, \mathrm{Eu}$

IO

$\mathrm{Eu}, \mathrm{Fl}$

CA

Galictis cuja

$\mathrm{Ca}, \mathrm{Eu}$

CA

$\mathrm{Fl}, \mathrm{Pa}$

CA

cangambá, jaritataca

irara, papa-mel

Lontra longicaudis

Procyonidae

Nasua nasua

$\mathrm{Ca}, \mathrm{Eu}, \mathrm{Fl}$

FO

furão

lontra

Procyon cancrivorous

$\mathrm{Ca}, \mathrm{Eu}, \mathrm{Fl}, \mathrm{Pa}$

FO

quati

guaxinim, mão-pelada 
Tabela 2. Lista das espécies de mamíferos de médio e grande porte encontradas na região da Bacia do rio Passa-Cinco, ambiente onde foram encontradas, hábito alimentar e nome comum das espécies. * Espécies domésticas e** espécies exóticas

\begin{tabular}{lccr}
\hline \multicolumn{1}{c}{ Espécie } & Ambiente & Dieta & Nome con \\
\hline $\begin{array}{l}\text { RODENTIA } \\
\text { Agoutidae }\end{array}$ & & & \\
$\begin{array}{l}\text { Cuniculus paca } \\
\text { Caviidae }\end{array}$ & $\mathrm{Ca}, \mathrm{Fl}, \mathrm{Pa}$ & $\mathrm{FH}$ & paca \\
$\begin{array}{l}\text { Cavia aperea } \\
\text { Dasyproctidae } \\
\text { Dasyprocta azarae }\end{array}$ & $\mathrm{Ca}$ & $\mathrm{HG}$ & preá \\
& $\mathrm{Ca}, \mathrm{Fl}$ & $\mathrm{FH}$ & cotia
\end{tabular}

\section{PERISSODACTYLA}

\section{Equidae}

Equus cabalus *

$\mathrm{Ca}, \mathrm{Eu}, \mathrm{Fl}, \mathrm{Pa}$

cavalo

\section{ARTIODACTYLA}

\section{Cervidae}

Mazama americana

$\mathrm{Ca}, \mathrm{Fl}, \mathrm{Pa}$

$\mathrm{FH}$

veado-mateiro

Mazama gouazoubira

$\mathrm{Ca}, \mathrm{Eu}, \mathrm{Fl}, \mathrm{Pa}$

$\mathrm{FH}$

veado-catingueiro

\section{Bovidae}

Bos taurus e Bos indicus * $\mathrm{Ca}, \mathrm{Eu}, \mathrm{Fl}, \mathrm{Pa}$

Bubalus bubalis *

$\mathrm{Eu}$

$$
\text { boi e zebu }
$$

búfalo

Ovidae

Ovies áries *

$\mathrm{Pa}$

ovelha

\section{Suidae}

Sus scrofa (javali) **

$\mathrm{Ca}, \mathrm{Eu}, \mathrm{Fl}$

$\mathrm{FO}$

javali

\section{LAGOMORPHA}

\section{Leporidae}

Lepus europaeus ** $\quad \mathrm{Ca}, \mathrm{Eu}, \mathrm{Fl}, \mathrm{Pa} \quad \mathrm{HG} \quad$ lebre européia

$\begin{array}{llll}\text { Sylvilagus brasiliensis } & \mathrm{Ca}, \mathrm{Eu}, \mathrm{Fl}, \mathrm{Pa} & \mathrm{HG} & \text { tapiti, coelho }\end{array}$

Ambientes: $\mathrm{Ca}$ - canavial; Eu - floresta implantada de eucalipto; Fl - floresta nativa e Pa - pastagem. Categorias de dieta: IO - insetívoro-onívoro; FO - frugívoro-onívoro; CA - carnívoro; FH - frugívoro-herbívoro e HG herbívoro-pastador. (Adaptadas de Eisenberg, 1981; Fonseca et al., 1996 e Robinson \& Redford, 1986a, 1986b) 


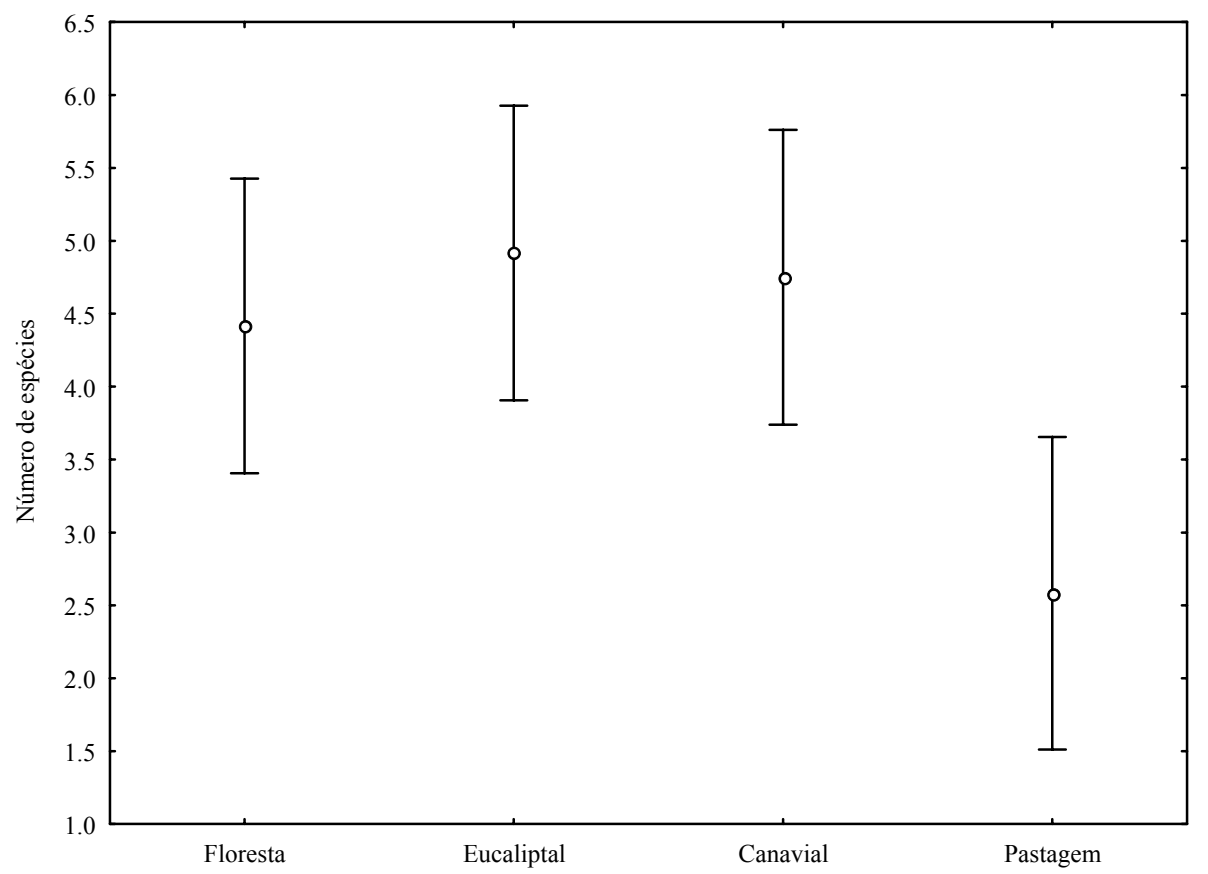

Figura 17 - Riqueza de espécies entre os ambientes amostrados (Nested Anova)

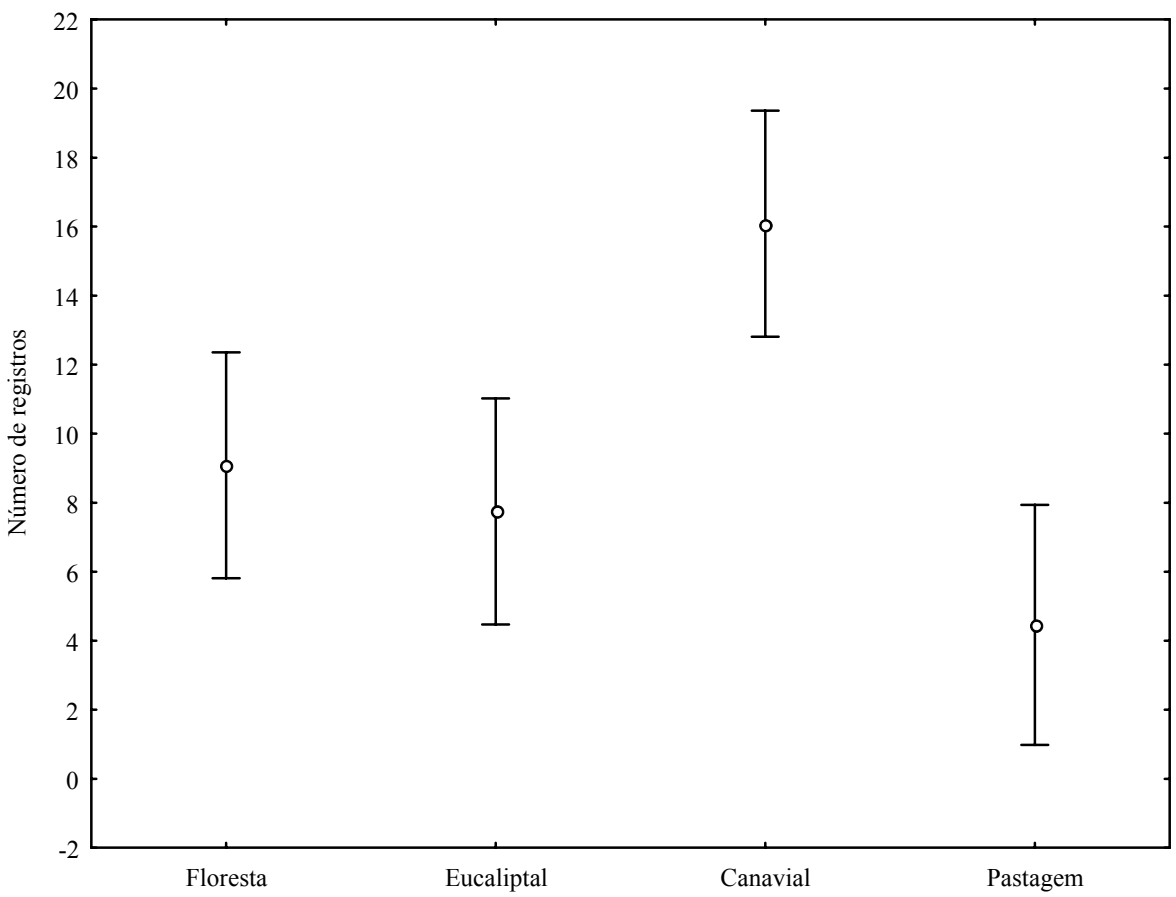

Figura 18 - Freqüência de ocorrência entre os ambientes amostrados (Nested Anova) 
A distribuição da riqueza de espécies por categoria trófica entre os ambientes pode ser observada na Figura 19. Não foi detectada diferença entre os blocos $\left(\mathrm{F}_{3,60}=\right.$ $1,183 ; \mathrm{p}>0,32)$. A Anova dois fatores detectou diferenças significativas entre as categorias tróficas, mas não entre os ambientes $\left(\mathrm{F}_{4,60}=11,07 ; \mathrm{p}<0,001 ; \mathrm{F}_{3,60}=2,50 ; \mathrm{p}\right.$ $>0,06$, respectivamente). O teste de Tukey HSD atribuiu a diferença encontrada à categoria dos Insetívoros-onívoros, como sendo diferente de todas as outras $(\mathrm{p}<0,001)$, e também entre Carnívoros e Herbívoros-pastadores $(p<0,01)$.

Observando-se o gráfico (Figura 19), pode-se notar um predomínio do grupo dos Carnívoros nos ambientes florestados (Floresta Estacional Semidecidual e floresta implantada de eucalipto), e que os Frugívoros-onívoros predominam no ambiente de floresta nativa. Os Insetívoros-onívoros aparecem em maior número no eucaliptal e nas áreas de pastagem, enquanto que nas áreas de canavial, destacam-se tanto os Insetívoros-onívoros quanto os Frugívoros-herbívoros.

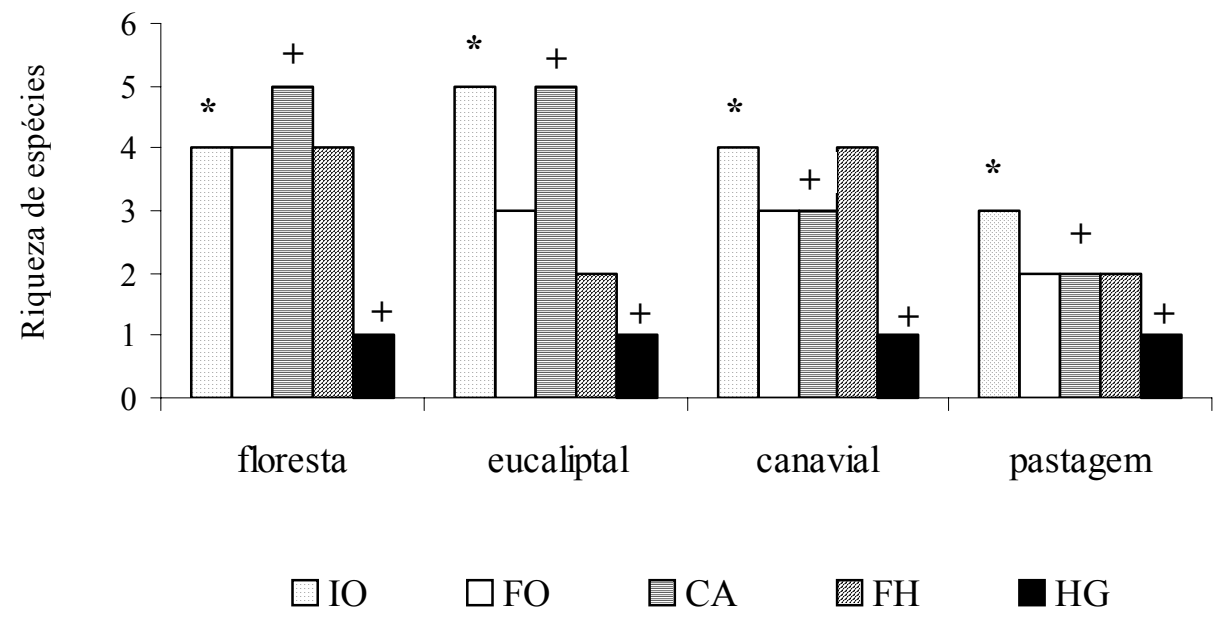

Figura 19 - Riqueza de espécies em cada um dos ambientes, de acordo as categorias tróficas definidas IO: insetívoro-onívoro, FO: frugívoro-onívoro, CA: carnívoro, FH: frugívoro-herbívoro e HG: herbívoro-pastador. * diferença significativa entre IO e os demais, + diferença significativa entre $\mathrm{CA}$ e $\mathrm{HG}$ 
Em relação à freqüência de ocorrência e à abundância relativa, o jaguarundi $(H$. yagouaroundi), o gato-maracajá (L. wiedii) e o gato-do-mato-pequeno (L. tigrinus) foram agrupados numa categoria denominada Pequenos Felinos, e os veados mateiro (M. americana) e catingueiro (M. gouazoubira), foram analisados como Mazama spp.. Isto foi feito devido à baixa ocorrência das espécies de felinos, aliada a um certo número de rastros não passíveis de diferenciação entre as espécies, o último também ocorrendo para os veados. Os resultados de freqüência de ocorrência obtidos para cada um dos ambientes podem ser observados na Tabela 3 .

Tabela 3. Freqüência de ocorrência, das espécies encontradas em cada um dos ambientes amostrados

\begin{tabular}{lcccc}
\hline & \multicolumn{4}{c}{ Frequência de Ocorrência } \\
& Cana & Eucalipto & Floresta & Pasto \\
\hline C. unicinctus & - & 3,9 & 1,2 & - \\
D. novemcinctus & 4,6 & 8,7 & 11,6 & 6,0 \\
E. sexcinctus & 18,2 & 8,7 & 3,5 & 6,0 \\
C. apella & - & - & 13,9 & - \\
C. nigrifrons & - & - & 4,6 & - \\
C. thous & 72,0 & 18,3 & 33,5 & 23,0 \\
C. brachyurus & 1,8 & 7,7 & - & 1,0 \\
Pequenos Felinos & 8,2 & 2,9 & 3,5 & - \\
L. pardalis & 0,9 & 1,0 & 3,5 & - \\
P. concolor & - & 1,0 & 4,6 & 2,0 \\
C. semistriatus & 1,8 & 2,8 & - & - \\
G. cuja & 0,9 & 3,9 & - & - \\
E. barbara & - & 1,9 & 1,2 & - \\
L. longicaudis & - & - & 1,2 & 3,0 \\
N. nasua & 1,8 & 1,0 & 8,1 & - \\
P. cancrivorous & 11,8 & 1,0 & 1,2 & 1,0 \\
Mazama spp. & 18,2 & 20,2 & 23,1 & 5,0 \\
S. scrofa & 15,5 & 1,0 & 8,1 & - \\
C. paca & 5,5 & - & 1,2 & 1,0 \\
D. azarae & 0,9 & - & 1,2 & - \\
L. europaeus & 13,7 & 5,8 & 1,2 & 1,0 \\
\hline
\end{tabular}

A comparação entre as freqüências de ocorrência de cada espécie nos quatro ambientes (Figura 20) apresentou diferença significativa somente para o cachorro-do- 
mato (C. thous) e a lebre européia (L. europaeus) $(\mathrm{H}=8,85$; g.l. $=3 ; \mathrm{p}=0,03 ; \mathrm{H}=8,97$; g.1. $=3 ; \mathrm{p}=0,03$, respectivamente), no entanto a comparação posterior de Dunn não detectou esta diferença nos ambientes. Pode-se observar que, mesmo sem a detecção da diferença entre os grupos, tanto o cachorro-do-mato como a lebre européia apareceram com maior freqüência no canavial.

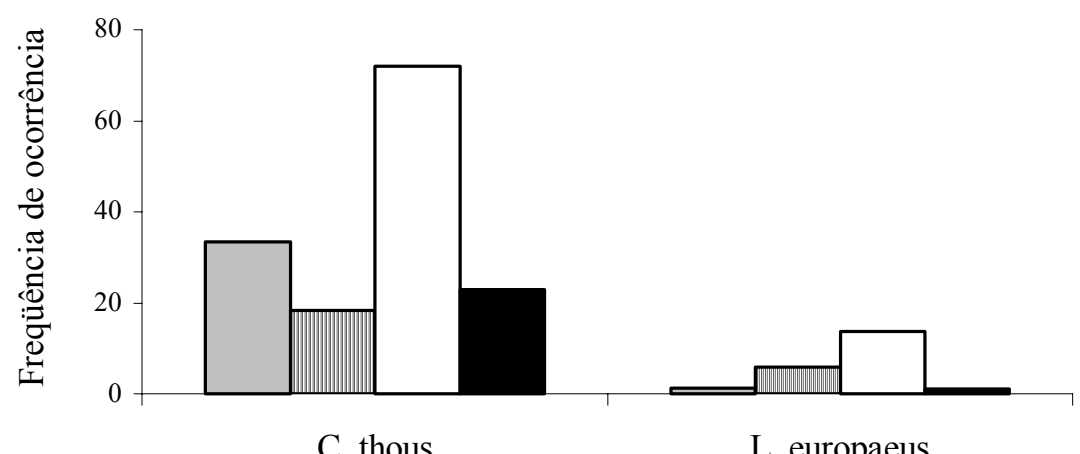

$\square$ Floresta $\square$ Eucaliptal $\square$ Canavial $\square$ Pastagem

Figura 20 - Freqüência de ocorrência do cachorro-do-mato (C. thous) e da lebre européia (L. europaeus) nos ambientes amostrados da Bacia do Rio Passa-Cinco

Quanto às demais espécies (Figura 21), mesmo sem resultados estatisticamente significativos, pode-se notar uma ocorrência 'preferencial' entre os ambientes. O canavial apresentou maior freqüência de ocorrência para cinco espécies, a floresta nativa e o eucaliptal aparecem com duas em cada ambiente, sendo que o lobo-guará $(C$. brachyurus) apresentou um valor de $\mathrm{p}=0,05$, nas áreas de eucalipto. No caso dos veados (Mazama spp.), a freqüência de ocorrência foi menor nas áreas de pastagem, sendo semelhante entre os demais ambientes.

Analisando-se a freqüência de ocorrência das espécies por categorias tróficas em cada ambiente, a Análise de Variância detectou diferenças significativas entre as categorias e em relação aos ambientes $\left(\mathrm{F}_{4,60}=12,96 ; \mathrm{p}<0,001 ; \mathrm{F}_{3,60}=4,50 ; \mathrm{p}<0,006\right.$, respectivamente). Neste caso, a análise foi feita com os dados transformados em postos, 
já que o teste de Homogeneidade de Variâncias apresentou diferença significativa, ou seja, detectou a heterogeneidade, violando a premissa da Anova (Zar, 1999). A atribuição de postos (ranks) aos dados originais faz com que a análise adquira um caráter não-paramétrico, minimizando violações nas premissas da Anova, já que não existe uma versão não-paramétrica para a Análise de Variância dois fatores. 


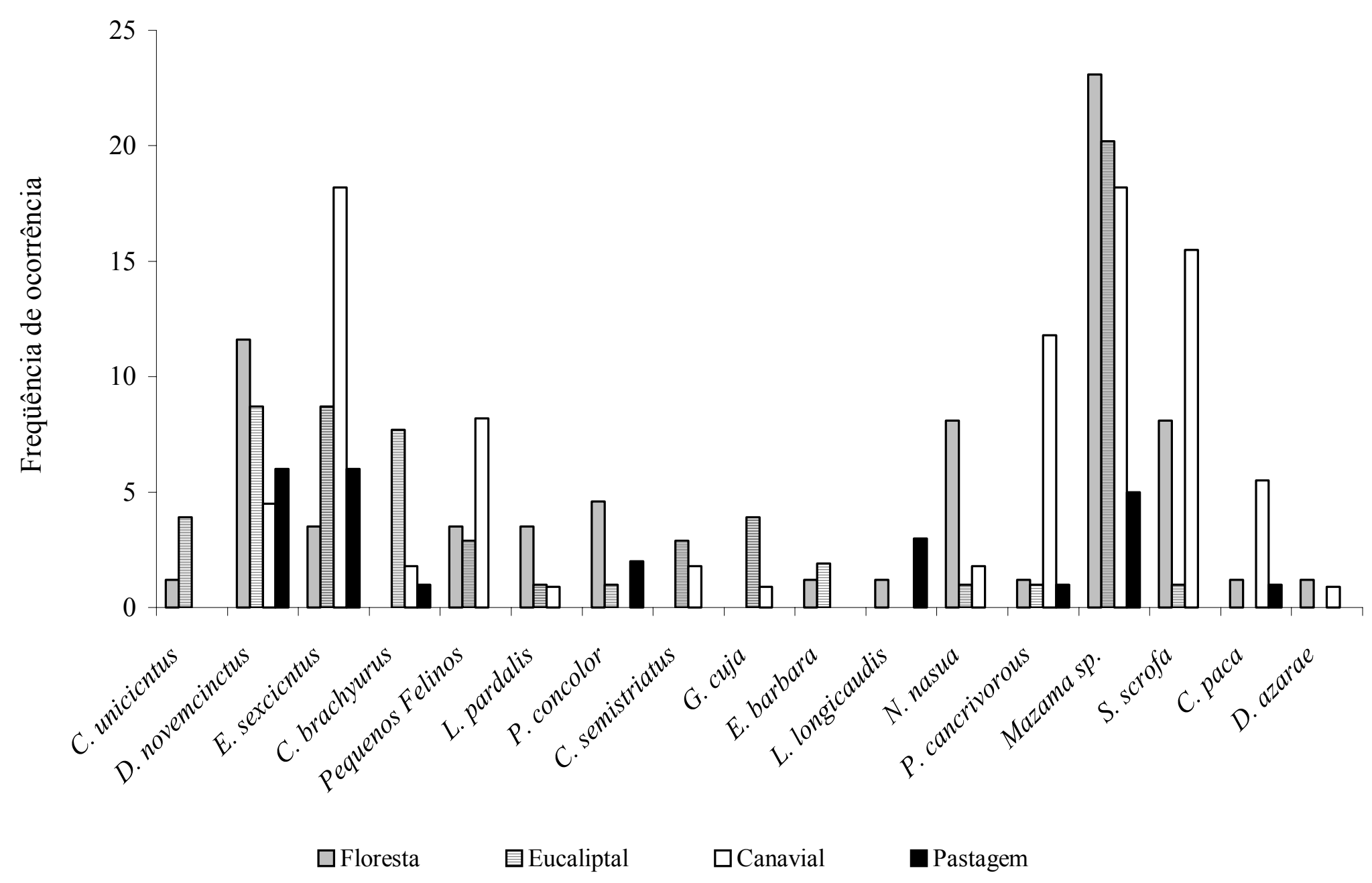

Figura 21 - Freqüência de ocorrência das espécies encontradas na bacia do Rio Passa-Cinco 
O teste de Tukey HSD, para as categorias tróficas em relação aos ambientes, mostrou uma diferença de médias dos postos entre o eucaliptal e a pastagem $(p<0,04)$ e entre o canavial e a pastagem $(\mathrm{p}<0,005)$. Já em relação às categorias de dieta, foi detectada diferença entre os Insetívoros-onívoros e todos os demais $(p<0,01)$ e também entre os Frugívoros-herbívoros e os Herbívoros-pastadores $(\mathrm{p}<0,01)$.

Percebe-se que nas áreas de canavial e de pastagem há um predomínio de espécies do grupo Insetívoro-onívoro, enquanto que os Frugívoros-herbívoros ocorrem predominantemente na floresta nativa e no canavial (Figura 22). Também pode ser observado que a floresta nativa é o ambiente que apresenta a distribuição mais equilibrada entre as categorias tróficas. Os carnívoros aparecem com uma baixa freqüência de ocorrência, que se torna menor desde a floresta nativa, passando pelo eucaliptal, canavial e atingindo o menor valor nas áreas de pastagem.

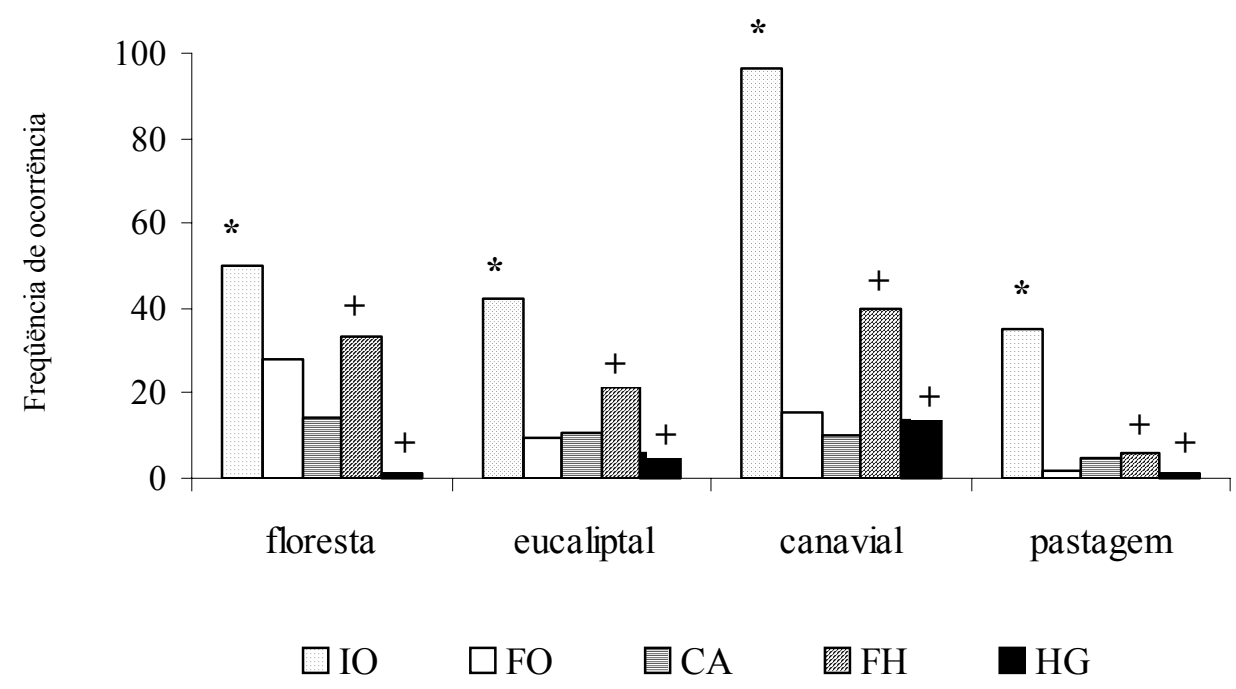

Figura 22 - Freqüência de ocorrência das categorias tróficas em cada um dos ambientes amostrados - IO: insetívoro-onívoro, FO: frugívoro-onívoro, CA: carnívoro, FH: frugívoro-herbívoro e HG: herbívoro-pastador. * diferença significativa entre IO e os demais, + diferença significativa entre FH e HG 
Quanto ao índice de abundância relativa, os resultados obtidos para cada um dos ambientes podem ser observados na Tabela 4. A comparação entre os índices de abundância relativa de cada espécie nos quatro ambientes apresentou diferença significativa somente para a lebre européia $(H=8,14 ;$ g.l. $=3 ; \mathrm{p}=0,04)$. Novamente, a comparação posterior de Dunn não detectou a diferença nos ambientes.

Tabela 4. Índice de Abundância Relativa (freqüência de ocorrência/10km percorridos) das espécies encontradas em cada um dos ambientes amostrados

\begin{tabular}{|c|c|c|c|c|}
\hline & \multicolumn{4}{|c|}{ Abundância Relativa } \\
\hline & Cana & Eucalipto & Floresta & Pasto \\
\hline C. unicinctus & - & 0,5 & 0,2 & - \\
\hline D. novemcinctus & 0,6 & 1,2 & 1,6 & 0,8 \\
\hline E. sexcinctus & 2,6 & 1,2 & 0,5 & 0,8 \\
\hline C. apella & - & - & 1,9 & - \\
\hline C. nigrifrons & - & - & 0,7 & - \\
\hline C. thous & 10,1 & 2,6 & 4,7 & 3,2 \\
\hline C. brachyurus & 0,3 & 1,1 & - & 0,1 \\
\hline Pequenos Felinos & 1,2 & 0,4 & 0,5 & - \\
\hline L. pardalis & 0,1 & 0,1 & 0,5 & - \\
\hline P. concolor & - & 0,1 & 0,7 & 0,3 \\
\hline C. semistriatus & 0,3 & 0,4 & - & - \\
\hline G. cuja & 0,1 & 0,5 & - & - \\
\hline E. barbara & - & 0,3 & 0,2 & - \\
\hline L. longicaudis & - & - & 0,2 & 0,4 \\
\hline N. nasua & 0,3 & 0,1 & 1,1 & - \\
\hline P. cancrivorous & 1,7 & 0,1 & 0,2 & 0,1 \\
\hline Mazama spp. & 2,6 & 2,8 & 3,3 & 0,7 \\
\hline S. scrofa & 2,2 & 0,1 & 1,1 & - \\
\hline C. paca & 0,8 & - & 0,2 & 0,1 \\
\hline D. azarae & 0,1 & - & 0,2 & - \\
\hline L. europaeus & 1,9 & 0,8 & 0,2 & 0,1 \\
\hline
\end{tabular}

Na Figura 23, observa-se a diferença entre os ambientes para L. europaeus, com abundância ligeiramente maior nas áreas de canavial, e para C. thous que, apesar de nãosignificativo, apresentou um valor de $p=0,06$, e cuja maior abundância ocorreu também nas áreas de canavial. Neste caso, também foi possível detectar tendências na 
abundância das demais espécies entre os diferentes ambientes, mantendo o padrão encontrado para a freqüência de ocorrência (Figura 24).

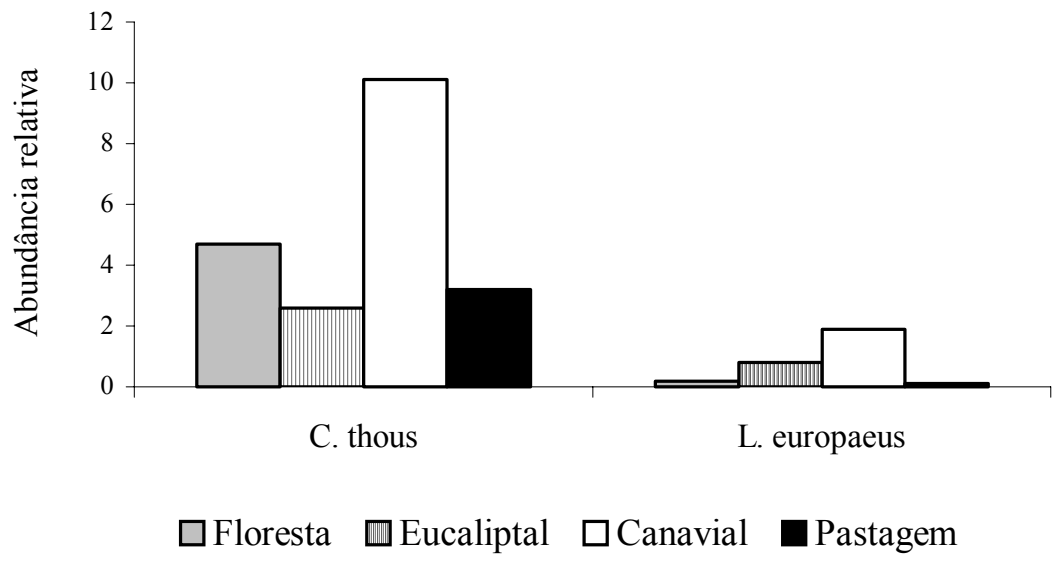

Figura 23 - Abundância relativa do cachorro-do-mato (C. thous) e da lebre européia (L. europaeus) nos ambientes amostrados da Bacia do Rio Passa-Cinco

Analisando-se a abundância relativa das espécies por categorias tróficas em cada ambiente, a Análise de Variância detectou diferenças significativas entre as categorias, e em relação aos ambientes $\left(\mathrm{F}_{4,60}=13,09 ; \mathrm{p}<0,001 ; \mathrm{F}_{3,60}=5,09 ; \mathrm{p}<0,003\right.$, respectivamente). Novamente a análise foi feita com os dados transformados em postos, pois o teste de Homogeneidade de Variâncias apresentou diferença significativa violando a premissa da Anova.

O teste de Tukey HSD, para as categorias tróficas em relação aos ambientes, mostrou uma diferença de médias dos postos entre o eucaliptal e a pastagem $(p<0,02)$ e entre o canavial e a pastagem $(p<0,002)$. Já em relação às categorias de dieta, foi detectada diferença entre os Insetívoros-onívoros e todos os demais $(p<0,001)$ e também entre os Frugívoros-herbívoros e os Herbívoros-pastadores $(p<0,01)$. 


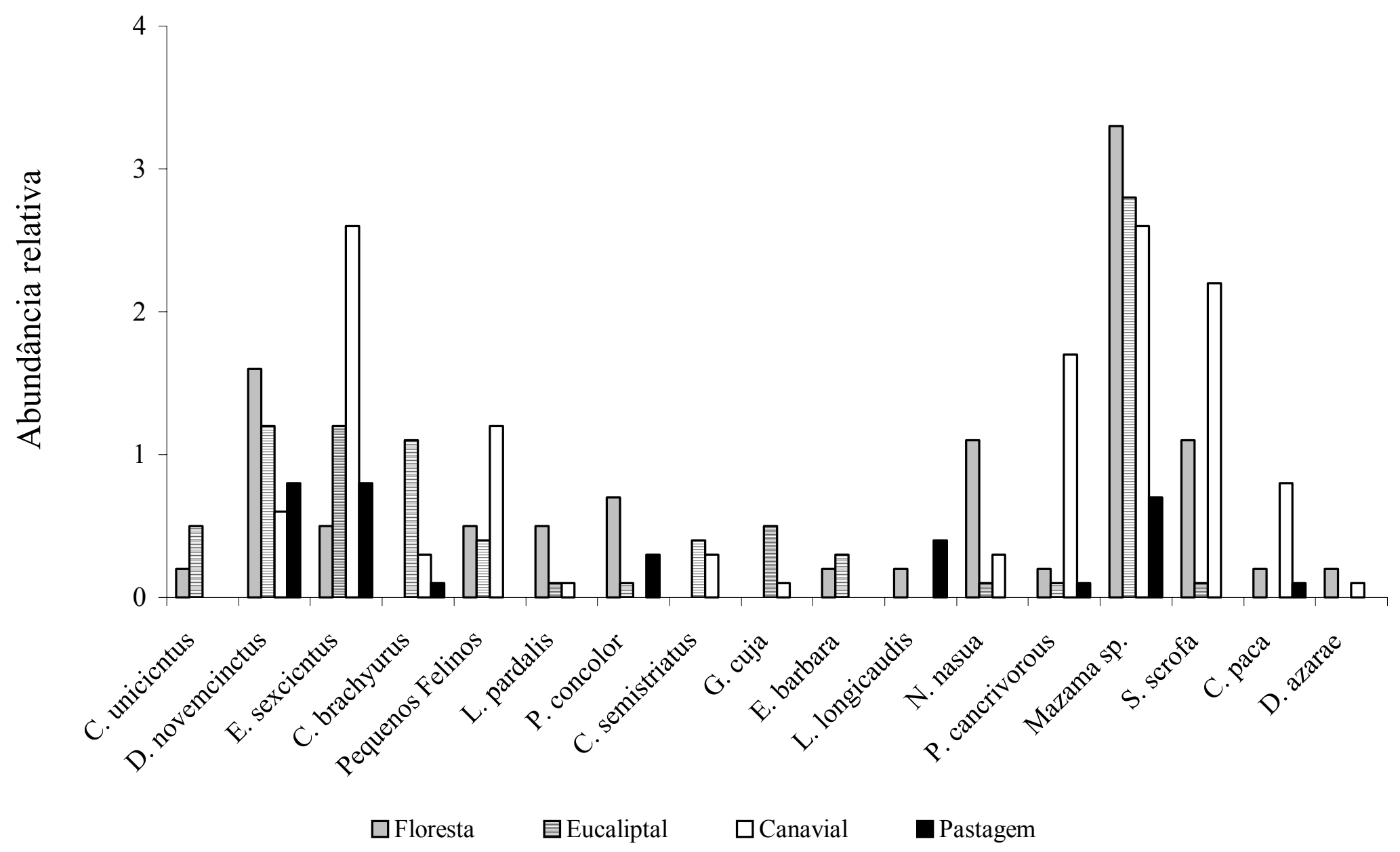

Figura 24 - Abundância relativa das espécies encontradas na bacia do Rio Passa-Cinco 
$\mathrm{Na}$ floresta nativa há um predomínio de espécies Insetívoras-onívoras, seguido por Frugívoros-herbívoros e Frugívoros-onívoros, sendo o ambiente que apresentou a maior abundância relativa da categoria dos Carnívoros (Figura 25). No eucaliptal e áreas de pastagens, houve um predomínio de espécies Insetívoras-onívoras, sem grandes diferenças entre as demais, e no canavial predominaram os Frugívoros-herbívoros.

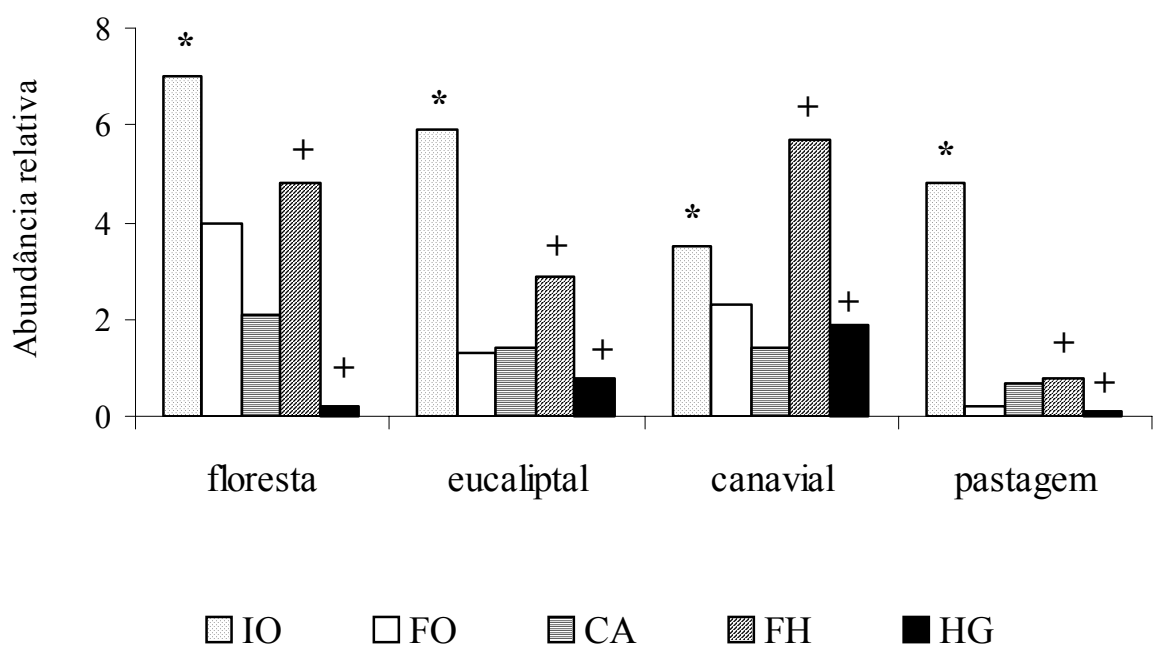

Figura 25 - Abundância relativa das categorias tróficas em cada um dos ambientes amostrados - IO: insetívoro-onívoro, FO: frugívoro-onívoro, CA: carnívoro, FH: frugívoro-herbívoro e HG: herbívoro-pastador. * diferença significativa entre IO e os demais, + diferença significativa entre FH e HG

\subsection{Diferença entre os ambientes quanto à diversidade}

Os índices de diversidade de Shannon (H'), de eqüitabilidade de Pielou (J') e de heterogeneidade de Simpson (1/D), calculados para cada sítio amostral, não apresentaram diferenças significativas, embora Simpson apresente um valor muito próximo ao significativo, demonstrando haver tendências a dominância de alguma espécie (Tabela 5). 
Tabela 5. Índice de Diversidade de Shannon (H'), Índice de Eqüitabilidade de Pielou (J') e Índice de Heterogeneidade de Simpson (1/D), obtidos para cada um dos sítios amostrais, com os respectivos valores de Kruskal-Wallis, graus de liberdade (g.l.) e o valor de $\mathrm{p}$

\begin{tabular}{lccc}
\hline & $\mathbf{H}^{\prime}$ & $\mathbf{J}^{\prime}$ & $\mathbf{1 / D}$ \\
\hline Canavial 1 & 1,73 & 0,72 & 4,28 \\
Canavial 2 & 1,26 & 0,70 & 2,89 \\
Canavial 3 & 1,54 & 0,74 & 3,91 \\
Canavial 4 & 1,80 & 0,75 & 4,35 \\
Eucaliptal 1 & 2,06 & 0,90 & 7,81 \\
Eucaliptal 2 & 1,46 & 0,61 & 13,15 \\
Eucaliptal 3 & 1,42 & 0,64 & 6,79 \\
Eucaliptal 4 & 0,88 & 0,49 & 6,60 \\
Floresta 1 & 1,83 & 0,76 & 4,44 \\
Floresta 2 & 1,15 & 0,59 & 3,98 \\
Floresta 3 & 0,72 & 0,52 & 3,44 \\
Floresta 4 & 2,26 & 0,91 & 7,66 \\
Pastagem 1 & 1,74 & 0,84 & 5,20 \\
Pastagem 2 & 0,85 & 0,77 & 3,00 \\
Pastagem 3 & 0,76 & 0,69 & 2,50 \\
Pastagem 4 & 1,98 & 1,02 & 5,16 \\
Kruskal-Wallis & $\mathbf{0 , 2 9}$ & $\mathbf{3 , 0 7}$ & $\mathbf{7 , 4 3}$ \\
g.l. & $\mathbf{3}$ & $\mathbf{3}$ & $\mathbf{3}$ \\
$\boldsymbol{p}$ & $\mathbf{0 , 9 6}$ & $\mathbf{0 , 3 8}$ & $\mathbf{0 , 0 6}$ \\
\hline
\end{tabular}

Para avaliar a diversidade de espécies nos ambientes, comparativamente aos Índices de Diversidade de Shannon (H'), de Eqüitabilidade de Pielou (J') e de Heterogeneidade de Simpson (1/D), as curvas de distribuição das espécies foram testadas quanto aos quatro diferentes modelos e, em todos os ambientes, ajustou-se ao modelo de Séries Logarítmicas (Figuras 26 a 29). 


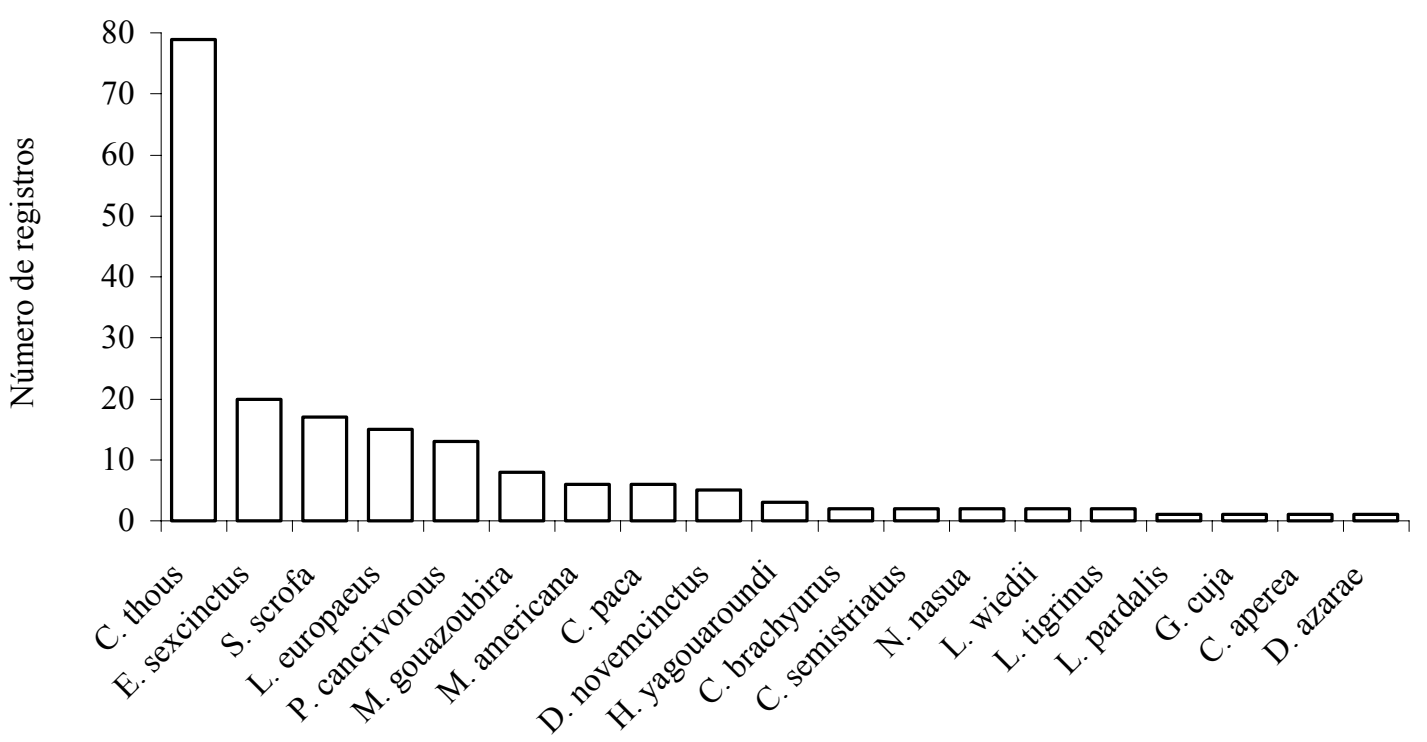

Figura 26 - Distribuição das espécies encontradas no canavial. Segue o modelo de distribuição de Séries Logarítmicas $\left(\chi^{2}=4,61 ;\right.$ g.1. $\left.=6 ; p>0,5\right)$

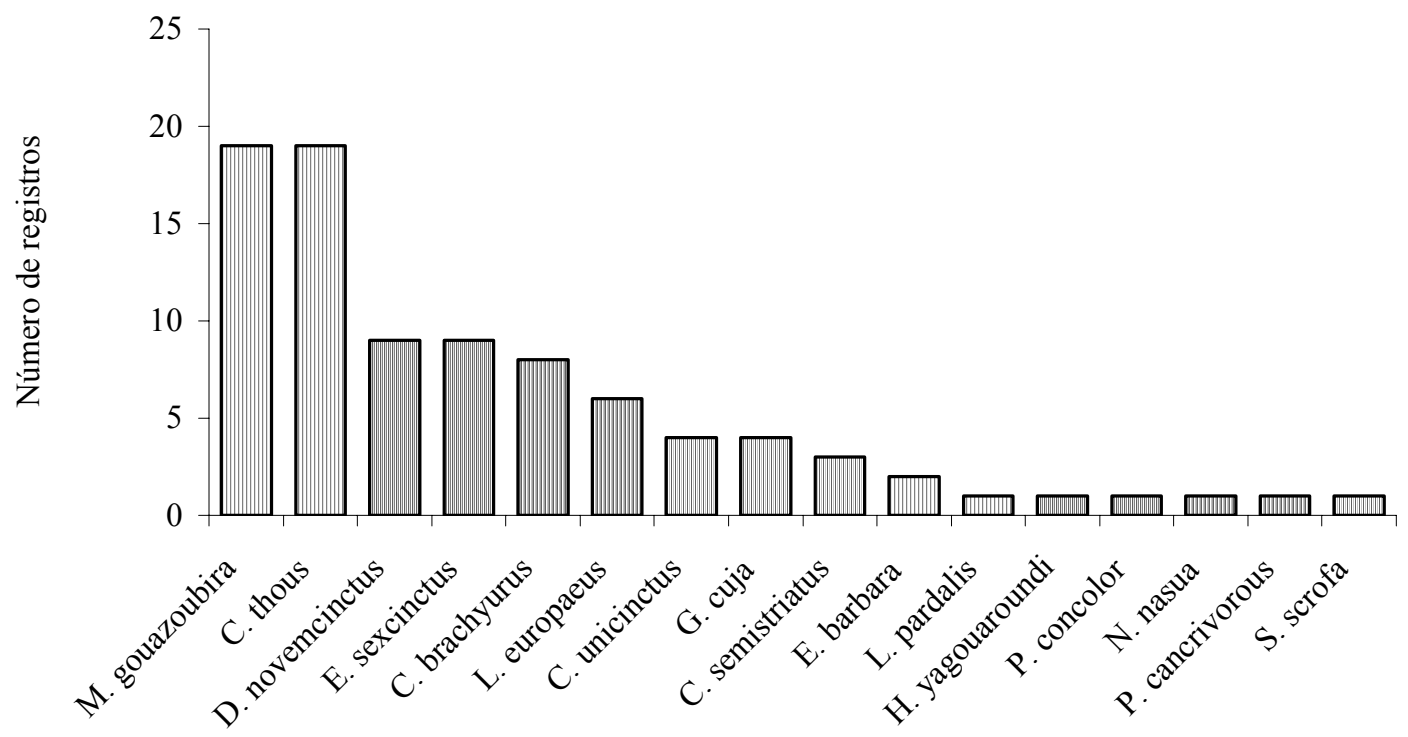

Figura 27 - Distribuição das espécies encontradas no eucaliptal. Segue o modelo de distribuição de Séries Logarítmicas $\left(\chi^{2}=1,47 ;\right.$ g.l. $\left.=4 ; p>0,8\right)$ 


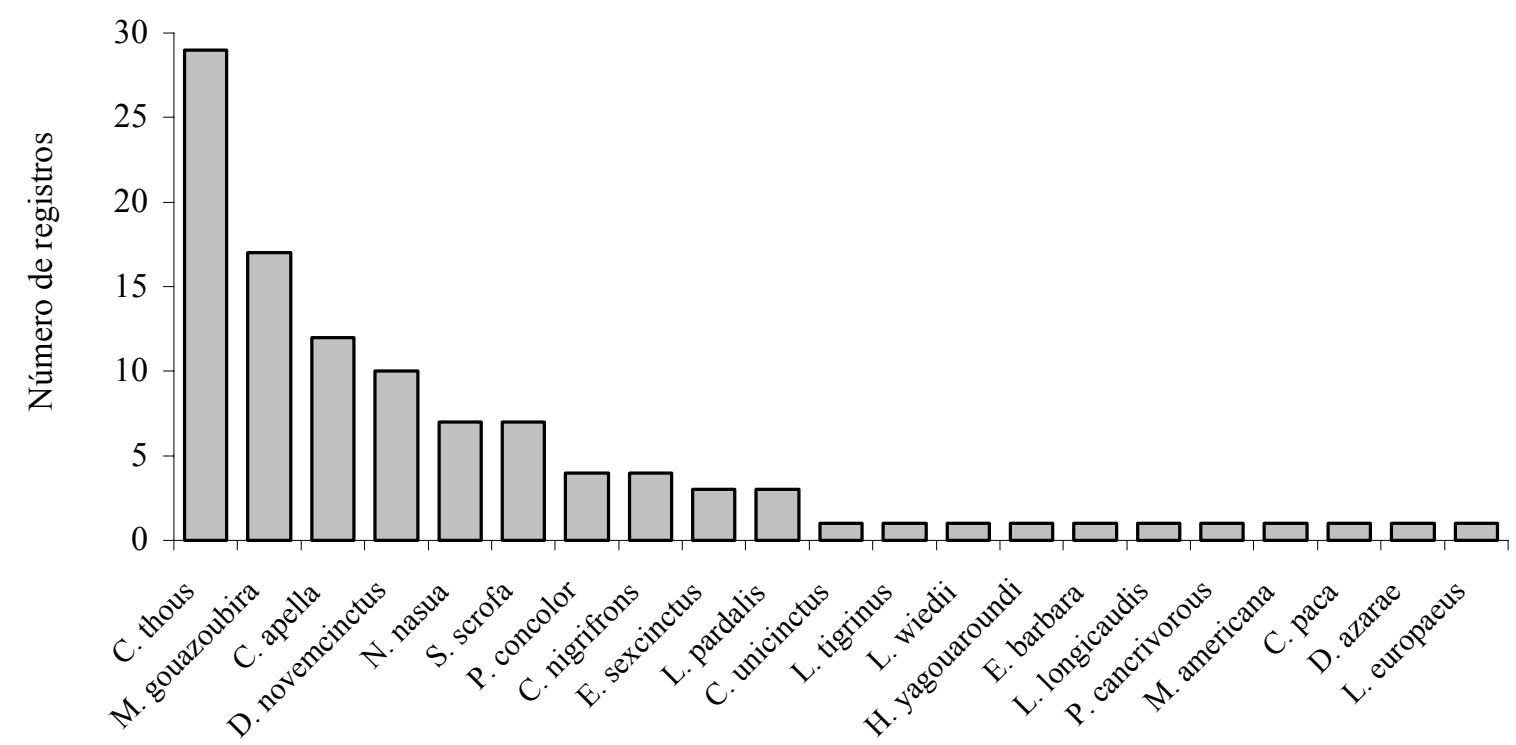

Figura 28 - Distribuição das espécies encontradas na Floresta Estacional Semidecidual. Segue o modelo de distribuição de Séries Logarítmicas $\left(\chi^{2}=1,37\right.$; g.1. $\left.=4 ; p>0,8\right)$

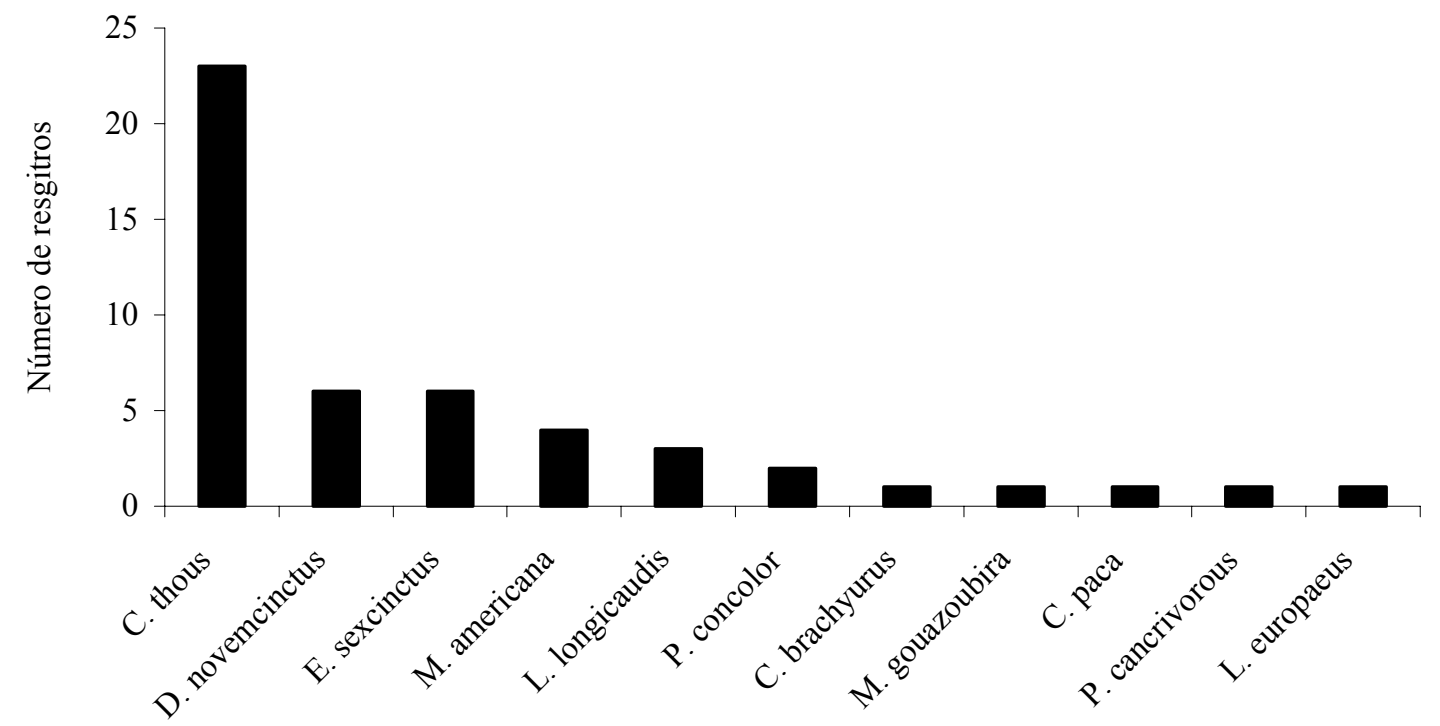

Figura 29 - Distribuição das espécies encontradas nas áreas de pastagem. Segue o modelo de distribuição de Séries Logarítmicas $\left(\chi^{2}=1,94 ;\right.$ g.1. $\left.=4 ; p>0,8\right)$ 
A Análise de Correspondência (Figura 30) mostra a relação entre as espécies registradas e os quatro ambientes amostrados. As espécies aparecem próximas aos ambientes onde ocorreram com maior freqüencia. Pode-se notar que a análise definiu dois eixos de autovalores contendo $82 \%$ da variância, correspondendo a 45,45\% (eixo 1) e $36,63 \%$ (eixo 2 ) da variância total.

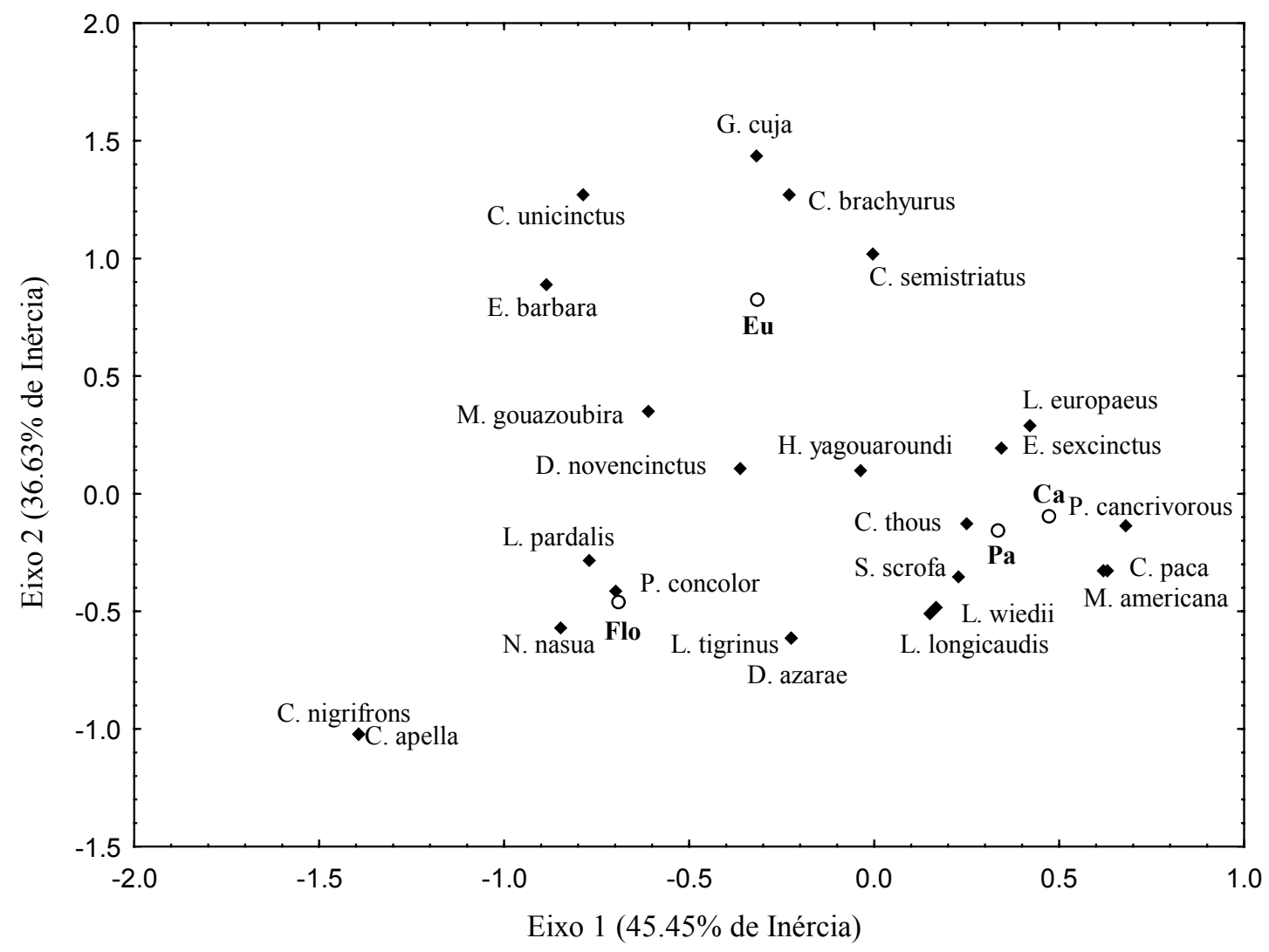

Figura 30 - Primeiro e segundo eixos resultantes da análise de correspondência, relacionando as espécies de mamíferos registradas aos ambientes amostrados (Autovalores: 0,248 - eixo 1; 0,200 eixo 2). Ca: canavial, Pa: pastagem, Eu: eucaliptal e Flo: Floresta Estacional Semidecidual

Percebe-se que as duas espécies de primatas (C. apella e C. nigrifrons), bem como N. nasua, L. pardalis, P. concolor, L. tigrinus, D. azarae estão mais próximas da floresta nativa. Já C. unicinctus, E. barbara, G. cuja, C. brachyurus, C. semistriatus estão mais próximos do eucaliptal. As espécies L. europaeus, E. sexcinctus, $P$. cancrivorous, M. americana, C. thous, C. paca, S. scrofa, L. wiedii e L. longicaudis 
ficaram mais próximas das áreas abertas, canavial e pastagem, que não apresentaram uma grande distinção entre si. Herpailurus yagouaroundi ficou próximo do eixo zero, mostrando-se como espécie não relacionada diretamente a nenhum dos ambientes e tanto M. gouazoubira como D. novemcinctus localizaram-se entre a floresta nativa e o eucaliptal.

\subsection{Estrutura da vegetação}

Os diagramas de perfil de quatro dos dezesseis sítios amostrais, um de cada ambiente, podem ser observados nas Figuras 31 a 33 .

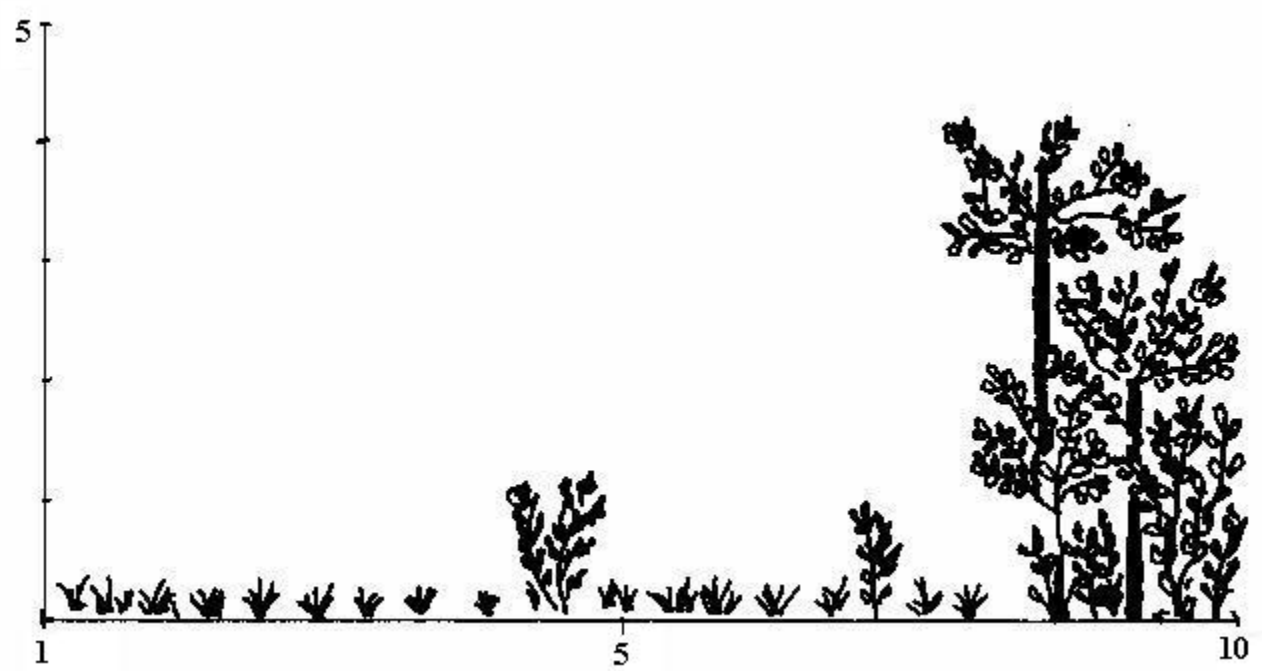

Figura 31 - Diagrama de perfil de um dos sítios amostrais em área de Pastagem

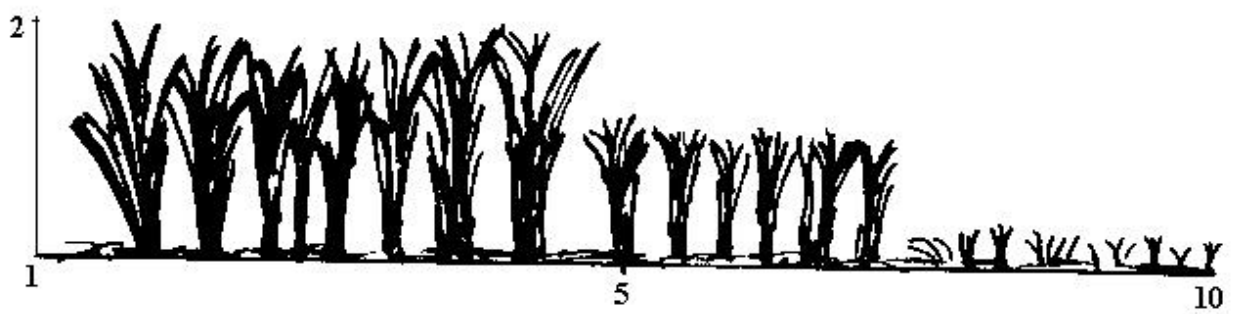

Figura 32 - Diagrama de perfil de um dos sítios amostrais em área de Canavial, mostrando os três estágios amostrados durante o estudo 

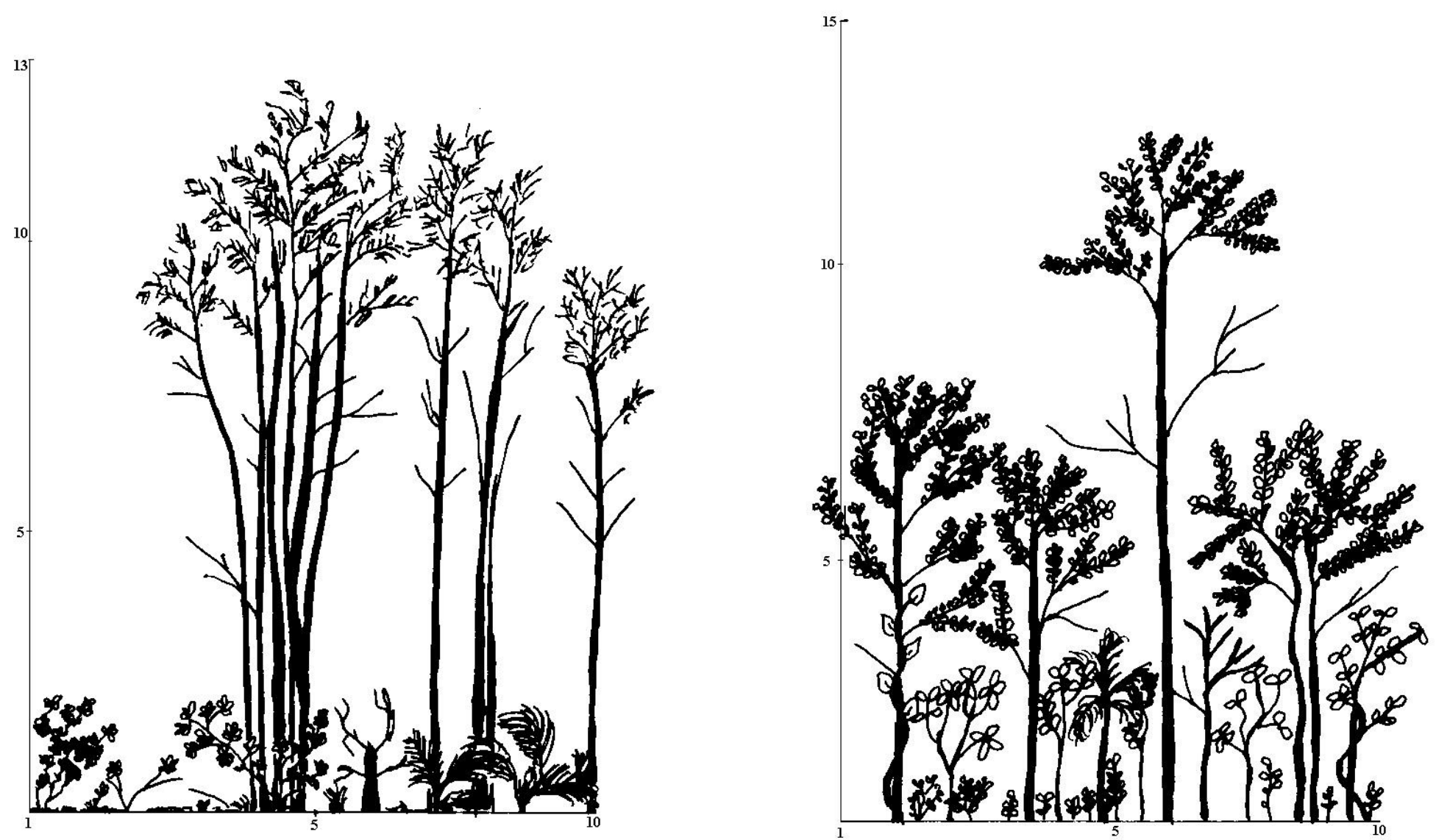
Quanto aos sítios amostrais de Floresta Estacional Semidecidual, dois deles apresentaram sub-bosque formado, com árvores variando entre seis a nove metros de altura, enquanto que nos outros dois não havia presença de sub-bosque. A altura média do estrato arbustivo, nos sítios com presença de sub-bosque, foi entre 12 a 20 metros, e nos outros entre seis a 15 metros. Em todos os sítios foram registradas lianas, em dois deles havia bambus e gramíneas e a altura da serrapilheira variou entre cinco e $12 \mathrm{~cm}$. Quanto ao número de morfoespécies, foram encontradas desde cinco até 15, e em três dos quatro sítios amostrais havia palmeiras. No levantamento da composição florística e fitossociológica realizado na Bacia do Passa-cinco por Mantovani et al. (1986), as famílias de maior importância foram Leguminosae, Myrtaceae e Meliaceae. Estes autores relataram também a presença de epífitas, embora não tão abundantes, principalmente das famílias Cactaceae e Bromeliaceae. Destacam as espécies Trichilia catigua e T. lagoensis, com altura até dez metros, e Copaifera langsdorfii (pau d'óleo), Bastardiopsis densiflora (pau jangada), Diatenopterix sorbifolia (sapuva), Chorisia speciosa (paineira), Peltophorum dubium (canafístula), Cariniana legalis (jequitibá) e Casearia gossypiosperma (pau de espeto) entre as espécies emergentes.

As áreas de plantios de eucalipto eram compostas principalmente pela espécie Eucalyptus grandis, com algum plantio de E. saligna e E. urophilla. Apresentaram uma altura entre 10 a 18 metros, sem sub-bosque. Em todos eles pôde-se observar um estrato herbáceo-arbustivo com grande quantidade de gramíneas e a presença da palmeira Atallea gearensis, sem a presença de lianas e bambus. A altura da serrapilheira variou de $4 \mathrm{~cm}$ a $7 \mathrm{~cm}$. O número de morfoespécies herbáceo-arbustivas variou entre quatro a dez. O manejo realizado consiste no fornecimento inicial de cálcio e magnésio, com posterior adubação com nitrogênio, fósforo e potássio, em três estágios de crescimento das árvores, sendo também aplicados herbicidas (Scout NA) e formicidas (Ruiz ${ }^{1}$ ). A idade dos talhões de eucalipto amostrados no presente estudo estão entre dois anos e dez meses e cinco anos.

\footnotetext{
${ }^{1}$ Ruiz, F.W. (Encarregado Administrativo - Parque Florestal Saligna). Comunicação pessoal, 2004.
} 
Em relação aos canaviais, todas as áreas amostradas são arrendadas por grandes empresas do setor sucroalcooleiro. O plantio é feito em duas épocas, setembro-outubro e janeiro a março. É feita a calagem do terreno e o solo é adubado com nitrogênio, fósforo e potássio, complementando-se com cobre e zinco quando há deficiência desses minerais. São utilizados controladores de pragas, principalmente para nematóides, cupins e coleópteros, e também herbicidas para o controle de ervas daninhas. A colheita tem início em maio, prolongando-se até novembro, e o procedimento de corte não é mecanizado, sendo que há utilização de queimadas para retirada de matéria orgânica seca, para posterior corte manual (Química Industrial Brasileira, 1985). Nestas áreas o estrato herbáceo apresentou entre uma a duas morfoespécies.

No caso das áreas de pastagem amostradas, tratam-se de pequenas propriedades nas quais o pasto não recebe nenhum tipo específico de manejo, sendo somente roçado quando há excesso de arbustos. Foram observadas de três a seis morfoespécies herbáceoarbustivas e em todos os sítios amostrais pôde ser observada a existência de algumas árvores esparsas, com aproximadamente cinco metros de altura. 


\section{DISCUSSÃO}

\subsection{Esforço amostral}

As curvas de acúmulo obtidas com o estimador Bootstrap mostram que o esforço amostral realizado por ambiente não foi suficiente para uma estabilização, ou seja, possivelmente não foram amostradas todas as espécies existentes em cada um dos ambientes. No entanto, a mesma curva feita para toda a região da bacia do Rio PassaCinco mostrou uma estabilização com aproximadamente 250 indivíduos registrados, representando mais de $95 \%$ das espécies identificadas.

Este resultado indica que, possivelmente, todas as espécies ocorrentes na região foram registradas, mas como estas apresentam diferente capacidade de utilização de cada um dos ambientes, para se registrar todas as espécies presentes em cada um deles seria necessário um esforço amostral maior. Por outro lado, a estabilização da curva total de acúmulo de espécies pode indicar que, para a maioria das espécies registradas, a paisagem é vista como um todo, ou seja, estas espécies são capazes de se movimentar ao longo dos gradientes encontrados na região, condição característica de espécies generalistas e com grande plasticidade.

A análise de Co-variância mostra que há diferença entre as inclinações das curvas das áreas de canavial contra pastagem, eucaliptal e floresta nativa, e também das áreas de eucaliptal contra pastagem. Tem-se que o acréscimo de espécies foi mais pronunciado nas áreas de canavial, e que no eucaliptal esse acréscimo foi maior somente quando comparado às áreas de pastagem. Estes resultados podem estar indicando que o substrato mais apropriado encontrado no canavial permite a detecção das espécies mais rapidamente e com maior facilidade quando comparado aos demais ambientes. Uma padronização nesta detecção das espécies pode ser obtida por meio da instalação de 
armadilhas de pegadas, o que permitiria uma comparação mais acurada entre os coeficientes obtidos em cada um dos ambientes.

\subsection{Diferença entre os ambientes quanto à riqueza e freqüência de ocorrência}

\subsubsection{Aspectos biológicos das espécies registradas}

Primeiramente serão apresentados aspectos biológicos das espécies encontradas, tratando de inferir, com estes, algo a respeito da distribuição das mesmas entre os diferentes ambientes. Considerando-se as espécies domésticas, no canavial foram encontrados cachorro, gato, cavalo e gado. No eucalipto, além das anteriores, com exceção do gato, também foram visualizados búfalos. Nos fragmentos de floresta nativa foram encontrados registros de cachorro, cavalo e gado, e no pasto foram registrados cachorro, gato, cavalo, gado e ovelhas.

Para os cães e gatos encontrados, deve-se considerar a possibilidade da existência de animais ferais na região, tão próxima de centros urbanos, embora no caso específico dos cães as pegadas sempre tenham sido observadas acompanhando rastros de pessoas, cavalos ou bicicletas. Já para os gatos, a possibilidade de animais ferais deve ser considerada de fato, pois foram observados rastros e visualizados animais em lugares distantes de residências. O comportamento de ambas as espécies também deve ser considerado, já que o cão pertence a um grupo de canídeos com hábitos sociais bem marcados (o grupo dos denominados "wolf-like"), como o de caçar em grupos e viver em matilhas, dependendo da presença de outros indivíduos, enquanto que os felinos apresentam hábitos mais solitários (Kleiman \& Eisenberg, 1973). Cabe ressaltar que a presença destas espécies domésticas nas áreas é importante, pois ambos são animais predadores, que acabam competindo por recursos alimentares com os animais silvestres, podendo ocasionar uma diminuição na população das presas (Butler et al., 2004; Edwards et al., 2002).

A presença de gado nos demais ambientes ocorre, já que estes animais estão distribuídos em toda a região, inclusive permanecendo soltos nas plantações de eucalipto 
e nos canaviais, em busca de alimento, e possuindo acesso a alguns dos fragmentos florestais nativos, geralmente em busca de sombra e água.

As duas espécies silvestres exóticas encontradas na região são oriundas da Eurásia, sendo que a lebre européia foi introduzida em diversos países e atualmente também ocorre na Irlanda, Canadá, Estados Unidos, Nova Zelândia, Austrália, Tasmânia e América do Sul (Grigera \& Rapoport, 1983). No Brasil, Lepus europaeus foi registrada pela primeira vez na região Sul, em 1965, e na região Sudeste por volta de 1995 (Auricchio \& Olmos, 1999). Apresenta uma rápida capacidade de disseminação e, mesmo em países onde a sua caça é permitida, como na Argentina, a espécie mantém número elevado de indivíduos (Bonino \& Montenegro, 1997; Parera, 2002). Na Argentina, além de causar prejuízos à agricultura, tendo sido declarada como peste, relata-se a diminuição na abundância da lebre da Patagônia (Dolichotis australis), do 'conejo del palo' (Pediolagus salinicola) e do tapiti (Sylvilagus brasiliensis) após a entrada da lebre européia no país (Grigera \& Rapoport, 1983). No Brasil, parecem utilizar uma grande variedade de habitats, como pastagens, plantações de Pinus spp.e Eucalyptus spp., além de áreas de agricultura (Auricchio \& Olmos, 1999).

No presente estudo foi registrada a presença de L. europaeus em toda a região, comprovando sua capacidade de se adaptar aos diferentes ambientes, apesar da maior freqüência de ocorrência nas áreas de canavial. Deve-se considerar a possibilidade de haver uma competição direta com a única espécie nativa de Lagomorpha, o tapiti, já que ambos ocorrem nas mesmas áreas e utilizam os mesmos recursos para a alimentação. Este tipo de competição já foi registrada em outros países, como ocorre na Argentina com a sobreposição de dietas entre a lebre européia e a lebre patagônica (Bonino et al., 1997). O estabelecimento da lebre européia na região também pode ter influência na dieta das populações de carnívoros, já que é um animal silvestre com aproximadamente três quilogramas e pode ser considerado uma nova fonte de recurso, principalmente para os canídeos e felinos, e especialmente em regiões bastante fragmentadas onde pode haver uma redução na disponibilidade de outras presas (Rau \& Jiménez, 2002).

Já o javali (Sus scrofa) foi introduzido em países como África do Sul, Austrália e Estados Unidos, além de América Central e vários países da América do Sul (González, 
2001). Em alguns destes casos, os animais fugiram de criadouros, como ocorreu em São Paulo, enquanto que em outros foi solto deliberadamente com fins cinegéticos, para promover o turismo de caça ou para satisfazer excentricidades de alguns fazendeiros, como é o caso da Argentina e do Uruguai. Com o tempo esta espécie tem se espalhado, ampliando sua distribuição, fato que vem provocando graves prejuízos econômicos, principalmente naquelas regiões de agricultura, como em cultivos de cana-de-açúcar, e também na ovinocultura (Parera, 2002). Na bacia do Rio Passa-Cinco, a espécie foi registrada com maior freqüência na região mais próxima à cidade de Ipeúna e da Serra de São Pedro onde, segundo relatos de moradores, houve uma fuga de animais de um criadouro. O registro dos animais nesta região foi bastante freqüente no canavial e no fragmento de floresta nativa, onde pode vir a provocar um grande impacto na comunidade de pequenos vertebrados. $\mathrm{O}$ registro de um único javali fora desta área, nas proximidades da cidade de Itirapina, foi descoberto posteriormente como sendo um animal que havia escapado de um morador que o criava para consumo, tendo sido capturado e morto pelo seu proprietário.

Quanto às espécies silvestres autóctones é importante ressaltar que foram registradas espécies com diferentes graus de ameaça, como poderá ser observado. Os animais de hábitos mais generalistas, como é o caso do tatu-galinha, tatu-peba, cachorrodo-mato, guaxinim, veado-catingueiro e tapiti foram encontrados em todos os ambientes.

Dentre os tatus, o tatu-galinha (D. novemcinctus) apresenta uma ampla distribuição e ocupa uma grande variedade de habitats, desde florestas decíduas a florestas tropicais pluviais, sendo freqüentemente encontrado em áreas rurais (Redford, 1994; Redford \& Fonseca, 1986; Schaller, 1983; Vaughan \& Shoenfelder, 1999). Tratase de um animal solitário, com hábitos diurnos e noturnos, dependendo da região, e bastante caçado devido à sua carne (Wetzel, 1982). Loughry \& McDonough (1998) compararam duas populações de tatu-galinha, uma na Flórida e uma no Brasil, encontrando, nesta última, animais menores, menos abundantes e com predomínio de atividade tarde da noite, sugerindo que o fato de serem bastante procurados por caçadores poderia ser o fator determinante de tais diferenças. No Passa-Cinco, a espécie obteve menor freqüência de ocorrência do que E. sexcinctus, fato também relatado por 
Bonato (2002) na Estação Ecológica de Itirapina, e apareceu em todos os ambientes, apesar de uma certa tendência às áreas florestadas onde apresentou maiores freqüências de ocorrência.

Já o tatu-peba (E. sexcinctus) é mais comum em áreas abertas e bordas de florestas e é uma espécie diurna, ocasionalmente ativa à noite (Redford, 1994; Schaller, 1983). De hábitos solitários, apresenta uma dieta bastante generalista, composta por vegetais, invertebrados e pequenos vertebrados, mas também podem ser observados grupos se alimentando de animais mortos (Bezerra et al., 2001; Parera, 2002). Também é bastante caçado devido à sua carne, enfrentando forte pressão de caça em algumas regiões (Redford \& Wetzel, 1985). Foi a espécie de Dasypodidae mais registrada neste estudo, com maior freqüência de ocorrência nos canaviais. Também foram encontradas tocas, em grande quantidade, nas áreas de pastagem, mas optou-se pela não identificação destas quando não houvesse um outro tipo de registro, como pegadas, que confirmasse a espécie.

O cachorro-do-mato (C. thous) é uma espécie exclusiva da América do Sul e ocupa uma variedade de habitats, como cerrados, florestas e campos (Langguth, 1975). Pode estar ativo em qualquer hora do dia, sendo diurno em áreas com poucos distúrbios e noturno em áreas com maior pressão antrópica (Parera, 2002; Yanosky \& Mercolli, 1990). É um animal oportunista, consumindo grande variedade de itens, desde invertebrados a pequenos vertebrados e frutos (Courtenay \& Maffei, 2004). Geralmente forma latrinas perto das áreas que utiliza para descansar (Brady, 1979). É considerado como um animal que causa danos a criações e, portanto, pode ser bastante caçado em algumas regiões (Bisbal, 1981; Dotto et al., 2001), embora não apresente graves problemas quanto à sua conservação, constando apenas do Apêndice II da CITES (CITES, 2005).

Cerdocyon thous foi a espécie mais registrada na bacia do Passa-Cinco, com a maioria destes registros ocorrendo em áreas de canavial. A maior freqüência de ocorrência nestas áreas pode estar ligada à facilidade de visualização dos registros nos carreadores de cana, o que não ocorre nos outros ambientes. No entanto, foram observados indivíduos em diferentes ocasiões caminhando nas plantações de cana, 
houve um freqüente encontro de fezes, além de ter sido encontrada uma carcaça e um esqueleto de $C$. thous em um dos sítios amostrais, indicando que a espécie realmente se utiliza bastante desse ambiente. Esta utilização pode estar relacionada à disponibilidade de presas nas áreas de canavial, já que foi encontrada grande abundância de roedores nestas mesmas áreas (Gheler-Costa ${ }^{2}$ ) e, segundo Oehler \& Litvaitis (1996), predadores generalistas podem apresentar uma resposta numérica a alterações de habitats, podendo ocorrer taxas de predação maiores nas bordas rodeadas por matrizes antropizadas, já que há uma grande diversidade e alta densidade de presas associadas a estes tipos de habitats. Courtenay \& Maffei (2004), destacam a facilidade com que esta espécie se adapta a ambientes com desenvolvimento de agricultura e horticultura (cana-de-açúcar, eucalipto e outros), assim como, habitats em regeneração.

O guaxinim (P. cancrivorous) também é encontrado em diferentes habitats, como florestas de galeria, vegetação xérica dos Chacos, até florestas úmidas da Amazônia, ocorrendo inclusive em campos, sempre próximo a cursos d'água (Yanosky \& Mercolli, 1990). São animais solitários que apresentam hábitos noturnos e alimentação variada, incluindo animais (insetos, moluscos, anfíbios, peixes) e vegetais (frutos) (Parera, 2002). Aparece como espécie provavelmente ameaçada para o Estado de São Paulo (São Paulo, 1998). Foi bastante registrado em áreas de canavial, principalmente numa região onde havia a proximidade de um corpo d'água, concordando com o sugerido acima. Cabe ressaltar o pequeno número de estudos realizados com a espécie, destacando-se Yanosky \& Mercolli $(1990,1993)$ com alguns comentários sobre o padrão de atividade de $P$. cancrivorous na Argentina, e Bisbal (1986) com um estudo sobre hábitos alimentares de espécies de carnívoros, dentre os quais o guaxinim, na Venezuela.

O veado-catingueiro (M. gouazoubira) habita vários tipos de ambientes, como bosques e cerrados, sendo comum em áreas abertas, podendo ser encontrado em áreas bastante secas, desde que próximo a alguma fonte de água (Rossi, 2000). São animais solitários e esquivos, com atividade preferencial nas primeiras e últimas horas do dia.

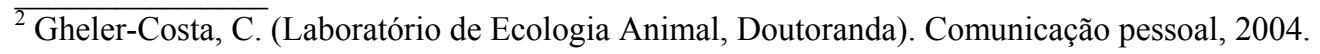


Alimenta-se principalmente de frutos, mas também pode consumir folhas e fungos (Bisbal, 1994). Mazama gouazoubira é uma espécie bastante tolerante às alterações ambientais, podendo ser encontrado em áreas degradadas e/ou cultivadas e é muito procurado por caçadores (Parera, 2002). Aparece na categoria DD ('data deficient') da União Mundial para a Natureza (IUCN, 2004). No presente estudo, foram encontrados de forma bastante equilibrada entre os ambientes, com exceção das áreas de pastagem, onde houve uma menor freqüência de ocorrência.

O tapiti (S. brasiliensis) ocorre do sul do México ao norte da Argentina, na Amazônia, Peru, Equador, Bolívia e Paraguai. Em Jujuy, Argentina, ocupa preferencialmente as bordas de florestas com áreas mais abertas, e no Paraguai foram coletados animais em floresta com bambus, plantações de laranjas e entre bromeliáceas (Eisenberg \& Redford, 1999). São animais solitários de hábitos crepusculares e noturnos, exclusivamente herbívoros, consumindo folhas, talos e raízes (Parera, 2002). No presente estudo não foi feita a quantificação desta espécie devido ao fato de terem sido encontrados poucos rastros e sua presença ser registrada, na maior parte dos casos, pelo encontro de fezes, o que dificulta uma quantificação com a metodologia aqui proposta.

Algumas espécies ocorreram em três ambientes: lobo-guará, jaguatirica, jaguarundi, onça-parda, quati, paca e veado-mateiro. Dentre estas, o lobo-guará $(C$. brachyurus) foi a única espécie não registrada na floresta. Trata-se do maior canídeo da América do Sul, com hábitos crepusculares e noturnos, ocupando áreas abertas como Chaco e Cerrado, sendo estritamente territorialista (Dietz, 1985). Atualmente são escassos na Argentina, com as populações diminuindo em número e extensão geográfica, enquanto que no Brasil vem ocorrendo uma mudança na sua distribuição, passando a ocupar áreas onde havia florestas e que sofreram alterações antrópicas, demonstrando uma adaptação às modificações de seu habitat preferencial, (Beccaceci, 1992; Courtenay, 1994). Continua, no entanto, sendo caçado como predador de criações domésticas e para a obtenção de 'amuletos' (Motta-Junior, 1997; Parera, 2002). Na lista do Ministério do Meio Ambiente (Brasil, 2003) e para o Estado de São Paulo (São Paulo, 1998), aparece como Vulnerável, constando também no Apêndice II da CITES e 
na categoria NR/NT ('near risk/near threathened') da União Mundial para a Natureza (IUCN, 2004). Na região de estudo foram encontrados registros principalmente nas plantações de eucalipto, que podem ser utilizadas como locais de descanso ou para facilitar a movimentação entre diferentes áreas (Rodden et al., 2004). Rodden et al. (2004), mencionam que esta espécie também pode ser vista em ambientes dominados por agricultura e pastagens.

As duas espécies de felinos, jaguatirica (L. pardalis) e jaguarundi ( $H$. yagouaroundi), não foram registradas no pasto. São espécies que podem ser encontradas numa grande variedade de habitats, sendo que a jaguatirica é um animal solitário na maior parte do ano e apresenta hábitos noturnos, podendo ser ativa às vezes durante o dia (Emmons, 1988). Apresenta uma dieta composta principalmente por pequenos mamíferos, mas também pode predar espécies de porte médio e grande, assim como anfíbios, répteis, aves, peixes e insetos (Emmons, 1987). É bastante procurada por caçadores pela sua pele e também devido a ataques a criações domésticas (Murray \& Gardner, 1997). É classificada como vulnerável pelo Ministério do Meio Ambiente (Brasil, 2003) e para o Estado de São Paulo (São Paulo, 1998), constando também do Apêndice I da CITES. No Passa-Cinco foi pouco registrada, com cinco rastros, sendo que $60 \%$ deles ocorreram nos fragmentos de floresta nativa. Emmons (1987), em trabalho feito no Peru, registrou indivíduos em áreas florestadas. Konecny (1989), em Belize, observou três indivíduos cuja área de vida estava totalmente inserida em áreas de floresta secundária, enquanto que Crawshaw \& Quigley (1989) encontraram que 89\% das localizações ocorriam em áreas de Floresta Semidecidual.

Já o jaguarundi pode ser ativo durante o dia e à noite, sendo que em Belize foi relatado como espécie de hábitos essencialmente diurnos (Konecny, 1989). Trata-se de um felino primariamente terrestre, encontrado numa variedade de habitats e freqüentemente registrado em bordas de florestas e áreas relativamente abertas, sendo considerado como o pequeno felino com maior flexibilidade de habitat (Oliveira, 1998a). Consta do Apêndice II da CITES e é classificado como provavelmente ameaçado para o Estado de São Paulo (São Paulo, 1998). Na região deste estudo foi registrado principalmente nos canaviais, o que pode estar relacionado à disponibilidade 
de presas, principalmente roedores, item bastante importante na dieta da espécie, seguido por lagartos e aves (Konecny, 1989), já que o levantamento de pequenos mamíferos realizado na mesma região apresenta uma grande abundância de roedores nos canaviais, como citado anteriormente. Também foi registrado na floresta plantada de eucaliptos e nos fragmentos florestais nativos. Silva (2001), trabalhando em fragmentos de Floresta Atlântica e plantios de eucalipto em Pilar do Sul, estado de São Paulo, também obteve registros de jaguarundi nos talhões de eucalipto, enquanto Emmons \& Feer (1990) indicam que esta espécie pode ser de ocorrência mais comum em florestas decíduas e secundárias que em florestas tropicais, fato registrado por Michalski (2000) na Floresta Nacional de Ipanema, São Paulo.

A onça-parda (P. concolor) foi registrada em áreas de floresta nativa, eucalipto $\mathrm{e}$ pastagem. Apresenta uma grande plasticidade ecológica e adaptação a alterações ambientais, sendo encontrada numa grande variedade de habitats, podendo ocorrer em florestas úmidas até a linha de árvores nos Andes, bem como em zonas abertas, pradarias e desertos (Oliveira, 1994). São animais solitários, exceto quando as fêmeas estão com filhotes, e podem ser ativos durante o dia ou à noite (Currier, 1983). Mesmo sendo um animal bastante resistente à pressão humana, em certas áreas é muito perseguido devido a sua predação sobre o gado e sobre ovinos (Conforti \& Azevedo, 2003; Verdade \& Campos, 2004), e suas populações estão ameaçadas em algumas regiões da sua distribuição (López-González \& González-Romero, 1998; Parera, 2002). $\mathrm{Na}$ região, relatos de moradores a respeito de predação de pumas sobre o gado foram freqüentes, no entanto em nenhum deles pôde-se observar a carcaça do animal predado para uma confirmação do fato. Classificado como vulnerável pelo Ministério do Meio Ambiente (Brasil, 2003) e também para o Estado de São Paulo (São Paulo, 1998), consta da categoria NT ('near threathened') da União Mundial para a Natureza (IUCN, 2004).

Os quatis (N. nasua) não foram registrados no pasto. São encontrados em diferentes habitats, variando desde a Caatinga até as florestas úmidas, mas geralmente em áreas arborizadas (Bisbal, 1986). Bastante tolerantes a modificações ambientais e em áreas com presença humana, sem serem molestados, acostumam-se ao contato com as pessoas (Parera, 2002). São animais que podem ser encontrados em grupos ou solitários, 
ativos durante o dia ou à noite e de hábitos escansoriais, além de apresentar uma dieta onívora e oportunista (Gompper e Decker, 1998).

A paca $(C$. paca) e o veado-mateiro (M. americana) foram registrados no canavial, floresta nativa e pastagem. Amplamente distribuídas em habitats mésicos, as pacas costumam ser relatadas como animais restritos a habitats florestais, sensíveis às alterações ambientais (Pérez, 1992). Apesar destas características, foram registrados animais em áreas abertas, mas cabe ressaltar que todas essas áreas estavam próximas a fragmentos florestais nativos e cursos d'água. São estritamente terrestres e noturnas, solitárias ou em pares que defendem seu território (Parera, 2002). É bastante procurada por caçadores, que a consideram como uma das melhores carnes 'de caça', tornando-a extinta em diversas regiões (Alho, 1982). Consta na lista de espécies ameaçadas do Estado de São Paulo (São Paulo, 1998). Foram poucos os registros de paca na região de estudo e freqüentemente os moradores relataram a procura de pacas por caçadores.

O veado-mateiro é, aparentemente, um animal de florestas, preferencialmente áreas úmidas (Rossi, 2000). Sua capacidade de adaptação aos ambientes secundários permite que se utilize de recursos alimentícios associados a eles, tais como folhas e fungos, que constituem uma parcela importante de sua dieta na estação seca, na ausência de flores e frutos (Eisenberg \& Redford, 1999; Ochoa et al.,1988). Aparece na categoria DD ('data deficient') da União Mundial para a Natureza (IUCN, 2004). Esta espécie apareceu somente na região mais próxima à Serra de São Pedro e Ipeúna, com poucos registros, sendo que em novembro e janeiro foram observados rastros de filhotes, o que concorda com o período de reprodução encontrado por Bisbal (1994).

Dentre as espécies registradas em dois ambientes, o tatu-de-rabo-mole $(C$. unicinctus) e a irara (E. barbara) ocorreram no eucalipto e na floresta nativa. As iraras são animais ativos durante o dia e à noite, mas preferencialmente diurnos, exceto em áreas com distúrbio humano contínuo (Parera, 2002). Podem ser observados indivíduos solitários ou grupos familiares, que habitam florestas, onde podem facilmente movimentar-se pelas árvores, sendo excelentes trepadores (Nowak, 1991). No presente estudo foram obtidos três registros, em área de fragmento nativo e de plantações de 
eucalipto. Michalski (2000), na Floresta Nacional de Ipanema, relata uma afinidade da espécie a corpos d'água e áreas alteradas, como plantações de eucalipto e capoeira.

Sobre os tatus-de-rabo-mole, pouco se conhece sobre sua biologia. Apresenta uma dieta especializada em formigas e cupins, além de uma alta especialização como escavador, concentrando boa parte de suas atividades sob a terra (Redford, 1994; Redford \& Fonseca, 1986; Wetzel, 1980). Meritt Júnior (1985) sugere que são animais ativos durante a noite, mas Bonato (2002), trabalhando na Estação Ecológica de Itirapina, observou que estes foram mais ativos durante o dia, entre 10:00 h e 14:00 h. $\mathrm{Na}$ Bacia do Rio Passa-Cinco foi pouco registrado (cinco registros), sendo encontrado somente em áreas florestadas, principalmente nos eucaliptos, onde houve uma observação direta de um animal por volta das 11 horas. É classificado como vulnerável na lista de espécies ameaçadas do Estado de São Paulo (São Paulo, 1998).

O cangambá (C. semistriatus) e o furão ( $G$. cuja) também foram registrados em dois ambientes, canavial e eucaliptal, sendo que ambos ocupam preferencialmente áreas abertas, ecótonos, agroecossistemas, e parecem tolerar proximidade a centros urbanos, podendo buscar refúgios em áreas florestadas. São animais solitários, onívoros e generalistas, sendo que o cangambá apresenta atividade preferencialmente crepuscular e noturna, enquanto que o furão pode ser ativo em qualquer horário do dia ou à noite (Bisbal, 1986; Donadio et al., 2001; Parera, 2002).

A lontra (L. longicaudis) foi registrada no pasto e na floresta nativa, somente na região próxima à Serra de São Pedro e a Ipeúna. Cabe ressaltar que a região é cortada pelo Córrego da Lapa e que na área de pastagem em questão foi observada uma represa, além de pequenas áreas de brejo, fato que pode explicar o registro deste animal numa área de pastagem. São animais solitários, de hábitos geralmente diurnos e semiaquáticos, cuja dieta compreende principalmente peixes e crustáceos, podendo incluir pequenos mamíferos, répteis, anfíbios e aves (Larivière, 1999; Pardini, 1998). É um animal versátil, que tolera mudanças no ambiente e ocupa áreas próximas a atividades humanas (Pardini \& Trajano, 1999). Consta do Apêndice I da CITES, aparece como vulnerável para o Estado de São Paulo (São Paulo, 1998) e está na categoria DD ('data deficient') da União Mundial para a Natureza (IUCN, 2004). 
Dentre as últimas espécies registradas em dois ambientes, cana e floresta nativa, temos dois pequenos felinos e a cotia. O gato-maracajá (L. wiedii) é um animal de florestas tropicais e subtropicais, sendo muito mais arborícola do que a jaguatirica, capaz de girar as patas descendo de uma árvore verticalmente, como os esquilos (Oliveira, 1994). Sua dieta consiste de pequenos vertebrados, como roedores arborícolas, esquilos e também cotias (Oliveira, 1998b). É classificado como vulnerável pelo Ministério do Meio Ambiente (Brasil, 2003), aparece como espécie em perigo para o Estado de São Paulo (São Paulo, 1998) e consta no Apêndice I da CITES. Sobre o gato-do-matopequeno (L. tigrinus) há pouco conhecimento sobre sua biologia, mas sua dieta baseia-se em pequenos vertebrados, como roedores e aves (Wang, 2002). É classificado como Vulnerável pelo IBAMA e para o Estado de São Paulo; está na categoria NT ('near threathened') da União Mundial para a Natureza (IUCN, 2004) e consta no Apêndice I da CITES. O encontro destes felinos em áreas de canavial, como já discutido anteriormente, pode ocorrer devido à alta disponibilidade de presas (roedores) nestas áreas. O registro de gatos-maracajá fora de áreas florestadas já foi relatado em plantações de café e de cacau na Bolívia, Venezuela e Costa Rica (Oliveira, 1998b; Mondolfi, 1986; Tello, 1986), além de visualizações em áreas antropizadas de Floresta Atlântica (Azevedo, 1996).

Já as cotias (D. azarae) são animais diurnos, que podem realizar suas atividades à noite quando muito perseguidos por caçadores (Alho, 1982). Alimentam-se de sementes e frutos, sendo importantes dispersores para espécies arbóreas e arbustivas, mas também responsáveis pela predação de sementes de algumas espécies (Silvius \& Fragoso, 2003; Peres et. al., 1997). Constam da lista de espécies ameaçadas do Estado de São Paulo (São Paulo, 1998) e são classificados como VU ('vulnerable') pela União Mundial para a Natureza (IUCN, 2004).

As demais espécies foram registradas somente em um dos ambientes. Três delas na floresta nativa e uma na cana. Dentre as encontradas na floresta nativa, aparece o tatuí (D. septencinctus), espécie sobre a qual não se têm muitos conhecimentos sobre aspectos biológicos e que, aparentemente, apresenta uma preferência por áreas abertas, sendo a menor das espécies do gênero e bastante parecido, externamente, com $D$. novemcinctus 
(Eisenberg \& Redford, 1999). Bonato (2002), na Estação Ecológica de Itirapina, registrou apenas dois indivíduos desta espécie que, no presente estudo, foi registrada uma única vez, fora do censo, com o encontro de um animal morto em uma armadilha de interceptação e queda utilizada para captura de pequenos mamíferos.

O macaco-prego (C. apella) é tolerante a uma variedade de tipos florestais, subtropicais e tropicais, incluindo zonas alteradas (González-Solís et al., 2002). Apresenta hábitos diurnos e sociais e possui uma dieta baseada especialmente em frutos, o que influencia diretamente sobre sua área de vida (Di Bitetti, 2001). Consta do Apêndice II na lista da CITES. Na área do Passa-Cinco não foi registrado com muita freqüência, mas estava presente em três dos fragmentos florestais nativos. Cabe ressaltar que a espécie encontrada pertence à subespécie $C$. apella nigritus. Já o macaco sauá $(C$. nigrifrons) é endêmico da Floresta Atlântica e possui uma dieta composta basicamente por frutas e sementes, ocasionalmente por folhas, sendo que espécies das famílias Myrtaceae, Moraceae e Sapotaceae são predominantes (Rylands et al., 1996; Roosmalen et al., 2002). Roosmalen et al. (2002), recentemente fizeram a revisão taxonômica do gênero e a espécie $C$. personatus nigrifrons, de ocorrência somente no Estado de São Paulo, foi considerada como uma nova espécie C. nigrifrons. Consta do Apêndice II na lista da CITES, da lista de fauna ameaçada do Ministério do Meio Ambiente (Brasil, 2003) e está na categoria VU ('vulnerable') da União Mundial para a Natureza (IUCN, 2004). Na região do estudo foram avistados somente em um dos fragmentos florestais nativos.

Na cana foi registrada a preá (C. aperea) uma única vez. Espécie de hábitos diurnos, que ocupa ambientes abertos e áreas de transição entre formações arbustivas e campos (Alho, 1982; Guichón \& Cassini, 1998). São animais estritamente herbívoros e em certas regiões considerados como pragas na agricultura (Parera, 2002).

\subsubsection{Comunidade de mamíferos de médio e grande porte e categorias tróficas}

A comparação da comunidade de mamíferos como um todo, com a Análise de Variância Aninhada, demonstrou uma menor riqueza de espécies, bem como menor 
freqüência de ocorrência, para as áreas de pastagem. Este fato pode estar relacionado à detecção de registros dificultada nos 'trilhos' formados pelo gado, aliada à própria presença destes animais na área, o que pode afugentar algumas espécies silvestres. Stephens et al. (2001) monitoraram o efeito das criações de animais domésticos sobre mamíferos de médio e grande porte no Parque Nacional de 'Bale Mountains', na Etiópia. Encontraram que o aumento do número de criações ocasionou diferentes graus de ameaça para as espécies de mamíferos, como competição direta por recursos alimentares; ataques causados pelos cães domésticos utilizados para proteção do gado; disseminação de doenças dos cães aos mamíferos silvestres e hibridização entre fêmeas de uma espécie silvestre (lobo da Etiópia) e machos de cães domésticos.

Já a maior freqüência de ocorrência observada nas áreas de canavial pode estar relacionada à maior facilidade de detecção dos registros, devido ao solo arenoso dos carreadores e a ausência de folhas no chão. Além deste fator, deve-se ressaltar que o uso de um mosaico de habitats difere entre as espécies de acordo a diversos fatores, e está relacionado, entre outros, à redução no risco de predação, busca por refúgio e forrageamento, já que a escala deste uso pelas diferentes espécies depende tanto de sua área de vida como de seus requerimentos particulares de recursos (Law \& Dickman, 1998). Maestas et al. (2003), em estudo com aves e mesopredadores em ambientes recém urbanizados, fazendas e áreas de reserva, notaram que as comunidades bióticas diferem ao longo do gradiente rural de uso de solo, e que para a conservação destas comunidades a manutenção das fazendas, sem urbanização, juntamente a presença de reservas, é importante, pois causa menor impacto no habitat.

Quanto às categorias tróficas, entre os Insetívoros-onívoros, grupo que aparece com a maior freqüência de ocorrência em todos os ambientes, estão espécies generalistas que acabam sendo beneficiadas pela fragmentação, pois são capazes de utilizar diversos tipos de habitats e de itens alimentares, caso do cachorro-do-mato neste estudo. Entre os Frugívoros-onívoros, a menor riqueza dos outros ambientes em relação à floresta nativa para os outros ambientes, embora não significativa, pode estar relacionada à maior necessidade de habitat requerida por espécies mais especializadas, que muitas vezes 
precisam buscar alimentos distribuídos espaço-temporalmente em manchas (Chiarello, 1999), como ocorre com os primatas em relação aos frutos (Müller, 1996; Peres, 1994).

Quanto à categoria dos Frugívoros-herbívoros, é importante ressaltar que $M$. gouazoubira sozinha, confere o segundo lugar em ocorrência para todos os ambientes, por ser a espécie com maior freqüência de ocorrência dentro deste grupo, criando um viés na formulação de uma correta interpretação, aliado ao fato de ser uma espécie de hábitos mais generalistas em comparação com as outras que compõem este grupo (Parera, 2002). Já na categoria Herbívoro-pastador, composta somente pela lebreeuropéia, tem-se uma espécie generalista que parece estar sendo beneficiada pela expansão da agricultura, como constatado neste estudo pela sua maior ocorrência nas plantações de cana-de-açúcar, e também relatado por Auricchio \& Olmos (1999).

Dentro da categoria dos Carnívoros aparecem tanto espécies com hábitos generalistas, como $P$. concolor, E. barbara e G. cuja, e também espécies mais exigentes quanto ao habitat, como os pequenos felinos, L. pardalis e L. longicaudis. Mesmo as espécies mais características de floresta apresentam variações quanto ao requerimento de permeabilidade da matriz, havendo espécies mais tolerantes que outras (Laurance, 1990; 1991 ; 1994). Este fato explica a ocorrência desta categoria em todos os ambientes mas, ainda assim, percebe-se uma forte dependência deste grupo em relação à floresta nativa, ambiente com uma maior estrutura vertical o que possibilita uma maior variedade de nichos, já que sua maior riqueza, freqüência de ocorrência e abundância relativa foram encontradas neste tipo de ambiente.

Desta forma, os dados obtidos com a análise das espécies em categorias tróficas corroboram os resultados do Modelo de Distribuição de espécies, destacando mais uma vez a presença de espécies generalistas predominantes na região da Bacia do Rio PassaCinco.

\subsection{Diferença entre os ambientes quanto à diversidade}

$\mathrm{O}$ índice de diversidade de Shannon ( $\left.\mathrm{H}^{\prime}\right)$ mostrou padrões de diversidade semelhantes entre os ambientes. A equitabilidade de Pielou (J') apresentou valores entre 
0,70 e 0,79 , indicando ambientes relativamente homogêneos, já que seu valor varia entre 0 e 1 . No entanto, o índice de heterogeneidade de Simpson (1/D) foi o que revelou as maiores diferenças entre os ambientes, embora apenas marginalmente significativas, ressaltando a presença de alguma dominância de espécies entre os ambientes. Esta dominância torna-se bastante clara no caso específico do canavial, onde o cachorro-domato aparece como a espécie mais abundante.

Grande parte das comunidades estudadas e descritas na literatura mostra um modelo de distribuição Log-normal, com algumas espécies muito abundantes, algumas raras e a maioria delas com abundância intermediária, o que geralmente indica comunidades grandes, maduras e variadas. Por outro lado, o modelo de Séries Geométricas apresenta poucas espécies dominantes e as demais claramente incomuns. Por último, o modelo 'Broken-Stick' reflete um estado muito mais equilibrado do que os demais, expressando uma condição de distribuição uniforme, com baixa dominância entre as espécies (Magurran, 1988).

O modelo de Séries Logarítmicas, aqui encontrado, prevê um número pequeno de espécies abundantes e uma alta proporção de espécies 'raras', isto é, pouco freqüentes, de forma que a classe que contém uma única espécie é sempre a maior. Sugere-se que este modelo é bastante aplicável em situações onde um ou poucos fatores são dominantes na comunidade, como disponibilidade de recursos alimentícios, luz ou água, e que as comunidades descritas por este modelo apresentam baixa homogeneidade, ou seja, a distribuição de abundância entre as espécies não é equilibrada (Magurran, 1988). Com esta definição, podemos ver claramente como este modelo ajusta-se à realidade das comunidades analisadas neste trabalho, onde todos os ambientes aparecem com uma ou duas espécies dominantes, sendo que as demais são pouco freqüentes. Comunidades com distribuição de espécies segundo este modelo possuem um preenchimento de nicho desigual, isto é, as espécies mais abundantes são as que apresentam uma maior capacidade de ocupar os nichos vazios, ou seja, o modelo reflete aspectos dinâmicos da comunidade (May, 1975).

$\mathrm{Na}$ área de estudo, percebe-se uma espécie, o cachorro-do-mato, como sendo a mais dominante em toda a região. Trata-se de uma espécie extremamente plástica, fator 
que aumenta suas chances de ocupar nichos vazios, como proposto pelo modelo. Sabe-se que as espécies generalistas são, geralmente, animais com grande mobilidade, hábeis para uso de diversos habitats e itens alimentares. Gehring \& Swihart (2003) observaram que mesopredadores podem ser beneficiados pela fragmentação de habitats devido à sua habilidade para usar diferentes habitats e itens alimentares, assim como, pela ausência de grandes predadores, mais vulneráveis às mudanças ambientais. Estes nichos vazios, mencionados pelo modelo, também poderiam ser ocupados por outros predadores de mesmo porte, mas que se tratam de espécies com maiores requerimentos de habitat, com menor capacidade de se adaptar à ambientes muito alterados, como ocorre com os felinos de pequeno porte.

Quando se comparam os valores obtidos com os diferentes índices utilizados e o modelo de distribuição das espécies nos ambientes, percebe-se que os índices de diversidade de Shannon (H') e de Simpson (1/D) confirmam o padrão de diversidade de espécies descrito pelo modelo de séries-logarítmicas, sendo que Simpson parece mais adequado, já que mostra a existência de dominância entre as espécies. Deste modo, como sugerido por vários autores (Alatalo \& Alatalo, 1977; May, 1975; Peet, 1974; Routeldje, 1979), o índice de Simpson foi, também neste estudo, mais aconselhável que o de Shannon para descrever a heterogeneidade dos diferentes habitats.

A análise de correspondência mostrou algumas espécies de hábitos florestais mais relacionadas às áreas abertas, como L. wiedii, L. longicaudis, M. americana e $C$. paca, como mencionado anteriormente. Todas as outras espécies relacionadas às áreas abertas são animais generalistas, com grande plasticidade e, portanto, capazes de se adaptar às mudanças. Algumas espécies generalistas - M. gouazoubira, D. novemcinctus e H. yagouaroundi - aparecem não relacionadas a nenhum dos ambientes, demonstrando sua capacidade de adaptação. As espécies mais relacionadas ao eucaliptal também possuem hábitos generalistas, sendo elas C. unicinctus, C. brachyurus, $C$. semistriatus, G. cuja e E. barbara. Pode-se notar que espécies de hábitos mais especializados, como os primatas e os felinos, aparecem relacionadas diretamente à floresta nativa, que é o ambiente que poderia apresentar a maior capacidade para suprir suas exigências de 
recursos, principalmente aqueles relacionados à disponibilidade de recursos alimentares e estratificação do habitat.

\subsection{Comparação com outros estudos}

$\mathrm{Na}$ Tabela 6 pode-se visualizar a riqueza de espécies encontrada neste e em outros trabalhos realizados com a comunidade de mamíferos de médio e grande porte, em áreas de Floresta Atlântica, Floresta Estacional e Cerrado, associadas em grau variável a agroecossistemas. As 27 espécies silvestres registradas na bacia do Rio PassaCinco também foram observadas nesses trabalhos. Por outro lado, também aparecem mencionadas nessa literatura 18 espécies com área de distribuição na região, que não foram registradas neste estudo. Deve-se considerar que alguns dos trabalhos citados foram realizados em áreas relativamente bem conservadas, com extensões consideráveis de floresta contínua, situação bastante distinta da região do presente estudo.

Tabela 6. Comparação entre o resultado obtido no presente estudo e outros trabalhos realizados no Domínio Atlântico. FA: Floresta Atlântica, FE: Floresta Estacional e Ce: Cerrado

\begin{tabular}{|c|c|c|c|c|}
\hline Estado & Ambiente & Área (ha) & Riqueza & Fonte \\
\hline SP & FA Floresta contínua, fragmentos e eucalipto & 2.250 & 25 & Silva, C.R. (2001) \\
\hline SP & FA floresta contínua e fragmentos & 14 a 8.000 & 17 & Negrão, M.F.F. (2003) \\
\hline SP & FE fragmento rodeado por eucalipto & 150 & 19 & Chiarello, A. (2000a) \\
\hline SP & FE floresta contínua & 5.069 & 24 & Michalski, F. (2000) \\
\hline SP & FE floresta contínua e fragmentos & 2.000 a 35.800 & 9 & Cullen Júnior, L. (2000) \\
\hline SP & FE remanescente & --- & 19 & Marinho-Filho, J. (1992) \\
\hline SP & FE fragmentos & 400 a 35.800 & 31 & Bassi, C. (2003) \\
\hline SP & FE fragmentos & --- & 26 & Dalponte, J. (1988) \\
\hline SP & 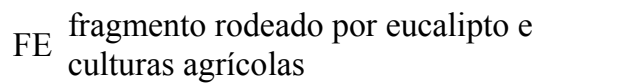 & 860 & 10 & Gheler-Costa et al. (2002) \\
\hline SP & $\begin{array}{l}\text { FE fragmento (23), eucalipto (17), cana (20) } \\
\text { e pasto (12) }\end{array}$ & $52.757^{*}$ & 27 & este estudo \\
\hline SP & Ce remanescente & 11.000 & 33 & Talamoni, S. et al. (2000) \\
\hline SP & Ce fragmento & --- & 16 & Brasileiro, C. et al. (2002) \\
\hline SP & Ce remanescente & 2.300 & 16 & Tozetti, A. M. (2002) \\
\hline SP & Ce remanescente & 1.225 & 22 & Lyra-Jorge, M.C. (1999) \\
\hline
\end{tabular}

* área total da bacia do Rio Passa-Cinco. Os sítios amostrais apresentaram áreas entre 70 a 500 ha 
Dentre as espécies não registradas, pode-se citar alguns primatas (Callitrix penicillata, C. aurita, C. jachus, Alouatta fusca e A. caraya), o tamanduá-mirim (Tamandua tetradactyla), e os ouriços (Sphigurus villosus, S. insidiosus e Coendou prehensilis), que podem não ter sido detectados pela metodologia utilizada, já que se tratam de espécies primariamente arborícolas, o que dificulta o registro de vestígios indiretos. No caso dos censos para observação direta, considera-se que a distância percorrida em cada ambiente foi baixa (cerca de $71 \mathrm{~km}$ ) para a detecção de um maior número de espécies, pois Cullen Júnior \& Rudran (2003) recomendam uma distância mínima de $80 \mathrm{~km}$ a ser percorrida em cada transecto estabelecido.

No caso dos pequenos primatas do gênero Callitrix spp., alguns estudos sugerem que em lugares onde aves de rapina e gatos maiores foram extintos, ocorre um aumento na pressão de predação por predadores de menor porte ('mesopredator release' - e.g. Palomares et al., 1995), como os gatos do mato - Leopardus spp. (Chiarello \& Melo, 2001; Passamani, 1995). Passamani et al., citados por Chiarello \& Melo (2001) relatam um experimento de reintrodução de C. geoffroy, em que os animais soltos não conseguiram sobreviver devido a predação sofrida por L. tigrinus e L. wiedii. No presente estudo, em áreas amostradas de floresta nativa foram registradas três espécies de pequenos felinos (jaguarundi, gato-do-mato e gato-do-mato-pequeno) e não foram registradas espécies do gênero Callitrix, embora seja área de ocorrência de pelo menos três espécies, o que pode estar de acordo com o sugerido acima.

Também não foram detectados o tamanduá-bandeira (Myrmecophaga tridactyla), a onça-pintada (Panthera onca), a anta (Tapirus terrestris), o veado-campeiro (Ozotoceros bezoarticus), o cateto (Pecari tajacu) e o queixada (Tayassu pecari), todas espécies que apresentam maior porte e grau de exigência em termos de requerimento de habitat, por necessitarem de grandes áreas de vida para encontro de recursos alimentares. O tamanduá-bandeira foi registrado em Pilar do Sul (Silva, 2001), na Floresta Nacional de Ipanema, em Iperó (Michalski, 2000), na Área de Relevante Interesse Ecológico Cerrado Pé-do-Gigante (Lyra-Jorge, 1999), na Bacia do Alto e Médio Guareí (Dalponte, 1988) e na estação Ecológica de Jataí (Talamoni et al., 2000). Não era registrado para a 
região de Itirapina há cerca de dez anos, até que em 2004 houve a visualização de um indivíduo, uma única vez, na Estação Ecológica de Itirapina (Hülle $\left.{ }^{3}\right)$.

A onça-pintada é registrada para o Estado de São Paulo na Serra do Mar (Parque Estadual) e no Parque Estadual do Morro do Diabo (Bassi, 2003). A anta é registrada para algumas regiões, como o oeste do Estado (Bassi, 2003; Cullen Júnior, 2000) e em Pilar do Sul (Silva, 2001), mas também é um animal com grandes requerimentos ambientais, e bastante procurado por caçadores. O veado-campeiro foi registrado apenas na Bacia do Alto e Médio Guareí (Dalponte, 1988), no entanto trata-se de um registro antigo, e a espécie não foi observada em nenhuma região dos outros estudos aqui citados.

Por fim, no caso dos porcos-do-mato, podem ocorrer na região, sendo que já foram registrados na Estação Ecológica de Jataí (Talamoni et al., 2000) e em fragmentos da região oeste do Estado (Bassi, 2003), além de Pilar do Sul (Silva, 2001), somente para o cateto. No entanto, devido à intensa alteração antropogênica existente na região do presente estudo, e considerando-se suas características biológicas, principalmente no caso do queixada, que vive em grupos com até 200 indivíduos e necessita grandes áreas de vida (Fragoso, 1999; Mayers \& Wetzel, 1987), possivelmente se trata de uma espécie localmente extinta.

Sabe-se que atividades de caça têm contribuído muito para a extinção local de algumas espécies e mesmo para a diminuição de populações em vastas áreas (e.g., Atkinson, 1989; Peres, 2000; 2001; Peres \& Terborgh, 1995). A maioria dos estudos enfocando esta atividade foram feitos na Amazônia (e.g., Ayres \& Ayres, 1979; Bodmer, 1995; Bodmer et al., 1994; 1997; Peres, 1994; 2000; 2001), com apenas alguns poucos trabalhos realizados em áreas de Floresta Atlântica (e.g., Chiarello, 2000c; Cullen Júnior et al., 2000; 2001). Estudos realizados na Amazônia, relatam que espécies com maior longevidade, baixas taxas de reprodução e gerações mais longas apresentam maior

\footnotetext{
${ }^{3}$ Hülle, N.L. (Laboratório de Ecologia e Evolução de Vertebrados). Comunicação pessoal, 2004.
} 
declínio populacional causado por caça quando comparadas às espécies de vida curta, maior capacidade reprodutiva e gerações mais curtas (e.g., Bodmer et al., 1997; Peres, 1994; 2000). Dentre estas espécies mais sujeitas aos efeitos da caça destacam-se as de maior porte, como é o caso dos porcos-do-mato, das antas, do veado-campeiro e dos primatas de maior porte.

Neste contexto, Cullen Júnior (1997) e Cullen Júnior et al. (2000) mostraram que os ungulados foram fortemente caçados, tornando-se extintos em fragmentos de Floresta Estacional Semidecidual, na região oeste do Estado de São Paulo. Chiarello (2000a) relatou a extinção local de antas e porcos-do-mato em fragmentos de Floresta Atlântica no Espírito Santo, enquanto Peres (1996) observou que a densidade de catetos e queixadas na Amazônia está inversamente relacionada à pressão de caça nas regiões estudadas. Peres (op. cit.) destaca o caso específico do queixada (T. pecari) que pode ser localmente extinto em regiões com pressão de caça intensa e constante.

Apesar da pressão de caça não ter sido avaliada neste estudo, muitos moradores relataram a constante presença de caçadores nos fragmentos florestais de toda a região. Este fato pode explicar a ausência de espécies de maior porte, como a anta e os porcosdo-mato, que não foram registrados. Conforme sugerido por Cullen Júnior et al. (2001), provavelmente a caça seja o principal fator responsável por alterações nas inter-relações biológicas dentro dos fragmentos, causando uma inversão ecológica na biomassa dos mamíferos encontrada quando há presença de seres humanos ao redor destas áreas.

Outra espécie não detectada foi a capivara (Hydrochoerus hydrochaeris), bastante comum no Estado de São Paulo. No entanto, os sítios amostrais não apresentavam o habitat requerido pela mesma, já que em nenhum deles havia a combinação corpo d'água e alimento. Por último, o tatu-de-rabo-mole (Cabassous tatouay) foi citado para Pilar do Sul (Silva, 2001), mas Bonato (2002) não apresenta registro desta espécie para a Estação Ecológica de Itirapina, mais próxima do presente estudo. É interessante destacar que o Estado de São Paulo está no limite norte de distribuição desta espécie, que se expande para o sul, chegando ao Paraguai, Uruguai e Argentina (Wetzel, 1982). 


\subsection{Considerações finais}

Todos os resultados obtidos indicam que os ambientes estudados apresentam diferentes graus de perturbação, gerando instabilidade na comunidade de mamíferos, o que provoca a ausência daquelas espécies com menor poder de adaptação, reduzindo, portanto, a diversidade encontrada. A ausência destas espécies pode estar relacionada à sua baixa densidade na área de estudo, provocada pela perturbação citada acima e também por incidência de atividades de caça, o que não foi mensurado na região, embora tenham sido obtidos indícios de sua existência. A metodologia utilizada pode ser considerada como outro fator relacionado à ausência de determinadas espécies, como já discutido.

As ausências constatadas, poderiam trazer à tona idéias de reintrodução de determinadas espécies na região. No entanto, este se trata de um assunto controverso e complexo, com muitos aspectos importantes a serem considerados (Bigalke, 1984). A reintrodução de espécies extintas localmente, ou com baixa abundância, implicam na discussão de problemas biológicos: a) falta de habitat apropriado para o estabelecimento da população liberada (Caughley \& Gunn, 1996); b) necessidade de criação em cativeiro dos animais a serem reintroduzidos; c) problemas reprodutivos da população cativa; d) transmissão de enfermidades (Snyder et al., 1996); e) comportamento de retorno; e) domesticação e f) perda de variabilidade genética por endogamia e exogamia (Templeton, 1994). Além destes, devem ser considerados também os problemas sociais gerados com o impacto sobre as populações humanas locais, bem como sua percepção sobre a espécie em questão; problemas econômicos já que se tratam de projetos com custo de execução elevado; e a necessidade de uma continuidade administrativa e de colaboração política (Jimémez Pérez, 1996).

Cabe ressaltar que, biologicamente, os fragmentos florestais existentes devem ser altamente avaliados, pois representam alguns dos últimos remanescentes de Floresta Estacional Semidecidual na região. Conforme sugerido por Cullen Júnior et al. (2001), deve-se pensar em medidas de conservação que considerem o desenvolvimento sócioeconômico da região, servindo-se de planejamentos eco-regionais e utilizando-se de metapopulações ainda sobreviventes. 
Algumas medidas podem ser implementadas na região, a fim de proporcionar a mitigação dos impactos existentes:

- O cumprimento do Código Florestal (Lei 4.771/65, com as alterações subseqüentes), que determina áreas de Reserva Legal e APPs (Áreas de Preservação Permanente), sendo necessário um aumento na fiscalização, bem como o incentivo a reflorestamentos a fim de se recuperar tais áreas.

- Experimentos financiados pelas grandes empresas de papel e celulose, realizados em parceria com Universidades Públicas, permitindo o desenvolvimento de um sub-bosque nos talhões de eucaliptos, de forma a possibilitar que um maior número de espécies utilizem estes talhões como corredores entre os fragmentos nativos.

- Divulgar a importância da conservação da fauna para a comunidade local, incentivando sua participação na elaboração de propostas de manejo e estratégias futuras de programas de educação ambiental. Podem ser realizadas palestras nas escolas da região, bem como uma participação conjunta às Associações Comunitárias.

Como já destacado por Redford (1992), mesmo que as imagens de satélite mostrem a existência dos fragmentos florestais, estes estão vazios de grande parte da fauna que, além de servir como alimento para o ser humano, é responsável por uma infinidade de serviços ecológicos necessários à nossa sobrevivência como polinização, dispersão e controle de pragas. $\mathrm{O}$ simples fato de um fragmento de floresta nativa existir não significa que esteja cumprindo seu papel ecológico. 


\section{CONCLUSÕES}

1) A riqueza de espécies da bacia do Rio Passa-Cinco é menor nas áreas de pastagem, embora sem diferenças significativas com a floresta nativa, fato ligado à heterogeneidade no número de espécies encontrado entre as florestas amostradas, o que resultou numa riqueza média mais baixa para este tipo de ambiente como um todo.

2) A freqüência de ocorrência dos mamíferos de médio e grande porte na bacia do Rio Passa-Cinco é maior nas áreas de canavial, o que pode estar ligado ao uso que espécies generalistas, como o cachorro-do-mato, fazem deste tipo de ambiente, mas também à facilidade de detecção dos mesmos.

3) As espécies de hábitos generalistas apresentam maior abundância relativa na região, com os Insetívoros-onívoros predominando em todos os ambientes amostrados.

4) A diversidade entre os ambientes amostrados é similar, ou seja, os fragmentos florestais nativos não suportam uma comunidade de espécies mais exigente quanto a requerimentos de habitat.

5) O índice de Simpson representa melhor as comunidades aqui amostradas, pois ressalta a dominância de determinadas espécies, como encontrado e descrito pelo modelo de distribuição de Séries Logarítmicas.

6) A comunidade de mamíferos de médio e grande porte encontrada na região da Bacia do Passa-Cinco é característica de ambientes instáveis, sujeita às modificações 
ambientais que estão ocorrendo na região e composta, principalmente, por espécies generalistas e plásticas.

7) Para estudos com a comunidade de mamíferos de médio e grande porte uma combinação de métodos - estações de pegadas, armadilhas fotográficas e censos noturnos - pode proporcionar resultados mais precisos. O primeiro, tornando mais fácil a identificação das pegadas e padronizando a amostragem entre os diferentes ambientes; o segundo possibilitando uma confirmação irrefutável da presença das espécies registradas por meio das pegadas; e o último aumentando as chances de obtenção de visualizações das espécies, o que permitiria estimativas mais acuradas para a densidade de algumas espécies. 
ANEXOS 
Anexo A. Espécies encontradas em cada sítio amostral, na bacia do Rio Passa-Cinco, São Paulo. * Espécies domésticas e ** exóticas

\begin{tabular}{|c|c|c|c|c|c|c|c|c|c|c|c|c|c|c|c|c|}
\hline & CA 1 & EU 1 & FL 1 & PA 1 & CA 2 & EU 2 & FL 2 & PA 2 & CA 3 & EU 3 & FL 3 & PA 3 & CA 4 & EU 4 & FL 4 & PA 4 \\
\hline \multicolumn{17}{|l|}{ XENARTHRA } \\
\hline \multicolumn{17}{|l|}{ Dasypodidae } \\
\hline Cabassous unicinctus & & $\mathrm{x}$ & $\mathrm{x}$ & & & $\mathrm{x}$ & & & & $\mathrm{x}$ & & & & & & \\
\hline Dasypus novemcinctus & & $\mathrm{x}$ & $\mathrm{x}$ & $\mathrm{x}$ & & $\mathrm{x}$ & & $\mathrm{x}$ & $\mathrm{x}$ & $\mathrm{x}$ & & $\mathrm{x}$ & $\mathrm{x}$ & $\mathrm{x}$ & $\mathrm{x}$ & $\mathrm{x}$ \\
\hline Dasypus septencinctus & & & $\mathrm{x}$ & & & & $\mathrm{x}$ & & & & & & & & & \\
\hline Euphractus sexcinctus & $\mathrm{x}$ & $\mathrm{x}$ & $\mathrm{x}$ & $\mathrm{x}$ & $\mathrm{x}$ & & & $\mathrm{x}$ & $\mathrm{x}$ & & & $\mathrm{x}$ & & & & $\mathrm{x}$ \\
\hline Dasypodidae n. id. & $\mathrm{x}$ & $\mathrm{x}$ & $\mathrm{x}$ & $\mathrm{x}$ & $\mathrm{x}$ & $\mathrm{x}$ & $\mathrm{x}$ & $\mathrm{x}$ & $\mathrm{x}$ & $\mathrm{x}$ & $\mathrm{x}$ & $\mathrm{x}$ & & $\mathrm{x}$ & $\mathrm{x}$ & $\mathrm{x}$ \\
\hline \multicolumn{17}{|l|}{ PRIMATES } \\
\hline \multicolumn{17}{|l|}{ Cebidae } \\
\hline Cebus apella & & & & & & & $\mathrm{x}$ & & & & $\mathrm{x}$ & & & & $\mathrm{x}$ & \\
\hline Callicebus nigrifrons & & & & & & & & & & & $\mathrm{x}$ & & & & & \\
\hline \multicolumn{17}{|l|}{ CARNIVORA } \\
\hline \multicolumn{17}{|l|}{ Canidae } \\
\hline Canis familiaris * & $\mathrm{x}$ & $\mathrm{x}$ & $\mathrm{x}$ & $\mathrm{x}$ & $\mathrm{x}$ & $\mathrm{x}$ & $\mathrm{x}$ & $\mathrm{x}$ & $\mathrm{x}$ & $\mathrm{x}$ & & $\mathrm{x}$ & $\mathrm{x}$ & $\mathrm{x}$ & $\mathrm{x}$ & \\
\hline Cerdocyon thous & $\mathrm{x}$ & $\mathrm{x}$ & $\mathrm{x}$ & $\mathrm{x}$ & $\mathrm{x}$ & $\mathrm{x}$ & $\mathrm{x}$ & $\mathrm{x}$ & $\mathrm{x}$ & $\mathrm{x}$ & $\mathrm{x}$ & $\mathrm{x}$ & $\mathrm{x}$ & $\mathrm{x}$ & $\mathrm{x}$ & $\mathrm{x}$ \\
\hline Chrysocyon brachyurus & $\mathrm{x}$ & $\mathrm{x}$ & & $\mathrm{x}$ & & $\mathrm{x}$ & & & & $\mathrm{x}$ & & & $\mathrm{x}$ & $\mathrm{x}$ & & \\
\hline \multicolumn{17}{|l|}{ Felidae } \\
\hline Felis catus $*$ & $\mathrm{x}$ & & & & $\mathrm{x}$ & & & $\mathrm{x}$ & & & & & & & & \\
\hline Leopardus pardalis & & & & & & & $\mathrm{x}$ & & & $\mathrm{x}$ & & & $\mathrm{x}$ & & $\mathrm{x}$ & \\
\hline Leopardus wiedii & $\mathrm{x}$ & & & & & & & & & & & & & & $\mathrm{x}$ & \\
\hline Leopardus tigrinus & $\mathrm{x}$ & & $\mathrm{x}$ & & & & & & & & & & $\mathrm{x}$ & & & \\
\hline Herpailurus yagouarundi & $\mathrm{x}$ & $\mathrm{x}$ & $\mathrm{x}$ & & $\mathrm{x}$ & & & & & & & & & & & \\
\hline
\end{tabular}


Anexo A. Espécies encontradas em cada sítio amostral, na bacia do Rio Passa-Cinco, São Paulo. * Espécies domésticas e ** exóticas

\begin{tabular}{|c|c|c|c|c|c|c|c|c|c|c|c|c|c|c|c|c|}
\hline & CA 1 & EU 1 & FL 1 & PA 1 & CA 2 & EU 2 & FL 2 & PA 2 & CA 3 & EU 3 & FL 3 & PA 3 & CA 4 & EU 4 & FL 4 & PA 4 \\
\hline Puma concolor & & & $\mathrm{x}$ & $\mathrm{x}$ & & & $\mathrm{x}$ & & & & & & & $\mathrm{x}$ & $\mathrm{x}$ & $\mathrm{X}$ \\
\hline \multicolumn{17}{|l|}{ Mustelidae } \\
\hline Conepatus semistriatus & $\mathrm{x}$ & $\mathrm{x}$ & & & & & & & & & & & & & & \\
\hline Eira barbara & & $\mathrm{x}$ & $\mathrm{x}$ & & & $\mathrm{x}$ & & & & & & & & & & \\
\hline Galictis cuja & $\mathrm{x}$ & & & & & $\mathrm{x}$ & & & & $\mathrm{x}$ & & & & & & \\
\hline Lontra longicaudis & & & & & & & & & & & & & & & $\mathrm{x}$ & $\mathrm{x}$ \\
\hline \multicolumn{17}{|l|}{ Procyonidae } \\
\hline Nasua nasua & & & & & & & & & $\mathrm{x}$ & & $\mathrm{x}$ & & $\mathrm{x}$ & $\mathrm{x}$ & $\mathrm{x}$ & \\
\hline Procyon cancrivorous & $\mathrm{x}$ & & & $\mathrm{x}$ & $\mathrm{x}$ & $\mathrm{x}$ & & & $\mathrm{x}$ & & & & & & $\mathrm{x}$ & \\
\hline \multicolumn{17}{|l|}{ RODENTIA } \\
\hline \multicolumn{17}{|l|}{ Agoutidae } \\
\hline Agouti paca & & & & & & & $\mathrm{x}$ & & $\mathrm{x}$ & & & & $\mathrm{x}$ & & & $\mathrm{x}$ \\
\hline \multicolumn{17}{|l|}{ Caviidae } \\
\hline Cavia aperea & $\mathrm{x}$ & & & & & & & & & & & & & & & \\
\hline \multicolumn{17}{|l|}{ Dasyproctidae } \\
\hline Dasyprocta azarae & & & $\mathrm{x}$ & & & & & & & & & & $\mathrm{x}$ & & & \\
\hline \multicolumn{17}{|l|}{ PERISSODACTYLA } \\
\hline \multicolumn{17}{|l|}{ Equidae } \\
\hline Equus cabalus * & $\mathrm{x}$ & & & & & $\mathrm{x}$ & & $\mathrm{x}$ & & $\mathrm{x}$ & & $\mathrm{x}$ & & $\mathrm{x}$ & & \\
\hline \multicolumn{17}{|l|}{ ARTIODACTYLA } \\
\hline \multicolumn{17}{|l|}{ Cervidae } \\
\hline Mazama americana & & & & & & & & & & & & & $\mathrm{x}$ & & $\mathrm{x}$ & $\mathrm{x}$ \\
\hline Mazama gouazoubira & $\mathrm{X}$ & $\mathrm{X}$ & $\mathrm{X}$ & $\mathrm{X}$ & $\mathrm{X}$ & $\mathrm{X}$ & $\mathrm{X}$ & & $\mathrm{X}$ & $\mathrm{X}$ & $\mathrm{X}$ & $\mathrm{X}$ & & $\mathrm{X}$ & $\mathrm{X}$ & \\
\hline
\end{tabular}


Anexo A. Espécies encontradas em cada sítio amostral, na bacia do Rio Passa-Cinco, São Paulo. * Espécies domésticas e ** exóticas

\begin{tabular}{|c|c|c|c|c|c|c|c|c|c|c|c|c|c|c|c|c|}
\hline & CA 1 & EU 1 & FL 1 & PA 1 & CA 2 & EU 2 & FL 2 & PA 2 & CA 3 & EU 3 & FL 3 & PA 3 & CA 4 & EU 4 & FL 4 & PA 4 \\
\hline \multicolumn{17}{|l|}{ Bovidae } \\
\hline Bos taurus/Bos indicus * & & & & $\mathrm{x}$ & & $\mathrm{x}$ & $\mathrm{x}$ & $\mathrm{x}$ & & $\mathrm{x}$ & $\mathrm{x}$ & $\mathrm{x}$ & $\mathrm{x}$ & $\mathrm{x}$ & & $\mathrm{x}$ \\
\hline Bubalus bubalis * & & & & & & $\mathrm{x}$ & & & & & & & & & & \\
\hline \multicolumn{17}{|l|}{ Ovidae } \\
\hline Ovies aries * & & & & & & & & $\mathrm{x}$ & & & & & & & & \\
\hline \multicolumn{17}{|l|}{ Suidae } \\
\hline Sus scrofa (javali) ** & & & & & & $\mathrm{x}$ & & & & & & & $\mathrm{x}$ & & $\mathrm{x}$ & \\
\hline \multicolumn{17}{|l|}{ LAGOMORPHA } \\
\hline \multicolumn{17}{|l|}{ Leporidae } \\
\hline Lepus europaeus ** & $\mathrm{x}$ & $\mathrm{x}$ & $\mathrm{x}$ & $\mathrm{x}$ & $\mathrm{x}$ & $\mathrm{x}$ & & $\mathrm{x}$ & $\mathrm{x}$ & $\mathrm{x}$ & & $\mathrm{x}$ & $\mathrm{x}$ & & & \\
\hline Sylvilagus brasiliensis & $\mathrm{x}$ & $\mathrm{x}$ & $\mathrm{x}$ & & $\mathrm{x}$ & $\mathrm{x}$ & & $\mathrm{x}$ & $\mathrm{x}$ & & & & $\mathrm{x}$ & & & \\
\hline Total domésticas & 3 & 1 & 1 & 2 & 2 & 4 & 2 & 5 & 1 & 3 & 1 & 3 & 2 & 3 & 1 & 1 \\
\hline Total silvestres & 13 & 12 & 13 & 8 & 7 & 11 & 7 & 5 & 9 & 8 & 5 & 5 & 12 & 6 & 12 & 7 \\
\hline
\end{tabular}




\section{REFERÊNCIAS BIBLIOGRÁFICAS}

AB'SABER, A.N. Os Domínios de natureza no Brasil. São Paulo: Ateliê Editorial. cap. 4, p.45-63, 2003. 159p.

ALATALO, R.; ALATALO, R. Components of diversity: multivariate analysis with interaction. Ecology, v.58, p.900-906, 1977.

ALHO, C.J.R. Brazilian rodents: their habitats and habits. In.: MARES, M.A.; GENOWAYS, H.H. (Ed.). Mammalian biology in South America. Pittsburgh: University of Pittsburgh, v.6, p.143-166, 1982.

ANDRÉN, H.; DELIN, A.; SEILER, A. Population response to landscape changes depends on specialization to different landscape elements. Oikos, v.80, p. 193-196, 1997.

ARANDA, J.M. Rastros de los mamíferos silvestres de México. Xalapa: Instituto Nacional de Investigaciones sobre Recursos Bióticos. 1981. 123p.

ATKINSON, I. Introduced animals and extinction. In.: WESTERN, D.; PEARL, M.C. Conservation for the twenty-first century. Oxford: Oxford University Press, p.5469, 1989. 
AURICCHIO, P.; OLMOS, F. Northward range extension for the European hare, Lepus europaeus (Pallas, 1778 Lagomorpha - Leporidae), in Brazil. Publicações Avulsas do Instituto Pau-Brasil de História Natural, v.2, p.1-5, 1999.

AYRES, J.M.; AYRES, C. Aspectos da caça no alto rio Aripuanã. Acta Amazônica, v.9, n.2, p.287-298, 1979.

AYRES, M.; M. AYRES JR.; D. L. AYRES; A. S. DOS AYRES. BioEstat 3.0: Aplicações estatísticas nas áreas das ciências biológicas e médicas. Brasília: Sociedade Civil Mamirauá, 2003. 290 p.

AZEVEDO, F.C.C. Notes on the behavior of the margay Felis wiedii (Schinz, 1821), (Carnivora, Felidae), in the Brazilian Atlantic Forest. Mammalia, v.60, n.2, p.325328, 1996.

BARROS-BATTESTI, D.M.; MARTINS, R.; BERTIM, C.R.; YOSHINARI, N.H.; BONOLDI, V.L.N.; LEON, E.P.; MIRETZKI, M.; SCHUMAKER, T.T.S. Land fauna composition of small mammals of a fragment of Atlantic Forest in the state of São Paulo, Brazil. Revista Brasileira de Zoologia, v.17, p.241-249, 2000.

BASSI, C. O. efeito da fragmentação sobre a comunidade de mamíferos nas matas do Planalto Ocidental, São Paulo, Brasil. São Paulo, 2003. 89p. Dissertação (Mestrado) - Instituto de Biociências, Universidade de São Paulo.

BECCACECI, M.D. The maned wolf, Chrysocyon brachyurus, in Argentina. In: INTERNATIONALES ZUCHTBUCH FUR DEN MÄNHENWOLF, Chrysocyon brachyurus (ILLIGER, 1811), Frankfurt, 1991. Anais. Frankfurt: Zoologischer Garten Frankfurt am Main, 1992. p.50-56. 
BECKER, M.; DALPONTE, J.C. Rastros de mamíferos silvestres brasileiros: um guia de campo. Brasília: Editora UnB e Edições IBAMA. 1999. 180 p.

BERGALLO, H.G.; ROCHA, C.F.D.; VAN SLUYS, M.; ALVES, M.A.S. O status atual da fauna do Estado do Rio de Janeiro: considerações finais. In.: BERGALLO, H.G.; ROCHA, C.F.D.; ALVES, M.A.S.; VAN SLUYS, M. (Org.). A fauna ameaçada de extinção do Estado do Rio de Janeiro. Rio de Janeiro: EdUERJ, 2000. p.145-150.

BERNARD, E.; FENTON, B. Species diversity of bats (Mammalia: Chiroptera) in forest fragments, primary forests, and savannas in central Amazonia, Brazil. Canadian Journal of Zoology, v.80, p. 1124-1140, 2002.

BEZERRA, A.M.R.; RODRIGUES, F.H.G.; CARMIGNOTTO, A.P. Predation of rodents by the yellow armadillo (Euphractus sexcinctus) in Cerrado of the Central Brazil. Mammalia, v.65, n.1, p.86-88, 2001.

BIGALKE, R.C. Criteria and their application in the reintroduction of large mammals. Acta Zoologica Fennica, v.172, p.165-168, 1984.

BISBAL, F.J.E. El zorro común (Cerdocyon thous). Publicaciones del Servicio Nacional de Fauna Silvestre, v.1, p.1-4, 1981.

BISBAL, F.J.E. Food habits of some neotropical carnivores in Venezuela (Mammalia, Carnivora). Mammalia, v.50, n.3, p.329-339, 1986.

BISBAL, F.J.E. Biología poblacional del venado matacán (Mazama spp.) (Artiodactyla: Cervidae) en Venezuela. Revista de Biología Tropical, v.42, n.1/2, p.305-313, 1994. 
BISSONETTE, J.A.; STORCH, I. Fragmentation: Is the message clear? Conservation Ecology, v.6, n.2, p.14-18, 2002.

BODMER, R.E. Managing Amazonian wildlife: biological correlates of game choice by distribalized hunters. Ecological Applications, v.5, n.4, p.872-877, 1995.

BODMER, R.E.; EISENBERG, J.F.; REDFORD, K.H. Hunting and the likelihood of extinction of Amazonian mammals. Conservation Biology, v.11, n.2, p.460-466, 1997.

BODMER, R.E.; FANG, T.E.; MOYA I, L.; GILL, R. Managing wildlife to conserve Amazonian Forests: population biology and economic considerations of game hunting. Biological Conservation, v.67, p.29-35, 1994.

BONATO, V. Ecologia e história natural de tatus do Cerrado de Itirapina, São Paulo (Xenarthra: Dasypodidae). São Paulo, 2002. 80p. Dissertação (Mestrado) - Instituto de Biologia, Universidade Estadual de Campinas.

BONINO, N.; MONTENEGRO, A. Reproduction of the European hare in Patagônia, Argentina. Acta Theriologica, v.42, n.1, p.47-54, 1997.

BONINO, N.; SBRILLER, A.; MANACORDA, M.M.; LAROSA, F. Food partitioning between the mara (Dolichotis patagonum) and the introduced hare (Lepus europaeus) in the Monte Desert, Argentina. Studies in Neotropical Fauna and Environment, v.32, p.129-134, 1997.

BRADY, C.A. Observations on the behavior and ecology of the crab-eating fox (Cerdocyon thous). In.: EISENBERG, J.F. (Ed.). Vertebrate ecology in the Northern Neotropics. Washington: Smithsonian Intitution Press, 1979. p.161-171. 
BRASIL. Diário Oficial da União: Instrução normativa Número 3, 27/05/2003: Lista nacional das espécies da fauna brasileira ameaçada de extinção . Imprensa Oficial, n.101, p.88-97, 2003.

BROSE, U.; MARTINEZ, N.D.; WILLIANS, R.J. Estimating species richness: sensitivity to sample coverage and insensitivity to spatial patterns. Ecology, v.84, n.9, p.2364-2377, 2003.

BUCKLAND, S.T.; ANDERSON, D.R.; BURNHAM, K.P.; LAAKE, J.L. Distance sampling: estimating abundance of biological populations. London: Chapman \& Hall. 1996. 446 p.

BUSCHBACHER, R. (Coord.). Expansão agrícola e perda da biodiversidade no Cerrado: origens históricas e o papel do comércio internacional. Brasília: WWF Brasil. 2000. 104 p.

BUTLER, J.R.A.; DU TOIT, J.T.; BINGHAM, J. Free-ranging domestic dogs (Canis familiaris) as predators and prey in rural Zimbabwe: threats of competition and disease to large wild carnivores. Biological Conservation, v.115, p.369-378, 2004.

CAPOBIANCO, J.P.R. (Org.). Dossiê Mata Atlântica 2001: projeto monitoramento participativo da Mata Atlântica. São Paulo: Ipsis Gráfica e Editora. 2001a. 15p.

CAPOBIANCO, J.P.R. Situação atual e perspectivas para a conservação da Mata Atlântica. In.: LIMA, A. (Org.). Documentos do ISA, v.7: aspectos jurídicos da proteção da Mata Atlântica. São Paulo: Instituto Socioambiental, p.9-15. 2001 b. 
CAPOBIANCO, J.P.R. Artigo-base sobre os biomas brasileiros. In.: CAMARGO, A.; CAPOBIANCO, J.R.P.; OLIVEIRA, J.A.P. (Org.). Meio Ambiente Brasil: avanços e obstáculos pós-Rio-92. São Paulo: Estação Liberdade: Instituto Socioambiental; Rio de Janeiro: Fundação Getúlio Vargas. p.117-155, 2002.

CASTRO, E.B.V. de; FERNANDEZ, F.A.S. Determinants of differential extintion vulnerabilities of small mammals in Atlantic forest fragments in Brazil. Biological Conservation, v.119, p.73-80, 2004.

CAUGHLEY, G.; GUNN, A. Conservation biology in theory and practice. Cambridge, Mass., USA: Blackwell Science, 1996. 459p.

CHIARELLO, A.G. Effects of fragmentation of the Atlantic forest on mammals communities in the south-eastern Brazil. Biological Conservation, v.89, p.71-82, 1999.

CHIARELLO, A.G. Conservation value of a native forest fragment in a region of extensive agricultura. Revista Brasileira de Biologia, v.60, n.2, p.237-247, 2000a.

CHIARELLO, A.G. Density and population size of mammals in remnants of Brazilian Atlantic Forest. Conservation Biology, v.14, n.6, p.1649-1657, 2000 b.

CHIARELLO, A.G. Influência da caça ilegal sobre mamíferos e aves das matas de tabuleiro do norte do estado do Espírito Santo. Boletim do Museu de Biologia Mello Leitão, v.11/12, p.229-247, 2000c.

CHIARELlO, A.G.; MELO, F.R. Primate population densities and sizes in Atlantic Forest remnants of northern Espírito Santo, Brazil. International Journal of Primatology, v.22, n.3, p.379-396, 2001. 
CITES. The Convention on International Trade in Endangered Species of Wild Fauna and Flora. 2003. http://www.cites.org/eng/app/appendices.shtml (Jan. 2005).

COLWELL, R.K. EstimateS: Statistical estimation of species richness and shared species from samples. Version 7.0. 1994-2004.

COLWELL, R.K.; CODDINGTON, J.A. Estimating terrestrial biodiversity through extrapolation. Philosophical Transaction of the Royal Society of London, v.345, p.101-118, 1994.

CONFORTI, V.A.; AZEVEDO, F.C.C. Local perceptions of jaguars (Panthera onca) and pumas (Puma concolor) in the Iguaçu National Park area, South Brazil. Biological Conservation, v.111, p.215-221, 2003.

CONSERVATION INTERNATIONAL, FUNDAÇÃO PRÓ-NATUREZA, FUNDAÇÃO BIODIVERSITAS E UNIVERSIDADE DE BRASÍlIA. Ações prioritárias para conservação da biodiversidade do Cerrado e do Pantanal. Conservation International, Fundação Pró-Natureza, Fundação Biodiversitas e Universidade de Brasília. 1999. 26 p.

COURTENAY, O. Conservation of the maned wolf: fruitful relations in a changing environment. Canid News, v.2, p.41-43, 1994.

COURTENAY, O.; MAFFEI, L. Crab-eating fox (Cerdocyon thous). In.: SILLEROZUBIRI, C.; HOFFMANN, M.; MACDONALD, D.W. (Ed.). Canids: foxes, wolves, jackals and dogs. Oxford: Information Press, 2004. p.32-38.

CRAWSHAW JÚNIOR, P.G.; QUIGLEY, H.B. Notes on the ocelot movement and activity in the Pantanal region, Brazil. Biotropica, v.21, p.377-379, 1989. 
CUARÓN, A.D. A global perspective on habitat disturbance and tropical rainforest mammals. Conservation Biology, v.14, n.6, p.1574-1579, 2000.

CULLEN JUNIOR, L. Hunting and biodiversity in Atlantic Forest fragments, São Paulo, Brazil. Flórida, 1997. 134p. Thesis (M.Sc.) - University of Florida.

CULLEN JUNIOR, L; BODMER, R.E.; VALLADARES-PÁDUA, C. Effects of hunting in habitat fragments of the Atlantic forests, Brazil. Biological Conservation, v.95, p.49-56, 2000.

CULLEN JUNIOR, L; BODMER, R.E.; VALLADARES-PÁDUA, C. Ecological consequences of hunting in Atlantic forest patches, São Paulo, Brazil. Oryx, v.35, n.2, p.137-144, 2001.

CULLEN JUNIOR, L; RUDRAN, R. Transectos lineares na estimativa de densidade de mamíferos e aves de médio e grande porte. In.: CULLEN JUNIOR, L.; RUDRAN, R.; PADUA-VALlaDARES, C. (Org.). Métodos de estudos em biologia da conservação e manejo da vida silvestre. Curitiba: Ed. UFRP; Fundação O Boticário de Proteção à Natureza, 2003. cap.7, p.181-201.

CURRIER, M.J.P. Felis concolor. Mammalian Species, v.200, p.1-7, 1983.

DALPONTE, J.C. Levantamento preliminar de mamíferos da bacia do médio e alto Rio Guareí, SP. Boletim Técnico do Instituto Florestal, v.42, p.107-120, 1988.

D'ANDREA, P.S.; GENTILE, R.; CERQUEIRA, R.; GRELlE, C.E.V.; HORTA, C.; REY, L. Ecology of small mammals in a Brazilian rural area. Revista Brasileira de Zoologia, v.16, p.611-620, 1999. 
DI BITETTI, M.S. Home-range use by the tufted capuchin monkey (Cebus apella nigritus) in a subtropical rainforest of Argentina. Journal of Zoology, v.253, p.3345, 2001.

DIETZ, J.M. Chrysocyon brachyurus. Mammalian species, v.234, p.1-4, 1985.

DIETZ, J.M.; COUTO, E.A.; ALFENAS, A.C.; FACCINI, A.; SILVA, G.F. da. Efeitos de duas plantações de florestas homogêneas sobre populações de mamíferos pequenos. Brasil Florestal, v.6, n.23, p.54-57, 1975.

DONADIO, E.; MARTINO, S.; AUBONE, M.; NOVARO, A.J. Activity patterns, home-range, and habitat selection of the common hog-nosed skunk, Conepatus chinga (Mammalia, Mustelidae), in northwestern Patagonia. Mammalia, v.65, n.1, p.49-54, 2001.

DOTTO, J.C.P.; FABIÁN, M.E.; MENEGHETI, J.O. Atuação de Pseudalopex gymnocercus (Fischer, 1814) e de Cerdocyon thous (Linnaeus, 1766) (Mammalia: Canidae) como fator de mortalidade de cordeiros no Sul do Brasil. Boletín de la Sociedad Biológica de Concepción, v. 72, p. 51-58, 2001.

EASTMAN, J.R. Idrisi 32. Worcester: Clark Labs University, 1999.

EDWARDS, G.P.; PREU, N. de; CREALY, I.V.; SHAKESHAFT, B.J. Habitat selection by feral cats and dingoes in a semi-arid woodland environment in central Australia. Austral Ecology, v.27, p.26-31, 2002.

EISENBERG, J.F. The Mammalian Radiations: an analysis of trends in evolution, adaptation, and behavior. Chicago; Londres: The University of Chicago Press, $1981.610 \mathrm{p}$. 
EISENBERG, J.F.; REDFORD, K.H. Mammals of the Neotropics: the Central Neotropics - Ecuador, Peru, Bolívia, Brasil. V.3. Chicago; Londres: The University of Chicago Press, 1999. v.3, 609 p.

EMMONS, L.H. Comparative Feeding Ecology of Felids in a Neotropical Rainforest. Behavioral Ecology and Sociobiology, v. 20, p.271-283, 1987.

EMMONS, L.H. A field study of ocelots (Leopardus pardalis) in Peru. Revue D'Ecologie, La Terre et la Vie, v.43, p.133-157, 1988.

EMMONS, L.H.; FEER, F. Neotropical rainforest mammals: a field guide. Chicago: University of Chicago Press, 1990. 281p.

ENVIRONMENTAL SYSTEMS RESEARCH INSTITUTE. Using ArcView GIS. New York: ESRI Press, 1996. 340p.

ESTES, J.A. Predators and ecosystem management. Wildlife Society Bulletin, v.24, n.3, p.390-396, 1996.

FAHRIG, L. How much habitat is enough? Biological Conservation, v.100, p.65-74, 2001.

FAHRIG, L. Effects of habitat fragmentation on biodiversity. Annual Review of Ecology, Evolution and Systematics, v.34, p.487-515, 2003.

FAUSTO, B. História concisa do Brasil. São Paulo: Editora da Universidade de São Paulo, Imprensa Oficial do Estado, 2001. p.9-77. 
FERNANDEZ, F.A.S. Efeitos da fragmentação de ecossistemas: a situação das unidades de conservação. In.: CONGRESSO DE UNIDADES DE CONSERVAÇÃO, 1. Curitiba, 1997. Anais. Curitiba: IAP: UNILIVRE: Rede Nacional Pró Unidade de Conservação, 1997. v.I, p.48-65.

FIGUEIREDO, M. DE S.L.; FERNANDEZ, F.A.S. Contrasting effects of fire in populations of two small rodents species in fragments of Atlantic Forest in Brazil. Journal of Tropical Ecology, v.20, p.225-228, 2004.

FONSECA, G.A.B.; HERMANN, G.; LEITE, Y.L.R.; MITTERMEIER, R.A.; RYLANDS, A.B.; PATTON, J.L. Lista anotada dos mamíferos do Brasil. Occasional Papers in Conservation Biology, n.4. 1996. 38p.

FONSECA, G.B.A. DA; PINTO, L.P.S.; RYLANDS, A.B. Biodiversidade e Unidades de Conservação. In.: CONGRESSO DE UNIDADES DE CONSERVAÇÃO, 1. Curitiba, 1997. Anais. Curitiba: IAP: UNILIVRE: Rede Nacional Pró Unidade de Conservação, 1997. v.I, p.262- 285.

FORMAN, R.T.T. Land Mosaics: the ecology of landscapes and regions. Cambridge: Cambridge University Press, 1995. 632p.

FRAGOSO, J.M.V. Perception of scale and resource partitioning by peccaries: behavioral causes and ecological implications. Journal of Mammalogy, v.80, n.3, p.993-1003, 1999.

FRANKLIN, J.F. Preserving biodiversity: species, ecosystems, or landscapes? Ecological Applications, v.3, n.2, p.202-205, 1993. 
GALLINA, S.; MANDUJANO, S.; GONZALEZ-ROMERO, A. Conservation of mammalian biodiversity in coffe plantations of Central Veracruz, Mexico. Agroforestry Systems, v.33, p.13-27, 1996.

GASCON, C.; LOVEJOY, T.E.; BIERREGAARD, R.O.; MALCOLM, J.R.; STOUFFER, P.C.; VASCONCELOS, H.L.; LAURANCE, W.F.; ZIMMERMAN, B.; TOCHER, M.; BORGES, S. Matrix habitat and species richness in tropical forest remnants. Biological Conservation, v.91, p.223-229, 1999.

GEHRING, T.M.; SWIHART, R.K. Body size, niche breadth, and ecologically scaled responses to habitat fragmentation: mammalian predators in an agricultural landscape. Biological Conservation, v.109, p.283-295, 2003.

GENTILE, R.; FERNANDEZ, F.A.S. Influence of habitat structure on a streamside small mammal community in a Brazilian rural area. Mammalia, v.63, n.1, p.29-40, 1999.

GHELER-COSTA, C.; VERDADE, L.M.; ALMEIDA, A.F. de. Mamíferos nãovoadores do campus "Luiz de Queiroz", Universidade de São Paulo, Piracicaba, Brasil. Revista Brasileira de Zoologia, v.19, n.2, p.203-214, 2002.

GOMPPER, M.E.; DECKER, D.M. Nasua nasua. Mammalian Species, v.580, p.1-9, 1998.

GONZÁLEZ, E. M. Guía de campo de los mamíferos de Uruguay: introducción al estudio de los mamíferos. Montevideo: Vida Silvestre, 2001. 339p. 
GONZÁLEZ-SOLÍS, J.; GUIX, J.C.; MATEOS, E.; LLORENS, L. Density estimates, group size and habitat use of monkeys (Mammals: Cebidae). In.: MATEOS, E.; GUIX, J.C.; SERRA, A.; PISCIOTTA, K. (Ed.). Census of vertebrates in a Brazilian Atlanctic Rainforest area: the Paranapiacaba fragment. Barcelona: Universitat de Barcelona, 2002. p.111-125.

GOODMAN, D. The theory of diversity-stability relations in ecology. Quarterly Review of Biology, v.50, p.237-266, 1975.

GRIGERA, D.E.; RAPOORT, E.H. Status and distribution of the European hare in South America. Journal of Mammalogy, v.64, n.1, p.163-166, 1983.

GUICHÓN, M.L.; CASSINI, M.H. Role of diet selection in the use of habitat by pampas cavies Cavia aperea pamparum (Mammalia, Rodentia). Mammalia, v.62, n.1, p.23$35,1998$.

HANSKI, I.; GILPIN, M.E. Metapopulation biology: ecology, genetics, and evolution. San Diego: Academic Press, 1997. 512p.

HENLE, K.; LINDENMAYER, D.B.; MARGULES, C.R.; SAUNDERS, D.A.; WISSEL, C. Species survival in fragmented landscapes: where are we now? Biodiversity and Conservation, v.13, p.1-8, 2004a.

HENLE, K.; DAVIES, K.F.; KLEYER, M.; MARGULES, C.R.; SETTELE, J. Predictors of species sensitivity to fragmentation. Biodiversity and Conservation, v.13, p.207-251, 2004b.

INSTITUTO BRASILEIRO DE GEOGRAFIA E ESTATÍSTICA. Brasil - uma visão geográfica nos anos 80. Rio de Janeiro: IBGE, p.102-112. 1988. 
JIMÉNEZ PÉREZ, I. Limitaciones de la reintroducción y cría en cautiverio como herramientas de conservación. Vida Silvestre Neotropical, v.5, n.2, p.89-100, 1996.

KOFFLER, N.F. Uso das terras da bacia do rio Corumbataí em 1990. Geografia, v.18, n.1, p.135-150, 1993.

KONECNY, M.J. Movement patterns and food habits of four sympatric carnivore species in Belize, Central America. In.: REDFORD, K.H.; EISENBERG, J.F. Advances in Neotropical mammalogy. Gainesville: Sandhill Crane Press, 1989. p.243-264.

KLEIMAN, D.G.; EISENBERG, J.F. Comparisons of canid and felid social systems from an evolutionary perspective. Animal Behaviour, v.21, p.637-659, 1973.

KREMSATER, L.; BUNNELL, F.L. Edge effects: theory, evidence and implications to management of western North American forests. In.: ROCHELLE, J.A.; LEHMANN, L.A.; WISNIEWSKI, J. (Ed.). Forest fragmentation: wildlife and management implications. Boston: Brill. p.117-153, 1999.

LANGGUTH, A. Ecology and evolution in the South American canids. In.: FOX, M.W. (Ed.). The wild canids: their systematics, behavioral ecology and evolution. Van Nostrand Reinhold, 1975. p.192- 210.

LARIVIÈRE, S. Lontra longicaudis. Mammalian Species, v.609, p.1-5, 1999.

LAURANCE, W.F. Comparative responses of five arboreal marsupials to tropical forest fragmentation. Journal of Mammalogy, v.71, p.641-653, 1990.

LAURANCE, W.F. Edge effects in tropical forest fragments: Application of a model for the design of nature reserves. Biological Conservation, v.57, n.2, p.205-219, 1991. 
LAURANCE, W.F. Rainforest fragmentation and the structure of small mammal communities in tropical Queensland. Biological Conservation, v.69, p.23-32, 1994.

LAURANCE, W.F.; LAURANCE, S.G.; FERREIRA, L.V.; RANKIN-DE-MERONA, J.M.; GASCON, C.; LOVEJOY, T.E. Biomass collapse in Amazonian forest fragments. Science, v.278, p.1117-1118, 1997.

LAURANCE, W.F.; LOVEJOY, T.M.; VASCONCELOS, H.L.; BRUNA, E.M.; DIDHAN, R.K.; STOUFER, P.C.; GASCON, C.; BIERREGAARD, R.O.; LAURANCE, S.G.; SAMPAIO, E. Ecosystem decay of Amazonian forest fragments: a 22-year investigation. Conservation Biology, v.16, p.605-618, 2002.

LAW, B.S.; DICKMAN, C.R. The use of habitat mosaics by terrestrial vertebrate fauna: implications for conservation and management. Biodiversity and Conservation, v.7, p.323-333, 1998.

LIMA, W. de P. Impacto ambiental do eucalipto. São Paulo: EDUSP, 1996. 301p.

LINDENMAYER, D.B.; CUNNINGHAM, R.B.; POPE, M.L. A large-scale "experiment" to examine the effects of landscape context and habitat fragmentation on mammals. Biological Conservation, v.88, p.387-403, 1999.

LINDENMAYER, D.B.; MCINTYRE, S.; FISCHER, J. Birds in eucalypt and pine forests: landscape alteration and its implications for research models of faunal habitat use. Biological Conservation, v.110, p.45-53, 2003.

LINDENMAYER, D.B.; MCCARTY, M.A.; PARRIS, K. M.; POPE, M. L. Habitat fragmentation, landscape context, and mammalian assemblages in southeastern Australia. Journal of Mammalogy, v.81, n.3, p.787-792, 2000. 
LYRA-JORGE, M.C. Avaliação do potencial faunístico da A.R.I.E. Cerrado Pé-deGigante (Parque Estadual de Vassununga, Santa Rita do Passa-Quatro - SP), com base na análise de habitats. São Paulo, 1999. 83p. Dissertação (Mestrado) - Instituto de Biociências, Universidade de São Paulo.

LÓPEZ-GONZÁLEZ, C.A.; GONZÁLEZ-ROMERO, A. A síntesis of current literature and knowledge about the ecology of the puma (Puma concolor Linnaeus). Acta Zoologica Mexicana, v.75, p.171-190, 1998.

LOUGHRY, W.J.; MCDONOUGH, C.M. Comparisons between nine-banded armadillo (Dasypus novemcinctus) populations in Brazil and the United States. Revista de Biologia Tropical, v.46, n.4, p.1173-1183, 1998.

MAB-UNESCO. Red mundial de reservas de Biosfera. Paris: UNESCO, 2003. 17p.

MAC ARTHUR, R.H.; WILSON, E.O. The theory of Island Biogeography. Princenton: Princenton University Press, 1967. 203p.

MAESTAS, J.D.; KNIGHT, R.L.; GILGERT, W.C. Biodiversity across a rural land-use gradient. Conservation Biology, v.17, n.5, p.1425-1434, 2003.

MAGURRAN, A.E. Ecological diversity and its measurement. Princeton: Princeton University Press, 1988. 179p.

MANLY, B.F.J. Multivariate statistical methods: a primer. 2. ed. Londres: Ed. Chapman \& Hall, 1994. 215p. 
MANTOVANI, W.; CATHARINO, E.L.M.; BORGES, H.B.N. Composição florística e fitossociológica. In.: KAGEYAMA, P.Y. (Org.). Estudo para implantação de matas ciliares de proteção na Bacia Hidrográfica do Passa-Cinco visando a utilização para abastecimento público. Piracicaba: FEALQ, 1986. p.34-102.

MARINHO-FILHO, J. Os mamíferos da Serra do Japi. In.: MORELlATO, P.C.L. (Org.). História natural da Serra do Japi. Campinas: Editora da Unicamp, 1992. $321 \mathrm{p}$.

MAY, R.M. Patterns of species abundance and species diversity. In.: CODY, M.L.; DIAMOND,J.M. (Ed.). Ecology and evolution of communities. Cambridge, Massachussets; London: The Belknap Press of Harvard University Press, 1975. p.81120.

MAYERS, J.J.; WETZEL, R.M. Tayassu pecari. Mammalian Species, v. 293, p. 1-7, 1987.

MERITT JUNIOR, D.A. Naked-tailed armadillos Cabassous sp. In.: MONTGOMERY, G.C. (Ed.). Evolution and ecology of sloths, armadillos and vermiliguas. Washington: Smithsonian Inst. Press, 1985. p.389-392.

MICHALSKI, F. Ecologia de carnívoros em área alterada no sudeste do Brasil. Porto Alegre, 2000. 96p. Dissertação (Mestrado) - Instituto de Biociências, Universidade Federal do Rio Grande do Sul.

MINITAB INC. Minitab release 14.1. 2003.

MONDOLFI, E. Notes on the biology and status of the small wild cats in Venezuela. In.: MILLER, S.D.; EVERETT, D.D. (Ed.). Cats of the world: biology, conservation, and management. Washington: National Wildlife Federation, 1986. p.125-146. 
MOTTA-JUNIOR, J.C. Ecologia alimentar do lobo-guará, Chrysocyon brachyurus (Mammalia: Canidae). Anais de Etologia, v.15, p.197-209, 1997.

MÜLLER, K.H. Diet and feeding ecology of masked titis (Callicebus personatus). In.: NORCONK, M.A.; ROSENBERGER, A.L.; GARBER, P.A. (Ed.). Adaptative radiations of Neotropical primates. New York: Plenum Press, 1996. p.383-4001.

MURCIA, C. Edge effects in fragmented forests: implications for conservation. Trends in Ecology and Evolution, v.10, n.2, p.58-62, 1995.

MURRAY, J.L.; GARDNER, G.L. Leopardus pardalis. Mammalian species, v.548, p.1-10, 1997.

MYERS, N.; MITTERMEIER, R.A.; MITTERMEIER, C.G.; FONSECA, G.A.B. DA; KENT, J. Biodiversity hotspots for conservation priorities. Nature, v.403, p.853$858,2000$.

NEGRÃO, M.F.F. Efeitos da fragmentação na comunidade de mamíferos médios e grandes na região de Caucaia, Mata Atlântica, São Paulo. Brasília, 2003. 79p. Dissertação (Mestrado) - Instituto de Ciências Biológicas, Universidade de Brasília.

NOWAK, R.M. Walker's mammals of the world. 5. ed. Baltimore: The Johns Hopkins University Press, 1983. 1629p.

OCHOA, G.; SÁNCHEZ, J.; BEVILACQUA, M.; RIVERO, R. Inventario de los mamíferos de la Reserva Florestal de Ticoporo y la Serranía de los Pijiguaos. Acta Científica Venezolana, v.39, p.269-280, 1988. 
OEHLER, J.D.; LITVAITIS, J.A. The role of spatial scale in understanding responses of medium-sized carnivores to forest fragmentation. Canadian Journal of Zoology, v.74, p.2070-2069, 1996.

OJASTI, J. Hunting and conservation of mammals in Latin America. Acta Zoologica Fennica, v.172, p. 177-181, 1984.

OLIVEIRA, A.U. Agricultura brasileira: Transformações recentes. In: ROSS, J.L.S. (Org.) Geografia do Brasil. 4. ed. São Paulo: EDUSP. p. 465-534, 2001.

OLIVEIRA, T.G. Neotropical cats: ecology and conservation. São Luís: EDUFMA, 1994. 244p.

OLIVEIRA, T.G. Herpailurus yagouaroundi. Mammalian Species, v.578, p.1-6, 1998a.

OLIVEIRA, T.G. Leopardus wiedii. Mammalian Species, v.579, p.1-6, 1998b.

PALOMARES, F.; GAONA, P, FERRERAS, P.; DELIBES, M. Positive effects on game species of top predators by controlling smaller predator populations: an example with Lynx, Mongooses, and Rabits. Conservation Biology, v.9, n.2, p.295605, 1995.

PARDINI, R. Feeding ecology of the Neotropical river otter Lontra longicaudis in an Atlantic Forest stream, south-eastern Brazil. Journal of Zoology, v.245, p.385-391, 1998.

PARDINI, R. Pequenos mamíferos e a fragmentação da Mata Atlântica de Una, sul da Bahia: processos e conservação. São Paulo, 2001. 147p. Tese (Doutorado) - Instituto de Biociências, Universidade de São Paulo. 
PARDINI, R.; TRAJANO, E. Use of shelters by the Neotropical river otter (Lontra longicaudis) in an Atlantic Forest stream, southeastern Brazil. Journal of Mammalogy, v.80, n.2, p.600-610, 1999.

PARERA, A. Los mamíferos de la Argentina y la región Austral de Sudamérica. Buenos Aires: Editorial El Ateneo, 2002. 453 p.

PASSAMANI, M. Field observation of a group of Geoffroy's marmosets mobbing a margay cat. Folia Primatologica, v.64, p.163-166, 1995.

PEET, R.K. The measurement of species diversity. Annual Review of Ecology and systematics, v.5, p.285-307, 1974.

PERES, C.A. Primate responses to phonological changes in an Amazonian Terra Firme forest. Biotropica, v.26, n.1, p.98-112, 1994.

PERES, C.A. Population status of white-liped Tayassu pecari and collared peccaries $T$. tajacu in hunted and unhunted Amazonian forests. Biological Conservation, v.77, p. 115-123, 1996.

PERES, C.A. Effects of subsistence hunting on vertebrate community structure in Amazonian forests. Conservation Biology, v.14, n.1, p. 240-253, 2000.

PERES, C.A. Synergistic effects of subsistence hunting and habitat fragmentation on Amazonian forest vertebrates. Conservation Biology, v.5, n.6, p.1490-1505, 2001.

PERES, C.A.; TERBORGH, J.W. Amazonian nature reserves: an analysis of the defensibility status of existing conservation units and design criteria for the future. Conservation Biology, v.9, n.1, p.34-46, 1995. 
PERES, C.A.; SCHIESARI, L.C.; DIAS-LEME, C.L. Vertebrate predation of Brazilnuts (Bertholletia excelsea, Lecythidaceae), an agouti-dispersed Amazonian seed crop: a test of the escape hypothesis. Journal of Tropical Ecology, v.13, p.69-79, 1997.

PÉREZ, E.M. Agouti paca. Mammalian Species, v.404, p.1-7, 1992.

PIRES, A.S.; LIRA, P.K.; FERNANDEZ, F.A.S.; SCHITTINI, G.M.; OLIVEIRA, L.C. Frequency of movements of small mammals among Atlantic Coastal Forest fragments in Brazil. Biological Conservation, v.108, p. 229-237, 2002.

QUÍMICA INDUSTRIAL BRASILEIRA. Cana. São Paulo: Quimbrasil, 1985. (Série Do Plantio à Colheita).

RAU, J.R.; JIMÉNEZ, J.E. Diet of puma (Puma concolor, Carnivora: Felidae) in coastal and Andean ranges of southern Chile. Studies on Neotropical Fauna and Environment, v.37, p.201-205, 2002.

REDFORD, K.H. The empty forest. BioScience, v.42, n.6, p.412-422, 1992.

REDFORD, K.H. The Edentates of the Cerrado.Edentata, v.1, n.1, p.4-10, 1994.

REDFORD, K.H.; WETZEL, R.M. Euphractus sexcinctus. Mammalian Species, v.252, p.1-4, 1985.

REDFORD, K.H.; FONSECA, G.A.B. Zoogeography of the Cerrado mammalian fauna and the role of gallery forests. Biotropica, v.18, p.126-135, 1986. 
REIS, N.R. dos; BARBIERI, M.N. da S.; LIMA, I.P. de. O que é melhor para manter a riqueza de espécies de morcegos (Mammalia, Chiroptera): um fragmento florestal grande ou vários fragmentos de pequeno tamanho? Revista Brasileira de Zoologia, v.20, p.225-230, 2003.

ROBINSON, J.G.; REDFORD, K.H. Intrinsic rate of natural increase in Neotropical Forest mammals: relationship to phylogeny and diet. Oecologia, v.68, p. 516-520, 1986a.

ROBINSON, J.G.; REDFORD, K.H. Body size, diet, and population density of Neotropical forest mammals. The American Naturalist, v. 128, n. 5, p. 665-680, 1986b.

ROCHA, I.R.D.; CAVALCANTI, R.B.; MARINHO FILHO, J.S; ARAÚJO, A.B; KITAYAMA, K. Fauna do Distrito Federal. In: PINTO, M.N. (Org.) Cerrado: caracterização, ocupação e perspectivas. Brasília: Editora Unb, 1994. p.405-431.

RODDEN, M.; RODRIGUES, F.; BESTELMEYER, S. Maned wolf (Chrysocyon brachyurus). In.: SILLERO-ZUBIRI, C.; HOFFMANN, M.; MACDONALD, D.W. (Ed.). Canids: foxes, wolves, jackals and dogs. Oxford: Information Press, 2004, p.38-43.

ROOSMALEN, M.G.M.; ROOSMALEN, T.; MITTERMEIER, R.A. A taxonomic review of the titi monkeys, genus Callicebus Thomas, 1903, with the description of two new species, Callicebus bernhardi and Callicebus stephennashi, from Brazilian Amazonia. Neotropical Primates, v.10, p.1-52, 2002. Supplement.

ROSSI, R.V. Taxonomia de Mazama Rafinesque, 1817 do Brasil (Artiodactyla: Cervidae). São Paulo, 2000. 174p. Dissertação (Mestrado) - Instituto de Biociências, Universidade de São Paulo. 
ROUTELDJE, R.D. Diversity indices: which ones are admissible. Journal of theoretical Biology, v.76, p.503-515, 1979.

RYLANDS, A.B.; FONSECA, G.B.; LEITE, Y.L.R.; MITTERMEIER, R.A. Primates of the Atlantic Forest: Origins, distribution, endemism, and communities. In.: NORCONK, M.A.; ROSENBERGER, A.L.; GARBER, P.A. (Ed.). Adaptative radiations of Neotropical primates. New York: Plenum Press, 1996. p.21-51.

SANTOS-FILHO, P.S. Fragmentação de habitats: implicações para conservação in situ. Oecologia Brasiliensis V1: estrutura, funcionamento e manejo de ecossistemas brasileiros, p.365-393, 1995.

SÃO PAUlO (ESTADO). Fauna ameaçada do Estado de São Paulo. São Paulo: Secretaria de Estado do Meio Ambiente, 1998. 59p.

SAUNDERS, D.A.; HOBBS, R.J.; MARGULES, C.R. Biological consequences of ecosystem fragmentation: a review. Conservation Biology, v.5, n.1, p.18-32, 1991.

SCHALLER, G.B. Mammals and their biomass on a Brazilian ranch. Arquivos de Zoologia, v.31, p.1-36, 1983.

STEPHENS, P.A.; D'SA, C.A.; SILLERO-ZUBIRI, C.; LEADER-WILLIANS, N. Impact of livestock and settlement on the large mammalian wildlife of Bale Mountains National Park, southern Ethiopia. Biological Conservation, v. 100, p. 307-322, 2001.

SIEGEL, S. Nonparametric statistics for the behavioral sciences. New York: McGraw Hill, 1956. 312p. 
SIH, A.; JONSSON, B.G.; LUIKART, G. Habitat loss: ecological, evolutionary and genetic consequences. Trends in Ecology and Evolution, v.5, n.4, p.132-134, 2000.

SILVA, C.R. Riqueza e diversidade de mamíferos não-voadores em um mosaico formado por plantios de Eucalyptus saligna e remanescentes de Floresta Atlântica no município de Pilar do Sul, SP. Piracicaba, 2001. 81p. Dissertação (Mestrado) Escola Superior de Agricultura “Luiz de Queiroz”, Universidade de São Paulo.

SILVIUS, K.M.; FRAGOSO, J.M.V. Red-rumped agouti (Dasyprocta leporina) home range use in an Amazonian Forest: implications for the aggregated distribution of forest trees. Biotropica, v.35, n.1, p.74-83, 2003.

SMA. Atlas das Unidades de Conservação Ambiental do Estado de São Paulo. São Paulo: Secretaria de Estado do Meio Ambiente, 2000. 64p.

SMALLWOOD, K.S.; FITZHUGH, E.L. A rigorous technique for identifying individual mountains lions Felis concolor by their tracks. Biological Conservation, v.65, p.51$59,1995$.

SNYDER, N.F.R.; DERRICKSON, S.R.; BEISSINGER, S.R.; WILEY, J.W.; SMITH, T.B.; TOONE, W.D.; MILLER, B. limitations of captive breeding in endangered species recovery. Conservation Biology, v.10, p.338-348, 1996.

SOKAL, R.R.; ROHLF, J.F. Biometria: Principios y métodos estadísticos en la investigación biológica. Madrid: H. Blume Ediciones, 1969. 814p.

STALLINGS, J.R. Small mammal inventories in an eastern Brazilian Park. Bulletin of Florida State Museum, Biological Sciences, v.34, n.4, p.153-200, 1989. 
STALLINGS, J.R. The importance of understorey on wildlife in a Brazilian eucalypt plantation. Revista Brasileira de Zoologia, v.7, n.3, p.267-276, 1990.

STATSOFT INC. Statistica - data analysis software system, version 6. 2001.

TALAMONI, S.A.; MOTTA-JUNIOR, J.C.; DIAS, M.M. Fauna de mamíferos da Estação Ecológica de jataí e Estação Experimental de Luiz Antônio. In.: SANTOS, J.E.; PIRES, J.S.R. (Ed.). Estudos integrados em ecossistemas: Estação Ecológica de Jataí. São Carlos: RiMa Editora, 2000. p.317-329.

TANIZAKI-FONSECA, K.; MOULTON, T.P. A fragmentação da Mata Atlântica no Estado do Rio de Janeiro e a perda da biodiversidade. In.: BERGALLO, H.G.; ROCHA, C.F.D.; ALVES, M.A.S.; SLUYS, M.V. (Org.). A Fauna ameaçada de extinção do Estado do Rio de Janeiro. Rio de Janeiro: EdUERJ, 2000. p.23-35.

TELLO, J.L. The situation of the wild cats (Felidae) in Bolivia. Lausane: CITES Secretariat, 1986. 67p.

TEMPLETON, A.R. Coadaptation, local adaptation, and outbreeding depression. In: MEFFE, G.K.; CARROL, C.R. (Ed.). Principles of conservation biology. Sunderland, Mass.: Sinauer Associates, 1994, p.152-153.

TESSLLER, M.B. Reflexões sobre a tutela jurídica da Mata Atlântica. In: LIMA, A. (Org.). Documentos do ISA, v.7: aspectos jurídicos da proteção da Mata Atlântica. São Paulo: Instituto Socioambiental, 2001. p.25-29.

THE WORLD CONSERVATION UNION. 2004 IUCN Red List of Threatened Species. 2004. www.redlist.org. (10 Jan. 2005). 
TOCHER, M. A comunidade de anfíbios da Amazônia central: diferenças na composição específica entre a mata primária e pastagens. In.: GASCON, C.; MOUTINHO, P. (Ed.). Floresta Amazônica: dinâmica, regeneração e manejo. Manaus: Instituto Nacional de Pesquisas Amazônicas (INPA), 1998. p.219-232.

TOZETTI, A.M. Diversidade e padrões de atividade de mamíferos de médio e grande porte em diferentes fisionomias de Cerrado na Estação Ecológica de Itirapina, SP. São Paulo, 2002. 77p. Dissertação (Mestrado) - Instituto de Biociências, Universidade de São Paulo.

VALENTE, R.O.A. Análise da estrutura da paisagem na bacia do rio Corumbataí. Piracicaba. Piracicaba, 2001. 144p. Dissertação (Mestrado) - Escola Superior de Agricultura “Luiz de Queiroz”, Universidade de São Paulo.

VALENTE, R.O.A.; VETTORAZZI, C.A. Mapeamento de uso e cobertura do solo da Bacia do Rio Corumbataí, SP. Circular Técnica do IPEF, n.196, 10p., 2003.

VAUGHAN, C.; SHOENFELDER, S. Dry season activity, movement, habitat and den utilization of nine-banded armadillo (Dasypus novemcinctus) in neotropical dry forest, Costa Rica. Revista de Biologia Tropical, v.47, n.4, p.1117-1119, 1999.

VERDADE, L.M.; CAMPOS, C.B. How much is a puma worth? Economic compensation as an alternative for the conflict between wildlife conservation and livestock production in Brazil. Biota Neotropica, v.4, n.2, p.1-4, 2004.

VOSS, R.S.; EMMONS, L.H. Mammalian diversity in Neotropical lowland rainforests: a preliminary assessment. Bulletin of the American Museum of Natural History, n.230, 115p., 1996. 
WANG, E. Diets of ocelots (Leopardus pardalis), margays (L. wiedii), and oncillas ( $L$. tigrinus) in the Atlantic Rainforest in southeast Brazil. Studies on Neotropical Fauna and Environment, v.37, n.3, p.207-212, 2002.

WEBER, W.; RABINOWITZ, A. A global perspective on large carnivores conservation. Conservation Biology, v.10, n.4, p.1046-1054, 1996.

WETZEL, R.M. Revision of the naked-tailed armadillos, genus Cabassous McMurtrie. Annals of Carnegie Museum, v.49, p.323-357, 1980.

WETZEL, R.M. Systematics, distribution, ecology, and conservation of South American Edentates. In.: MARES, M.A.; GENOWAYS, H.H. (Ed.). Mammalian biology in South America. Pittsburgh: University of Pittsburgh, v.6, p.345-375, 1982.

WILCOX, B.A.; MURPHY, D.D. Conservation strategy: the effects of fragmentation on extinction. The American Naturalist, v.125, p.879-887, 1985.

WILSON, E.O. A situação atual da diversidade biológica. In: WILSON, E. O. (Org.). Biodiversidade. Rio de Janeiro: Editora Nova Fronteira, 1988. p.3-24.

WILSON, D.E.; COLE, F.R.; RUDRAM, R.; NICHOLS, J.D.; FOSTER, M.S. (Ed.). Measuring and monitoring biological diversity: standard methods for mammals. Washington \& London: Smithsonian Institution Press. 1996. 409p.

WOLFF, J.O.; SCHAUBER, E.M.; EDGE, W.D. Effects of habitat loss and fragmentation on the behavior and demography of gray-tailed voles. Conservation Biology, v.11, n.4, p.945-956, 1997. 
WRIGHT, J.S.; GOMPPER, M.E.; DE LEON, B. Are large predators keystone species in Neotropical forests? The evidence from Barro Colorado Island. Oikos, v.71, p.279-294, 1994.

YANOSKY, A.A.; MERCOLLI, C. Uso del bañado por mamíferos nocturnos, con especial referencia a Cerdocyon thous Linnaeus, 1766 y Procyon cancrivorous Cuvier, 1798. Spheniscus, v.8, p.11-20, 1990.

YANOSKY, A.A.; MERCOLLI, C. Activity pattern of Procyon cancrivorous (Carnivora: Procyonidae) in Argentina. Revista de Biologia Tropical, v. 41, n. 1, p.157-159, 1993.

ZAR, J.H. Biostatistical Analysis. 5. ed. Englewood Cliffs: Ed. Prentice Hall, 1999. $718 \mathrm{p}$. 